


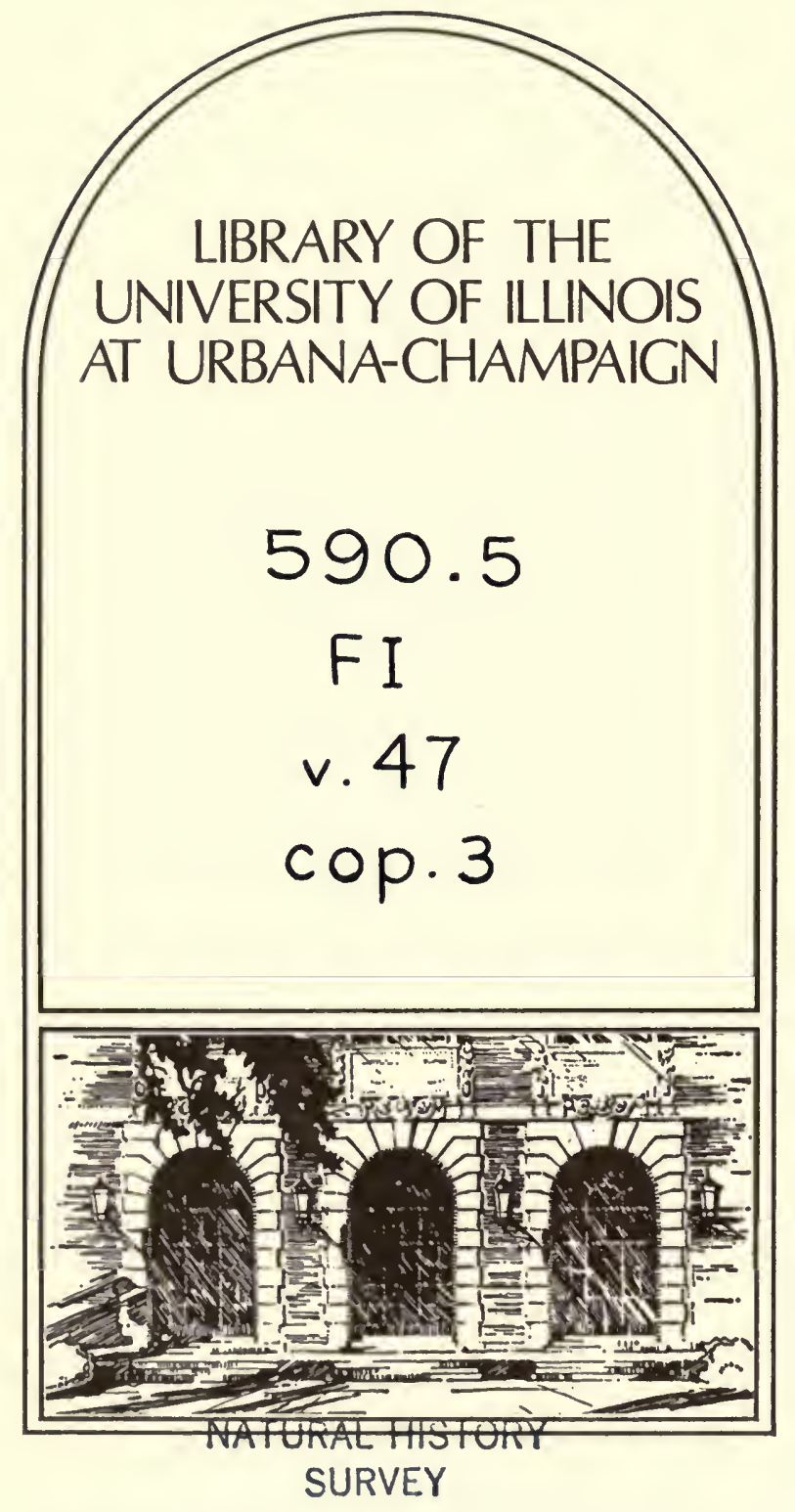







\title{
FIELDIANA: ZOOLOGY
}

\author{
$A$ continuation of the \\ ZOOLOGICAL SERIES \\ of \\ FIELD MUSEUM OF NATURAL HISTORY
}

VOLUME 47

NATURAL HISTORY SURIEY

FEB 111971

LIRRARY

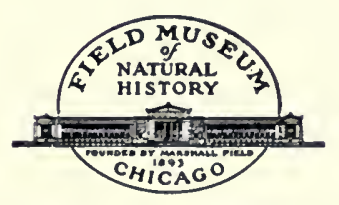

FIELD MUSEUM OF NATURAL HISTORY CHICAGO, U.S.A. 



\section{TABLE OF CONTENTS}

1. The Millipeds of Panama (Diplopoda). By H. F. Loomis

2. The Systematics, Evolution and Zoogeography of Staphylinid Beetles Associated with Army Ants (Coleoptera, Staphylinidae). By Charles

H. Seevers . . . . . . . . . . . . 137 



\title{
THE MILLIPEDS OF PANAMA (DIPLOPODA)
}

\author{
H. F. LOOMIS
}

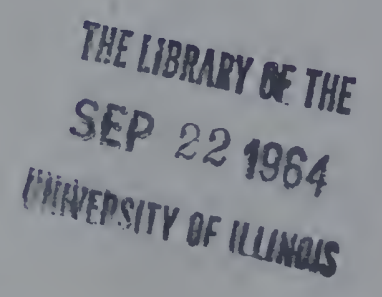

FIELDIANA：ZOOLOGY

VOLUME 47, NUMBER 1

Published by

CHICAGO NATURAL HISTORY MUSEUM

JANUARY 31, 1964 


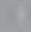

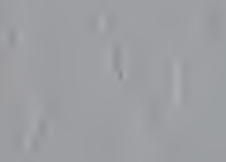

1

+

$+1$

I
II

I

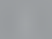

I)

(1)

1

i.

a

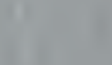

$+$

A.

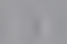

1
1
1

7

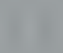

is

(1)

1)

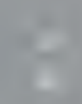

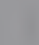

1

\section{(n)}

n 




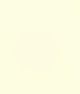





\title{
THE MILLIPEDS OF PANAMA (DIPLOPODA)
}

\author{
H. F. LOOMIS \\ United States Department of Agriculture \\ Agricultural Research Service
}

\author{
FIELDIANA: ZOOLOGY \\ VOLUME 47, NUMBER 1 \\ Published by \\ CHICAGO NATURAL HISTORY MUSEUM \\ JANUARY 31, 1964
}


Edited by Lillian A. Ross

Library of Congress Catalog Card Number: 64-16516

PRINTED IN THE UNITED STATES OF AMERICA BY CHICAGO NATURAL HISTORY MUSEUM PRESS 


\section{$5 \frac{9}{1} 0 \cdot 5$ \\ V. 47 \\ copp. 3 CONTENTS}

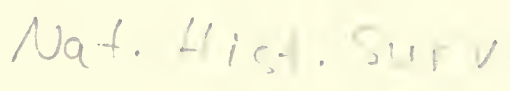

Subclass Pselaphognatha .

Order Polyxenida . . . . . . . . . . . . . . . . . . . . . 9

Family Polyxenidae . . . . . . . . . . . . . . . . . . . . . . . 9

Subclass Chilognatha . . . . . . . . . . . . . . . . . 9

Order Glomeridesmida . . . . . . . . . . . . . . . . . . . . . . . 9

Family Glomeridesmidae . . . . . . . . . . . . . . . . . . . . 9

Order Polydesmida . . . . . . . . . . . . . . . . . . . . . . . . 14

Suborder Polydesmidea . . . . . . . . . . . . . . . . . . . . . 14

Family Chelodesmidae . . . . . . . . . . . . . . . 15, 130

Family Chytodesmidae . . . . . . . . . . . . . . . . . . . 19

Family Comodesmidae . . . . . . . . . . . . . . . . . . . . . 26

Family Cryptodesmidae . . . . . . . . . . . . . . . . . . 30

Family Cyrtodesmidae . . . . . . . . . . . . . . . . . . 32

Family Dorsoporidae . . . . . . . . . . . . . . . . 51

Family Euryuridae . . . . . . . . . . . . . . . . 51

Family Oniscodesmidae . . . . . . . . . . . . . . . . . . 56

Family Peridontodesmidae . . . . . . . . . . . . . . . . . 58

Family Platyrhacidae . . . . . . . . . . . . . . . 59

Family Rhachodesmidae . . . . . . . . . . . . . . . . 64

Family Sphaeriodesmidae . . . . . . . . . . . . . . . . . . . 65

Family Stylodesmidae . . . . . . . . . . . . . . . 65

Family Trichopolydesmidae . . . . . . . . . . . . . . . . 79

Suborder Strongylosomidea . . . . . . . . . . . . . . . . . . . . 98

Family Strongylosomidae . . . . . . . . . . . . . . . 9 98, 131

Order Chordeumida . . . . . . . . . . . . . . . . . 99

Family Cleidogonidae . . . . . . . . . . . . . . . . . . . 99

Family Dybasiidae . . . . . . . . . . . . . . . 100

Order Stemmiulida . . . . . . . . . . . . . . . 105

Family Stemmiulidae . . . . . . . . . . . . . . . . 105

Order Spirobolida . . . . . . . . . . . . . . . . . . . . 112

Family Rhinocricidae . . . . . . . . . . . . . . . . . . . 112

Family Spirobolellidae . . . . . . . . . . . . . . 114

Order Spirostreptida . . . . . . . . . . . . . . . . . 116

Family Spirostreptidae . . . . . . . . . . . . . 116, 131

Family Epinannolenidae . . . . . . . . . . . . . . . . 119

Order Polyzoniida . . . . . . . . . . . . . . . . . . 121

Family Polyzoniidae . . . . . . . . . . . . . . . . . . . 121

Family Siphonophoridae . . . . . . . . . . . . . . . . 122

Order Platydesmida . . . . . . . . . . . . . . . . . . . . . . . 126

Family Platydesmidae . . . . . . . . . . . . . . . 126 
. 


\section{The Millipeds of Panama}

The millipeds or diplopods of the Canal Zone and adjacent areas of Panama now are fairly well known, somewhat over 60 species having been reported, many of them from several locations. East and south of this region, to the Colombian border, only two or three species are known, and scarcely more than a dozen have been credited to the great area between the environs of the Canal Zone and Costa Rica. The number of formerly documented species occurring in the entire country is 77 , on the basis of interpretations in this paper. ${ }^{1}$

During the first three months of 1959, Henry S. Dybas, of Chicago Natural History Museum, made extensive entomological collections in Panama, in the western mountainous sections of Chiriquí Province, not far from Costa Rica; in the lowlands about Almirante, Bocas del Toro Province; and in Cocle Province. Some collecting also was done in an eastern locality between the Canal Zone and Chepo, Panama Province, as well as in the Canal Zone itself. Much use was made of Berlese funnels in gathering the humus fauna, and the results, in terms of millipeds taken by this and other means, were excellent. It has been my privilege to report on these millipeds, which probably constitute the largest single collection ever made in the Western Hemisphere in point of specimens and possibly of species.

The collection is noteworthy in containing a new family; representatives of three families not known before in Panama; 14 new genera; 69 species described for the first time; and two previously known species added to the fauna. In the subclass Pselaphognatha, three species, thought to be new, have been sent to Dr. Bruno Conde, University of Nancy, France, for critical determination. Thus the entire Dybas milliped collection nearly doubles the number of species that has been ascribed to Panama.

In spite of this material advance in knowledge of the Panama millipeds, only a very small part of the Republic so far has been thoroughly searched. Since the tropics generally have a more abundant milliped fauna than the temperate zone, and many species are decidedly localized, there can be no doubt that the vast area remain-

${ }^{1}$ Add species in Addendum (p. 130). 
ing in Panama for original collecting, with habitats ranging from tropical lowlands to mountains as high as 11,000 feet, and ecological situations varying from semi-desert to extreme rain-forest, contains several times the number of milliped species presently recorded.

Difficulties encountered in the past in studying Panama millipeds include widely scattered and often inadequate descriptions; lack of illustrations of essential structural parts; indefinite locality records; few keys to any of the groups involved; and type specimens difficult of access in private collections, scattered through many museums, of ten misplaced, or even no longer in existence. To overcome some of these difficulties for future workers, in addition to describing and illustrating the new species in this paper, accepted species, previously reported, are listed with citations, and keys having application only to Panamanian taxonomic groups are presented. With the large amount of material available, both in the present collection and others that I have seen before, it is now possible to propose settlement, in various ways, of some of the identification problems involving already published species; others remain a challenge.

Unless otherwise stated in the legends for the figures, all drawings were made from the holotype specimen from which most characters included in the descriptions also were derived. Where detailed collection data are given for any of the species, i.e., locality, date, elevation, and details of collection, as "Berlese" or "(B-638) forest floor litter," Dybas was the collector if another person is not named.

All holotype specimens, with one exception mentioned in the text, are deposited in Chicago Natural History Museum. Where available, a paratype specimen of each species has been deposited in the United States National Museum. All other specimens have been returned to the former museum.

Grateful acknowledgment is made to Richard L. Hoffman for aid in several ways in preparing this paper, and for his generosity in allowing publication of notes and drawings he made in the United States National Museum and on a recent visit to museums in Europe, that have important bearings on species in the following text.

\section{Class DIPLOPODA}

\section{KEY TO SUBCLASSES OF DIPLOPODA OF PANAMA}

Body soft; segments few, 9 or 10 , with dense tufts of long, peculiarly shaped setae;

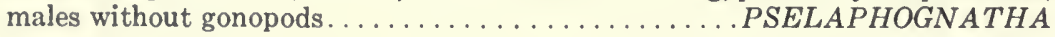

Body usually well chitinized; segments 18 to very many; setae simple, if present, not in dense tufts; males with gonopods. . . . . ........ CHILOGNATHA 


\section{Subclass PSELAPHOGNATHA \\ Order POLYXENIDA \\ Family POLYXENIDAE}

\section{BARROXENUS Chamberlin}

Barroxenus Chamberlin, 1940, Bull. Univ. Utah, (9), 30, p. 3.

\section{Barroxenus panamanus Chamberlin}

Barroxenus panamanus Chamberlin, 1940, Bull. Univ. Utah, (9), 30, pp. 3-4.

Locality.-Canal Zone: Barro Colorado Island.

\section{Subclass CHILOGNATHA}

\section{KEY TO ORDERS OF CHILOGNATHA OF PANAMA}

1. Gonopods at posterior end of body, developed from last pair of legs of male.

GLOMERIDESMIDA

Gonopods at anterior end of body, at least one pair of legs of segment 7 being

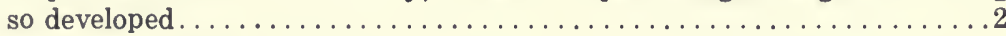

2. Segments numbering 18 to $21 \ldots \ldots \ldots \ldots \ldots \ldots$ POL DESMIDA

Segments considerably exceeding 21 in number................

3. Segments numbering 30 and without repugnatorial pores. .CHORDEUMIDA Segments considerably exceeding 30 ; pores present..............

4. Body laterally compressed; segments with fine, oblique, longitudinal striations. STEMMIULIDA

Body terete or dorsoventrally compressed; segments not obliquely striate . . . 5

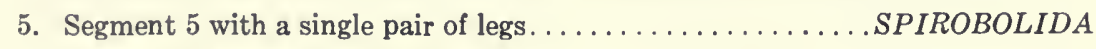
Segment 5 with two pairs of legs. . . . . . . . . . . . . . . . 6

6. Body terete; head about as wide as body; mouthparts of normal size; males with seven pairs of legs preceding gonopods........SPIROSTREPTIDA

Body more or less flattened; head narrower than body; mouthparts rudimentary; eight pairs of legs preceding gonopods................

7. Gnathochilarium with component parts distinguishable; legs very widely separated by the sterna........................ PLATYESMIDA

Gnathochilarium a single long plate; legs narrowly separated by the sterna.

POLYZONIIDA

\section{Order GLOMERIDESMIDA}

\section{Family GLOMERIDESMIDAE}

\section{GLOMERIDESMUS Gervais}

Glomeridesmus Gervais, 1844, Ann. Sci. Nat. Zool., (3), 2, p. 61. 


\section{KEY TO SPECIES OF GLOMERIDESMUS OF PANAMA}

1. Penultimate segment with posterior corners broadly rounded...... rotundatus Penultimate segment with posterior corners acute and more or less produced

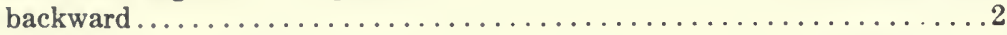

2. Entire head, last segment and posterior two-thirds of penultimate segment colorless; other segments dark ...................... bicolor

Entire body concolorous, except for spotting; ranging from brownish to almost

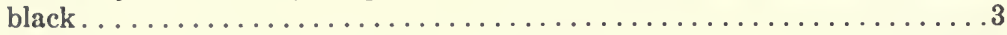

3. Size large, $7.5 \mathrm{~mm}$. to $8 \mathrm{~mm}$. long; color blackish........... barricolens Size smaller, $6.5 \mathrm{~mm}$. or less long; color more brownish . . . . . . . . .

4. Antennae separated by about twice the width of an antennal socket; postantennal pit subtriangular............................ parvior

Antennae separated by little more than the width of a socket; postantennal

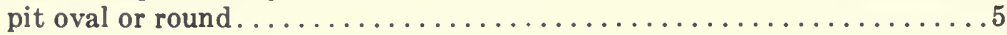

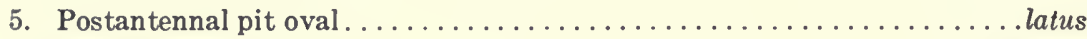
Postantennal pit round $\ldots \ldots \ldots \ldots \ldots \ldots \ldots \ldots \ldots \ldots \ldots \ldots \ldots \ldots \ldots \ldots$ circular

\section{Glomeridesmus barricolens Chamberlin}

Glomeridesmus barricolens Chamberlin, 1940, Bull. Univ. Utah, (9), 30, p. 4. Locality.-Canal Zone: Barro Colorado Island.

\section{Glomeridesmus bicolor, new species. Figure 1, A.}

Diagnosis.-Apparently most closely related to $G$. circularis, as indicated by the nearly round postantennal pit and the shape of the posterior segments, but distinguished by the larger size and contrasting coloration.

Description.-Body strongly fusiform, $6.5 \mathrm{~mm}$. long, $1.7 \mathrm{~mm}$. wide. Head, antennae, legs, posterior two-thirds of penultimate segment and last segment colorless in contrast to the other segments, which are nearly black with slightly lighter inconspicuous spots arranged as in circularis but much smaller.

FIG. 1. A, Glomeridesmus bicolor, segment 1, lateral view.

B-F, Glomeridesmus circularis: B, head, lateral view; C, segment 1, lateral view; $\mathrm{D}$, last two segments, lateral view; E, pleurae of mid-body; F, right gonopod, dorsal view. view.

$\mathrm{G}-\mathrm{H}$, Glomeridesmus rotundatus: $\mathrm{G}$, antenna; $\mathrm{H}$, last three segments, lateral

I-M, Trichomorpha capillata: I, segments 18-20, dorsal view; J, left gonopod, ventral view; $K$, right gonopod, mesal view; $L$, second leg of paratype male, posterior view; M, part of sternum and two basal joints of seventh leg of male, posterior view.

$\mathrm{N}-\mathrm{S}$, Docodesmiella magna: $\mathrm{N}$, antenna; $\mathrm{O}$, segment 1, dorsal view; $\mathrm{P}$, lateral keels of segments 8 and 9 , dorsal view; $Q$, outer part of keel of segment 5 , showing pore, vertical view; $R$, segments 17-19 of male, dorsal view; $S$, left gonopod, lateral view.

T-U, Docodesmiella spathulata: T, segment 1, dorsal view; U, lateral keels of segments 8 and 9, dorsal view. 


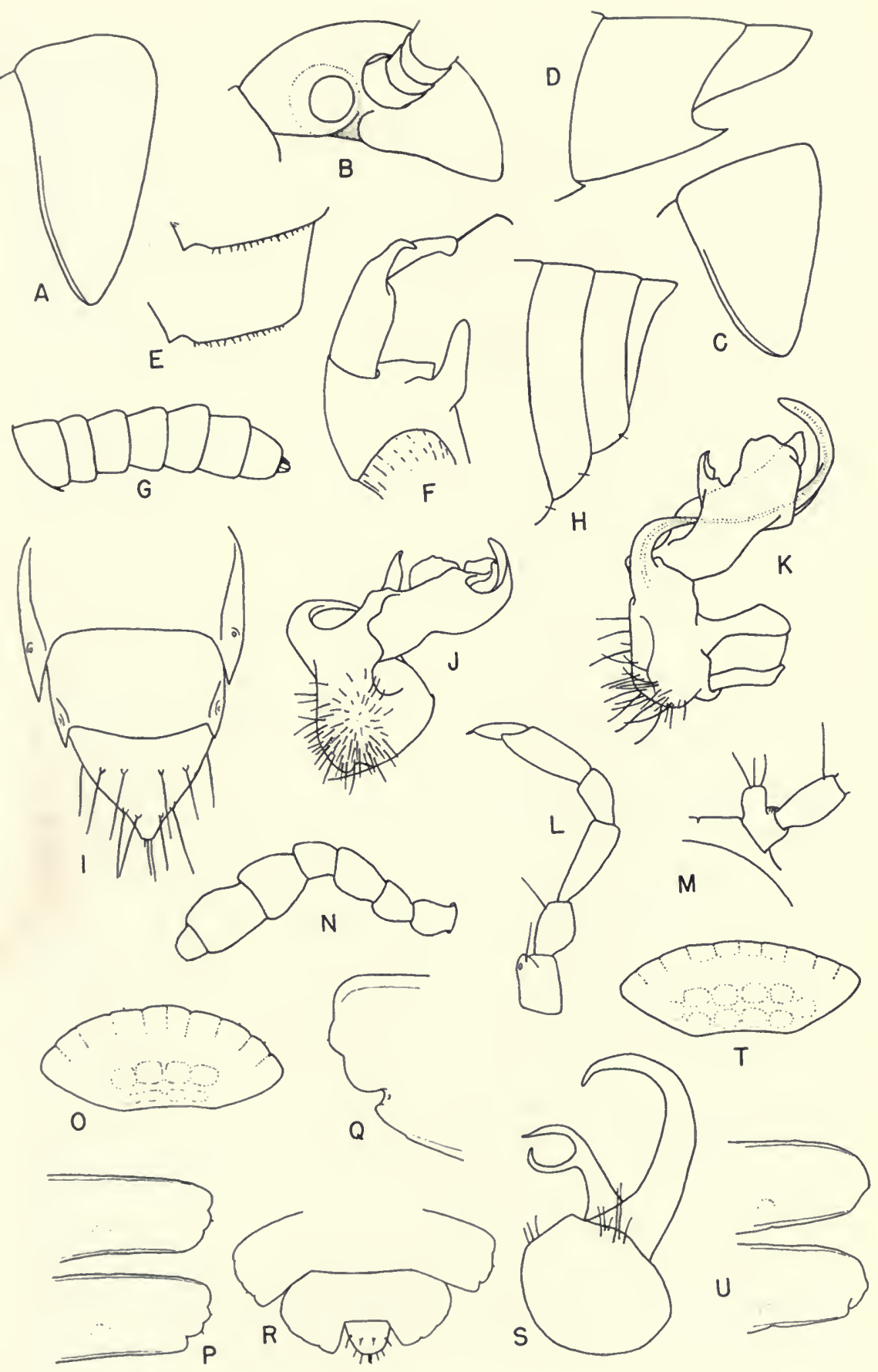


Head with antennae slightly more separated than those of circularis and longer but not as clavate; postantennal pit close to the socket, large, almost round, its upper side a little fiattened. Segment 1 (fig. 1, A) considerably shorter in relation to its over-all width than that of circularis, the lateral angle more sharply rounded. Segments crossed by a series of setae too badly rubbed for the full number to be counted with accuracy; dorsal striae well defined. Segments 18 and 19 with posterior angles as in circularis; segment 20 broadly but evenly rounded behind, the margin minutely fimbriate. Pleurae at mid-body with exposed portion showing one or two strong striae in front, posterior margin fimbriate, straight all the way to the inner posterior, slightly produced angle. Penes and last legs of male not extruded.

Holotype.-Male, Almirante, Bocas del Toro Province, March 27, 1959, (B-638) forest floor litter.

Paratype.-Cocle Province: Male, El Valle, "trail to Las Minas," Feb. 23, 1959, alt. $2400 \mathrm{ft} .,(\mathrm{B}-350)$ log debris. The specimen is like the holotype except that the head shows some color but is distinctly lighter than the ensuing segments.

Glomeridesmus circularis, new species. Figure 1, B-F.

Diagnosis.-Intermediate in size between $G$. barricolens and $G$. parvior, for which only one or two structural characters were given. The angulation of the posterior corners of the caudal segments may resemble the former species but the projection of the penultimate segment is larger and more acute than Chamberlin showed in his illustration of the Guatemalan G. centralis, with which he compared barricolens. G. circularis differs from $G$. latus in the round postantennal pit and larger angles of the penultimate segment.

Description.-Males with 20 segments, females with 21 . Length of largest male (holotype) $5 \mathrm{~mm}$., width $1.2 \mathrm{~mm}$.; largest female $5 \mathrm{~mm}$. long, $1.3 \mathrm{~mm}$. wide; body strongly fusiform. Fully colored specimens grayish-brown in alcohol, caudal end of body lighter; head with clypeal area light, front dark, crossed between upper limits of antennal sockets by a thin, upwardly bowed, light line; vertex dark except at its caudal limit; segments with two small anterior and submedian light spots partly covered by the foregoing segment and narrowly separated from each other.

Head with antennae separated by about the diameter of a socket, joints nearly equal in length but joint 5 wider than the others; postantennal pit (fig. 1, B) larger than a socket beneath surface but its opening smaller, circular, and not rimmed. Segment 1 as shown in figure $1, C$. Segments crossed at about the posterior third by a row of eight long erect setae, those on the last segment, however, projecting back beyond the posterior margin; posterior corners strongly projecting on only the penultimate segment (fig. 1, D); last segment exposed for different lengths in the specimens, broad and truncately rounded behind as in latus; pleurae of midbody as shown in figure $1, \mathrm{E}$, with no transverse striae on exposed surface. In no specimen are the penes extruded and only the holotype has gonopods extended as shown in figure $1, \mathrm{~F}$. 
Holotype.-Male, "Barca area," Finca Lerida, near Boquete, Chiriquí Province, March 14, 1959, alt. 5650 ft., (B-491) concentrated floor litter.

Paratypes.-Bocas del Toro Province: Female, this species? Almirante, Apr. 1, 1959, (B-703) forest floor litter.

Chiriquí Province: Two females, with holotype. Six young, road west of Finca Palo Santo, near Nueva California, March 5, 1959, (B-377) chips, etc., at base of cut stump. Four males, four females and fragment, (B-487 and 488) concentrated floor litter and chips in logging area; male, female, (B-489) concentrated litter and chips at base of cut stump; two males, female, three young, (B-490) concentrated floor litter, "Barca area," Finca Lerida, near Boquete, March 14, 1959, alt. $5650 \mathrm{ft}$. Two females, four young, "Casita Alta," Finca Lerida, March 17, 1959, 7750 ft., (B-526) forest floor litter.

Cocle Province: Several males, females and young, El Valle, Feb. 23, 1959, alt. 2200-2400 ft., (B-347, 348) thatch and log debris from nest of "snapping ant."

\section{Glomeridesmus latus Loomis}

Glomeridesmus latus Loomis, 1961, Proc. U. S. Nat. Mus., (3454), 113, pp. 7880 , illus.

Localities.-Chiriquí Province: Female, this species?, road west of Finca Palo Santo, near Nueva California, March 5, 1959, (B-385) leaf debris in ravine.

Cocle Province: Male, trail to "Las Minas," El Valle, Feb. 23, 1959, alt. 2400-2600 ft., (B-348) thatch and log debris from nest of "snapping ant."

Panama Province: Cerro Campana.

\section{Glomeridesmus parvior Chamberlin}

Glomeridesmus parvior Chamberlin, 1940, Bull. Univ. Utah, (9), 30, p. 4.

Locality.-Canal Zone: Five young, Barro Colorado Island, Jan. $25,1959,(B-147)$ leaves and drift between rocks in stream bed.

Glomeridesmus rotundatus, new species. Figure 1, G-H.

Diagnosis.-Resembles G. latus in small size, separation of antennae, shape of postantennal pit, and last segment, but distinguished from that species and others by having posterior corners of segments, including the penultimate, very broadly rounded. 
Description.--Body of holotype $2.5 \mathrm{~mm}$. long, .5 mm. wide, with 20 segments; colorless in alcohol; shape scarcely fusiform, the anterior end almost as wide as the median portion, the caudal end narrowing very slightly and gradually. Head with the antennae short, thick, not clavate (fig. 1, G), and separated from each other by little more than the diameter of a socket; postantennal pit slightly more triangular than in latus but same distance from the socket. Segment 1 rather long at middle, the outer limits broadly rounded. Ensuing segments with dorsal striae very weakly defined; setae apparently much as described for circularis, but many missing; posterior corners of segments, including the penultimate, broadly rounded with no suggestion of produced angles (fig. $1, \mathrm{H}$ ). Last segment broadly truncaterounded behind, much as in latus. Pleurae with exposed portion lacking striae; posterior margin sparsely fimbriate, convex to the acute inner corner. Penes or last pair of male legs not extended but the terminal element of the latter long and slender as in circularis.

Holotype.-Male, Almirante, Bocas del Toro Province, March 30, 1959, (B-676) forest floor litter.

Paratype.-Male, 19-segmented, with holotype.

\section{Order POL YDESMIDA}

\section{KEY TO SUBORDERS OF POLYDESMIDA OF PANAMA}

Opening of segment through which gonopods project not constricted lengthwise at middle, as long as or longer than either side; coxae of gonopods joined.

POLYDESMIDEA

Opening of segment through which gonopods project more or less constricted lengthwise at middle, the opening shorter than on either side; coxae of gonopods free of each other.....................STRONGYLOSOMIDEA

\section{Suborder POLYDESMIDEA}

\section{KEY TO FAMILIES OF POLYDESMIDEA OF PANAMA}

1. Body capable of being tightly rolled into a sphere or a thick, laterally com-

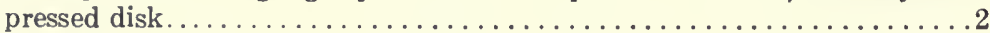

Body incapable of being tightly rolled $\ldots \ldots \ldots \ldots \ldots \ldots \ldots \ldots \ldots$

2. Pores not on the lateral keels but located high on the sides of the dorsum; some of the anterior keels with special flanges on inner or ventral side.

Dorsoporidae

Pores, if present, always on the lateral keels; ventral surface of keels without

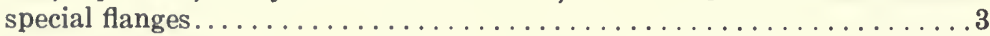

3. Surface of segments strongly hispid, irregularly roughened, tubercular, or a combination of these; supplementary margin of segments fimbriate or crenate; gonopods with large subglobose coxae partially enclosing the distal

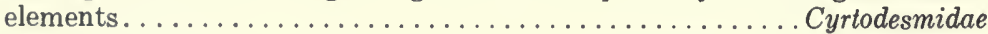

Surface of segments never conspicuously hispid or generally roughened, at most with a few broad seried tubercles; supplementary margin unbroken or lacking; distal elements of gonopods rising at or near the apex of the relatively small non-inclusive coxae. . . . . . . . . . . . . . . . . 
4. Posterior portion of segments sharply marked off into elongate rectangular areas; pores present at or near middle of keels.......... Oniscodesmidae

Segments lacking posterior rectangular areas; pores absent or at least partially hidden by overlapping metazonite of preceding segment.

Sphaeriodesmidae

5. Segment 1 about as wide as or wider than head, its anterior margin expanded forward and divided into rounded lobes, serrations or subquadrate areas. .6

Segment 1 not as wide as head; anterior margin little or not expanded forward and not divided into lobes, serrations or quadrate areas. . . . . . . . . 9

6. Pores opening through special tubercles on or near the outer margin of the

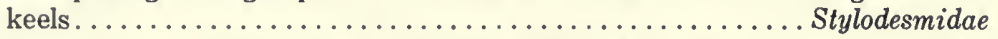

Pores not in special tubercles but opening through channels in the outer margin of keels or from their upper surface. .................

7. Anterior border of segment 1 and outer margins of keels transparent, with opaque intrusions from inner surface............. Cryptodesmidae

Margins of segment 1 and of keels opaque, similar to inner surface. . . . 8

8. Outer and posterior margins of keels with prominent seta-bearing teeth.

Peridontodesmidae

Outer and posterior margins of keels usually somewhat lobed but not promi-

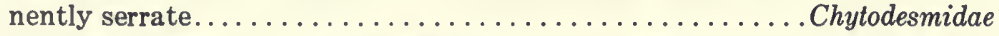

9. Body-shape suggestive of Polydesmus; number of segments 18-21; living animals very active...................... Trichopolydesmidae

Body-shape not suggestive of Polydesmus; segments 20; living animals usually rather sluggish . . . . . . . . . . . . . . . . . . . .

10. Body small, $10 \mathrm{~mm}$. or less long; sides of segment 2 extending below those of segments 1 and 3 ; dorsum setose; coxae of gonopods large and enclosing

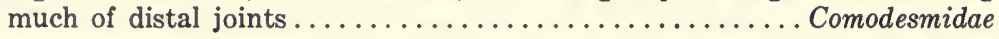

Size medium to large; segment 2 not extending below segments 1 and 3 ; dorsum rarely with conspicuous setae; coxae of gonopods not enlarged or enclosing distal joints. . . . . . . . . . . . . . . . . . . . .

11. Pores on dorsal surface of keels which have rather thin, unrimmed outer margins that are irregularly dentate or tubercular......... Platyrhacidae

Pores opening from more or less thickened outer rim of the keels which may have several small teeth but is not irregular or tubercular. . . . . . . . . 12

12. Last segment broadly rounded behind................ Euryuridae

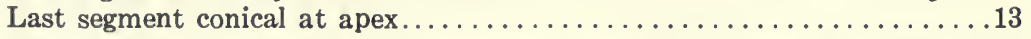

13. Gonopods with definite oval or elongate concavity in mesal face containing

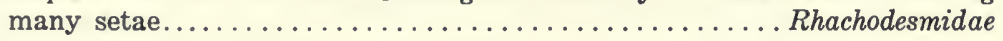

Gonopods without a marked setose concavity in the mesal face.

Chelodesmidae

\section{Family CHELODESMIDAE}

\section{KEY TO GENERA OF CHELODESMIDAE OF PANAMA}

1. Size small to medium; segments smooth or setose above....... Trichomorpha

Size larger; segments definitely tuberculate above...............

2. Size intermediate, under $45 \mathrm{~mm}$. long; dorsum flattened or weakly convex; keels with posterior corners produced and acute............ Alocodesmus

Size large, $55 \mathrm{~mm}$. or more long; dorsum convex; posterior corners of keels produced only on caudal segments....................... 


\section{ALOCODESMUS Silvestri}

Alocodesmus Silvestri, 1896, Boll. Mus. Zool. Torino, (254), 11, p. 5.

Alocodesmus angustatus Silvestri ( $=A$. dromeus Chamberlin), new synonymy.

Alocodesmus angustatus Silvestri, 1896, Boll. Mus. Zool. Torino, (254), 11, p. 5 , illus.

Alocodesmus dromeus Chamberlin, 1922, Proc. U. S. Nat. Mus., (8), 60, p. 48, illus.

Locality.-Canal Zone.

Although Chamberlin noted similarity of dromeus to angustatus he appears to have overlooked the fact that the latter species was described from "Darien." R. L. Hoffman suggested the above synonymy, with which I am in full agreement.

\section{CHONDRODESMUS Silvestri}

Chondrodesmus Silvestri, 1897, Boll. Mus. Zool. Torino, (305), 12, p. 13, illus. Dirhabdophallus Pocock, 1909, Biol. Centr.-Amer., p. 161, illus.

\section{KEY TO SPECIES OF CHONDRODESMUS OF PANAMA}

1. Size very large, $15 \mathrm{~mm}$. wide; pore calluses dorsal............. pittieri Size smaller, less than $12 \mathrm{~mm}$. wide; pore calluses lateral. . . . . . . . . 2

2. Size intermediate, $9-11.5 \mathrm{~mm}$. wide $\ldots \ldots \ldots \ldots \ldots \ldots \ldots \ldots \ldots \ldots \ldots \ldots \ldots$ panenus Size small, $6 \mathrm{~mm}$. or less in width....................

\section{Chondrodesmus atrophus Chamberlin}

Chondrodesmus atrophus Chamberlin, 1925, Proc. Biol. Soc. Washington, 38, p. 42.

Localities.-Canal Zone and adjacent Panama Province.

\section{Chondrodesmus panamenus Chamberlin}

Chondrodesmus panamenus Chamberlin, 1922, Proc. U. S. Nat. Mus., (8), 60, p. 46, illus.

Chondrodesmus chamberlini Hoffman, 1950, Proc. Biol. Soc. Washington, 63, p. 70.

Locality.-Canal Zone.

\section{Chondrodesmus pittieri Loomis}

Chondrodesmus pittieri Loomis, 1961, Proc. U.S. Nat. Mus., (3454), 113, p.83, illus.

Locality.-Panama Province. 
TRICHOMORPHA Silvestri (=Typophallus Chamberlin and Desmacrides Chamberlin), new synonymy.

Trichomorpha Silvestri, 1897, Boll. Mus. Zool. Torino, (305), 12, p. 11, illus.

Typophallus Chamberlin, 1940, Bull. Univ. Utah, (9), 30, p. 10.

Desmacrides Chamberlin, 1940, Bull. Univ. Utah, (9), 30, pp. 11-12.

\section{KEY TO SPECIES OF TRICHOMORPHA OF PANAMA}

1. Size small, $10-12 \mathrm{~mm}$. long; dorsum densely setose.............. capillata

Size larger, at least $18 \mathrm{~mm}$. long; dorsal setae few or none...........2

2. Gonopods with each distal joint a wide, elongate plate broadly oblique at apex. evidens

Gonopods with each distal joint narrower throughout, more or less bent outward near middle, apex not strikingly oblique................

3. Body $28-34 \mathrm{~mm}$. long; keels strongly elevated; second joint of male legs not

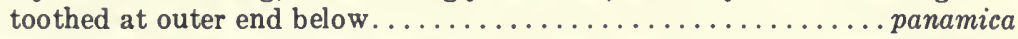

Body 18-24 mm. long; keels nearly horizontal; second joint of male legs with a small acute tooth at outer ventral end................ nidicola

In my earlier paper (1961) the question was raised as to the validity of two species of this genus to which Chamberlin (1925) gave the names of recta and nidicola. The present collection offers nothing to change this suspicion, and disposition of these names is proposed hereafter.

Trichomorpha capillata, new species. Figure 1, I-M.

Diagnosis.-Distinguished by the very small size, dense dorsal setae rising from inconspicuous granules on the shining surface, and the lack of a median sulcus across the metazonites. The gonopods indicate relationship with the much larger $T$. tuberculosa Chamberlin, of Colombia.

Description.-Holotype male $10.5 \mathrm{~mm}$. long, $1.2 \mathrm{~mm}$. wide; female allotype $12 \mathrm{~mm}$. long, $1.5 \mathrm{~mm}$. wide, the dorsum more convex than in the male. Color in alcohol light brown, the two outer joints of antennae conspicuously white.

Head with sharp median sulcus on vertex, its forward end not reaching between antennae, which are separated by a space about equal to one of the sockets; surface of head shining, with densely scattered, rather short setae.

Segment 1 broad, anterior margin evenly rounded, posterior margin triarcuate; lateral margins each with two acute setiferous teeth in advance of the squarely angular posterior corner; dorsal surface with dense scattering of long fine setae inclined somewhat backward and rising from very small conic tubercles or granules on the shining surface. Ensuing segments through the penultimate, with dorsal surface, including the keels, supporting setae on granules similar to those of segment 1; metazonites without a transverse sulcus or depression; keels with a small tooth at anterior corner followed by two setae in the outer margin; posterior cor- 
ners produced backward acutely, especially on caudal segments to the 18 th, those of segment 19 greatly reduced (fig. 1, I); posterior margins of metazonites smooth, containing approximately 20 setae. Last segment lacking fine dorsal setae but crossed at middle by a row of six macrosetae, the outer one on each side in the margin, the inner four on small tubercles, behind these a subapical row of four similar setiferous tubercles.

Gonopods directed cephalad with the outer half bent sharply outward (fig. 1, J-K). First three pairs of male legs with fifth joint as shown in figure 1, L. Sternum between third legs with a pair of small rounded tubercles; sternum between fourth legs with tubercles higher, thin and transverse. Seventh legs with coxal joints as shown in figure $1, \mathbf{M}$. Sterna in both sexes sulcate lengthwise but not across.

Holotype.-Male, west of Finca Palo Santo, near Nueva California, Chiriquí Province, March 10, 1959, alt. 5000 ft., (B-457) concentrated floor litter at base of log and cut stump.

Paratypes.-Chiriquí Province: Male and female with holotype. Fourteen young, "Barca area," Finca Lerida, near Boquete, March 14, 1959, alt. $5650 \mathrm{ft}$., (B-487, 488, 490, 491) concentrated forest floor litter and chips in logging area. Seventeen young, March 17, 1959, alt. $7750 \mathrm{ft}$., (B-526) forest floor litter; three young, March 18, 1959, alt. $6900 \mathrm{ft}$., (B-543) concentrated forest floor debris in damp ravine, "Casita Alta," Finca Lerida.

Panama Province: One hundred young, Chilibrillo Cave, near Chilibre, Feb. 7, 1959, (B-222) from drift along stream in cave.

Trichomorpha evidens (Chamberlin) new combination (=Trichomorpha fratrellus Chamberlin), new synonymy.

Typophallus evidens Chamberlin, 1940, Bull. Univ. Utah, (9), 30, p. 11.

Trichomorpha fratrellus Chamberlin, 1947, Proc. Biol. Soc. Washington, 60, p. 64 , illus.

Locality.-Canal Zone.

Trichomorpha nidicola Chamberlin (=Trichomorpha extrema Chamberlin), new synonymy.

Trichomorpha nidicola Chamberlin, 1925, Proc. Biol. Soc. Washington, 38, p. 42.

Trichomorpha extrema Chamberlin, 1925, Proc. Biol. Soc. Washington, 38, p. 43.

Locality.-Canal Zone.

It is thought that the specimens Chamberlin described under the two names above belong to the same species; hence nidicola must be used, since it has page priority. 
Trichomorpha panamica Chamberlin (=Trichomorpha recta Chamberlin and Desmacrides dichrus Chamberlin), new synonymy. Trichomorpha panamica Chamberlin, 1925, Proc. Biol. Soc. Washington, 38, p. 43.

Trichomorpha recta Chamberlin, 1925, Proc. Biol. Soc. Washington, 38, p. 43. Desmacrides dichrus Chamberlin, 1940, Bull. Univ. Utah, (9), 30, p. 12.

Trichomorpha kraussi Chamberlin, 1947, Proc. Biol. Soc. Washington, 60, p. 63, illus.

Localities.-Canal Zone: Male, Barro Colorado Island, Jan. 21, 1959 , old $\log$.

Cocle Province: Male, El Valle, Feb. 19, 1959, alt. $2400 \mathrm{ft}$.

\section{Family CHYTODESMIDAE}

\section{KEY TO GENERA OF CHYTODESMIDAE OF PANAMA}

1. Dorsum of segments with conspicuous folds; pores opening upward from dorsal surface of keels . . . . . . . . . . . . . . . . . Ptyxodesmus

Dorsum of segments lacking folds; pores opening outward into an incision of

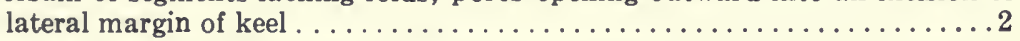

2. Anterior margin of segment 1 considerably expanded, divided into 10 rectangular areas; dorsal tubercles lacking conspicuous setae ...... Docodesmiella Anterior margin of segment 1 shorter, divided into 14-18 smaller, less uniform areas; dorsal tubercles each with a distinct median seta..... Trichodesmiella

\section{DOCODESMIELLA Loomis}

Docodesmiella Loomis, 1961, Proc. U. S. Nat. Mus., (3454), 113, pp. 80-81, illus.

It is necessary to modify somewhat the characters of the genus on the basis of the species added here and reinspection of genotype specimens. Females of the new species have 20 segments rather than 19 as was reported for $D$. insularis, but additional specimens of that species may show 20 segments, the males of all species having 19 segments. Also, all species have pores opening outward from the bottom of a more or less conspicuous sinus between outer lobes 3 and 4 of the keels of poriferous segments, and a sinus or small indentation, most evident in insularis, may be present near the middle of the posterior margin of the keels behind a submedian concavity of the dorsal surface.

\section{KEY TO SPECIES OF DOCODESMIELLA OF PANAMA}

1. Outer margin of keels considerably rounded, not obviously lobed; principal branch of gonopods quite uniform in width throughout, its apex rounded. 
Outer margin of keels more elongate and obviously lobed; principal branch of

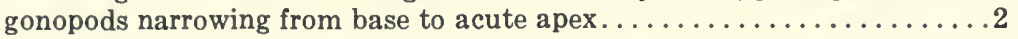

2. Body about $3 \mathrm{~mm}$. long; keels obliquely descending............ insularis Body $4.5 \mathrm{~mm}$. or more long; keels broader and more nearly horizontal . . magna

\section{Docodesmiella insularis Loomis}

Docodesmiella insularis Loomis, 1961, Proc. U. S. Nat. Mus., (3454), 113, pp. 81-82, illus.

Locality.-Canal Zone: Two females, Jan. 1959, Berlese, log debris; 3 young, Jan. 14, 1959, Berlese, woody frass at base of dead stump.

\section{Docodesmiella magna, new species. Figure 1, N-S.}

Diagnosis.-Considerably larger and flatter than D. insularis; antennae less moniliform; keels never with an open sinus on posterior margin, and the gonopods showing specific differences.

Description.-Length 4.5-5.5 mm.; width 1-1.3 mm., the males a little more slender than the females, which have 20 segments with dorsum more convex; keels slightly more horizontal and broader than in insularis.

Head with labrum and clypeus smooth, shining and quite convex, the latter with an anterior row of six erect setae and two adjacent posterior rows, each containing 16-20 smaller setae; front rising convexly behind the clypeus, the junction slightly depressed; sides of head strongly inflated laterad of each antenna; front and vertex very finely and evenly granular with abundant erect, minute and inconspicuous, short setae; a small rounded tubercle, larger than the granules, behind each antenna; vertex with a fine median groove; antennae (fig. 1, N) separated by nearly twice the diameter of a socket, more slender and less moniliform than in insularis, with joint 5 relatively longer and more slender.

Segment 1 (fig. 1, 0) distinctly ellipsoidal, the outer angles reaching laterally almost as far as the anterior corners of segment 2; anterior margin quite long, more or less reflexed, the ten marginal areas faintly marked and forming weak crenations in front, the two median areas narrower than adjacent ones, the third area on each side slightly wider than any other, the median surface with two transverse rows of poorly marked, weakly convex, quadrangular areas, four large ones in front and four smaller ones near back margin.

Beginning with segment 2 the dorsum of the metazonites has a pair of large transverse swellings near the anterior margin, followed by four smaller ones of which the inner two are wider than long, the outer one on each side rounded and more elevated than any of the dorsal swellings; a row of four transverse swellings along back margin; all dorsal swellings with a minute median seta. Segment 2 with three marginal crenations, the anterior one largest; ensuing keels (fig. 1, P) with front and back margins narrowly rimmed, a concavity in the surface near the back margin adjacent to the body, sometimes followed by a tiny nick, but not a sinus, in the margin; outer margins with lobes distinct, more so in females, three lobes on the poreless keels and four on poriferous ones, each lobe with a tiny projecting seta; pores small, opening laterad from the bottom of a small dorsally 
inconspicuous sinus or cleft between lobes 3 and 4 (fig. 1, Q); caudal end of body as shown in figure $1, R$, the last segment quite small and with a median transverse row of four small seta-bearing tubercles; preanal scale considerably broader than long, triangular, subacute at apex; anal valves with thin high margins.

Gonopods (fig. 1, S) each with principal branch somewhat hollowed behind throughout its length, the apex slender and acute.

Holotype.-Male, Finca Lerida, near Boquete, Chiriquí Province, March 17, 1959, alt. $7800 \mathrm{ft}$., (B-524) concentrated forest floor litter.

Paratypes.-Chiriquí Province: Eight males, seven females, with holotype. Over 35 mature and young, Cerro Punta, March 7, 1959, alt. $7000 \mathrm{ft} .,(\mathrm{B}-425)$ forest floor debris on steep slope. Six males, female, (B-488) concentrated litter and chips in logging area; two males, female, (B-489) concentrated litter and chips at base of cut stump; six males, three females, (B-490) concentrated floor litter, "Barca area," Finca Lerida, March 14, 1959, alt. $5650 \mathrm{ft}$. Three males, "Barca area," Finca Lerida, March 15, 1959, alt. $5650 \mathrm{ft}$., Berlese, G. A. Solem, leg. Six females, six males, many young, Finca Lerida, March 17, 1959, alt. $7750 \mathrm{ft}$., (B-525) concentrated forest floor litter under palms, etc. Three males, two females, one young, "Casita Alta," Finca Lerida, March 18, 1959, alt. 6900 ft., (B-543) concentrated forest debris in damp ravine.

Bocas del Toro Province: Female, Almirante, March 27, 1959, (B-638) forest floor litter.

Docodesmiella spathulata, new species. Figure 1, T-U; figure 2, A-B.

Diagnosis.-A smaller species than D. magna, the first segment relatively shorter, narrower and with less extensive anterior border; outer margin of keels of male more rounded and much less obviously lobed; the gonopods also differing.

Description.-Maximum length of males $3.5 \mathrm{~mm}$., width $.8 \mathrm{~mm}$.; females to $4.5 \mathrm{~mm}$. long, $1 \mathrm{~mm}$. wide.

In comparison with males of magna, antennae of holotype somewhat more crassate, sockets each followed by a smaller, less conspicuous, tubercle.

Segment 1 (fig. 1, T) shorter and narrower than in magna, the outer angles far from reaching outward as far as the anterior corners of segment 2; anterior border much shorter, not reflexed, with less evident quadrate areas which are not crenate on the margin and lack a projecting seta; swellings of the two rows on inner surface more similar in size, rounded in outline, and with an additional swelling more or less evident opposite the space between the two rows on either side.

Ensuing segments with dorsal sculpture much as in magna but the swellings lack a median seta, having but a very minute central point or aciculum, if anything. Keels with outer margin rounded (fig. $1, \mathrm{U}$ ), the lobes scarcely evident and 
without projecting setae; rim of the anterior and posterior margins appearing to continue around the outer margin but that margin turned up rather than rimmed; posterior margin with a tiny nick or indentation behind a surface concavity near middle of keel; pores opening laterad from a slight cleft between the last two lobes. Penultimate segment with keels widely separated and considerably exceeded by the rather large last segment as shown in figure $2, \mathrm{~A}$.

Gonopods (fig. 2, B) with terminal joint larger, more uniform in width, and more evenly hollowed throughout than in magna, the apex broadly rounded and slightly inflexed; at rest this joint is held close to the body, encircling the anterior portion of the opposite coxal joint.

Females differing from males, and rather closely resembling those of magna (except in size), in having the outer margin of the keels not upturned, less rounded and with lobes more evident, sometimes with a tiny projecting median point scarcely large enough to be called a seta; dorsal areas of the metazonites also appearing to have a central aciculum present more of ten than in the males.

Holotype.-Male, "Casita Alta," Finca Lerida, near Boquete, Chiriquí Province, March 17, 1959, alt. 7750 ft., (B-526) forest floor litter.

Paratypes.-Chiriquí Province: About 170 males, females and young, with holotype. Male, (B-487) concentrated forest floor litter and wood chips in logging area; male, (B-489) concentrated forest floor litter and chips at base of cut stump; five males, two females, one young, (B-491) concentrated floor litter, "Barca area," Finca Lerida, March 14, 1959, alt. $5650 \mathrm{ft}$. Six males, two females, many young, alt. $7800 \mathrm{ft}$. (B-524) concentrated forest floor litter; male, alt. $7750 \mathrm{ft}$., (B-525) concentrated forest floor litter under palms, etc., Finca Lerida, March 17, 1959. Seven males, seven females, "Casita Alta," Finca Lerida, March 18, 1959, alt. 6900 ft., (B-543) concentrated forest debris in deep ravine. Four males, one female,

Frg. 2. A-B, Docodesmiella spathulata: A, segments 17-19, dorsal view; B, right gonopod, lateral view.

C-G, Ptyxodesmus spiculatus: C, segments 1 and 2, dorsal view; D, segment 5, dorsal view; E, segments 18-20, dorsal view; F, right gonopod, lateral view; G, right gonopod, ventral view.

$\mathrm{H}-\mathrm{K}$, Trichodesmiella multiloba: $\mathrm{H}$, segments 1 and 2 , dorsal view; I, lateral keels of segments 7 and 8 , dorsal view; J, segments 18 and 19, dorsal view; K, preanal scale.

L, Hypsiloporus montanus, right gonopod, lateral view.

M, Hypsiloporus serratus, right gonopod, lateral view.

$\mathrm{N}$, Inodesmus globulosus, lateral keel of segment 5 , vertical view.

O-R, Diaphanacme latus: $\mathrm{O}$, head and ventral side of segments 1 and $2 ; \mathrm{P}$, lateral keel of segment 7, dorsal view; $Q$, preanal scale; $R$, left gonopod, mesoposterior view.

S-U, Cyrtodesmus velutinus (Gervais and Goudot), holotype drawings by R. L. Hoffman: S, lateral keels of segments 2 and 3, vertical view; T, keel of mid-body segment showing pore, vertical view; U, left gonopod, posterior view. 

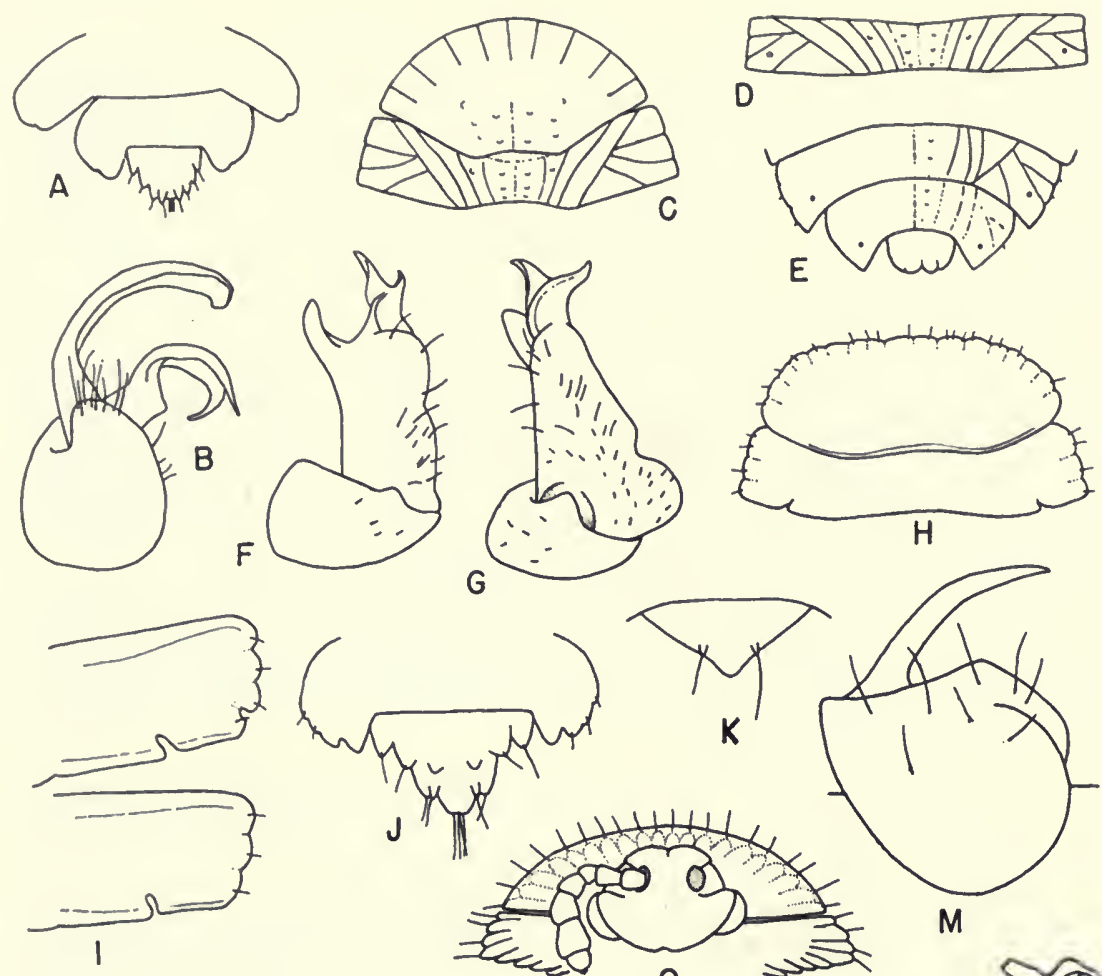

$G$
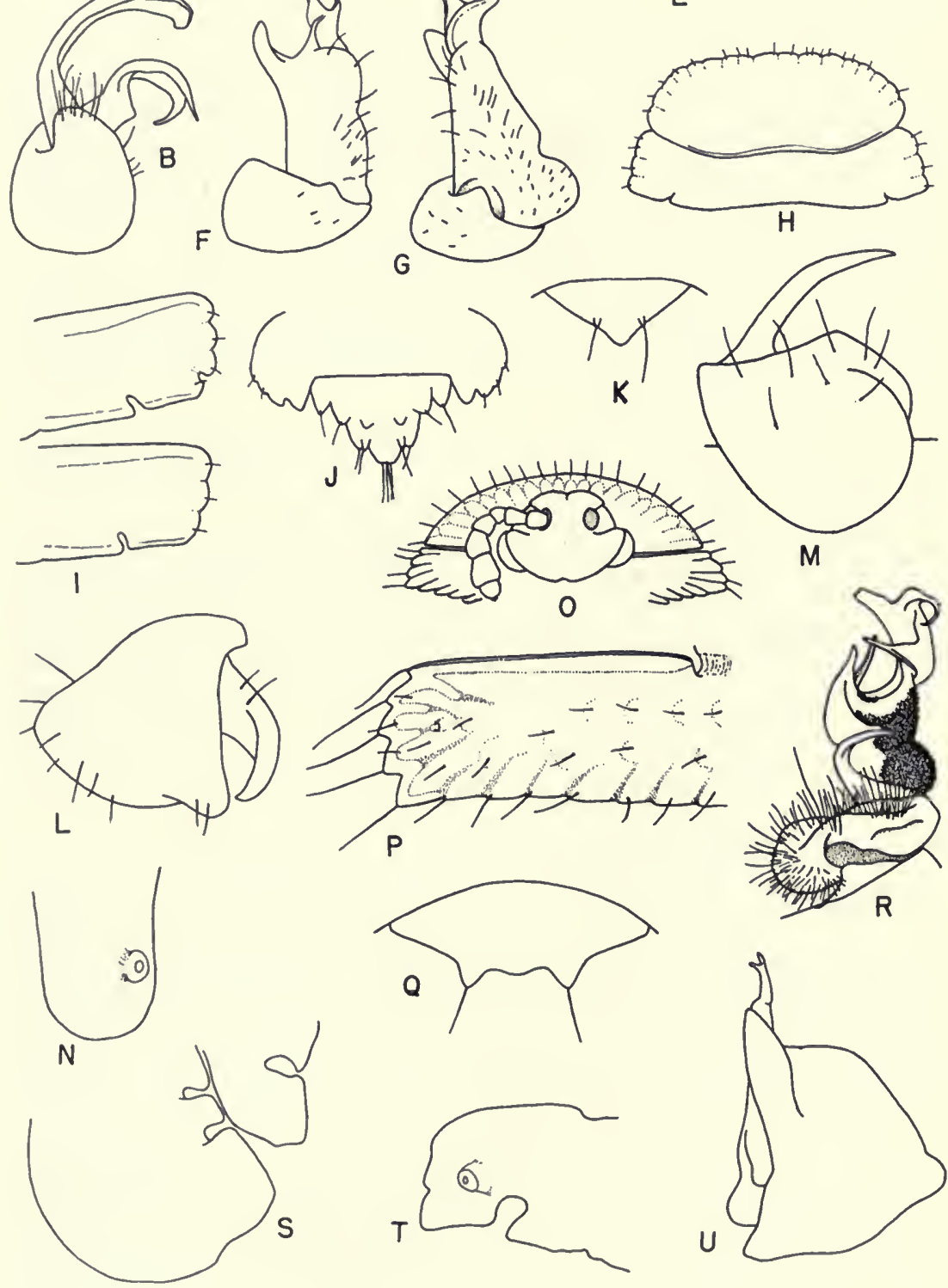
road west of Finca Palo Santo, near Nueva California, March 6, 1959, alt. $4900 \mathrm{ft} .,(\mathrm{B}-393)$ floor debris in ravine. Six males, Finca Palo Santo, west of Nueva California, March 9, 1959, alt. $4900 \mathrm{ft}$., (B-433) floor debris in ravine.

\section{PTYXODESMUS, new genus}

Genotype.-Ptyxodesmus spiculatus, new species.

Diagnosis.-Body shaped as in Docodesmus Cook, to which it seems most closely related, but differing in lobation of segment 1 and the keels of the other segments, reduced size of the gonopod coxae, and the striking sculpturing of the dorsum of the metazonites, in which character it is unique in the family.

Description.-Size small, the body only about a third as wide as long, moderately convex at middle from which the sides and broad keels descend slightly in a straight line. Number of segments 20 ; dorsal surface with tiny groups of minute spicules most evident on lateral keels; sides of dorsum and base of keels with prominent oblique longitudinal folds.

Head strongly flattened; anterior half of vertex with tiny groups of spicules, the posterior half reticulated and faintly furrowed at middle; antennae short, heavy, clavate, and geniculate at joint 4.

Segment 1 with anterior margin long, horizontal, and composed of 10 quadrate areas; disk moderately convex, faintly tuberculate, and medianly sulcate, as are ensuing segments. Keels of segments 2-19 outwardly 3 -lobed, the pores opening from the surface of the third lobe on the usual segments. Last segment large, much exposed, broadly rounded behind, the margin apparently normally 4-lobed. Anal valves very flat and shining, margins thickened; preanal scale large, subtriangular. Gonopods extending forward between legs 6 and 7 ; coxal joints quite small and supporting but not enclosing the stout and straight terminal joints, each of which ends in three short processes.

\section{Ptyxodesmus spiculatus, new species. Figure 2, C-G.}

Description.-Body $3.7 \mathrm{~mm}$. long, $1.2 \mathrm{~mm}$. wide; color in alcohol light brown.

Head much flattened; vertex with a short, sharp median sulcus in front, ending in a small concave area, the sulcus fine across the posterior half; surface slightly raised above the front, which is a little convex, smooth and shining; anterior surface roughened by numerous clusters of minute spicules; posterior surface smooth but dulled by fine reticulations. Antennae short and stout; joints 1-4 and 6 subequal in length and thickness but joint 5 considerably thicker and nearly as long as joints 2-4 together; separation of antennae about half again as wide as a socket.

Segments 1 and 2 as shown in figure 2, C, the strong oblique folds beginning on the latter and continuing through segment 19 , although less prominent there, the folds lapping outward, being highest along their outer limits where they end in a sharp declivity; outermost fold on each side the longest and most distinct. Lateral keels thin and broad, with three outer areas separated by sulci; outer margin of each area with a projecting seta. Dorsal surface of segments with rather 
closely and evenly distributed tiny groups of several very minute spicules, most evident on lateral keels; mid-dorsum with a few faint tubercles as shown in illustrations. Pores opening in the upper surface of the third keel-area, part of which includes the outer posterior margin of the keel as shown in figure 2, D. Posterior end of body abruptly rounded as shown in figure $2, \mathrm{E}$.

Last segment large and much exposed, equally convex above and below with the usual cluster of four long setae in the ventral surface half way between the valves and the apical margin, which normally is probably 4-lobed rather than as shown in illustration; a macroseta on each side below, a short distance inside the mid-lateral margin; another seta in the margin opposite the posterior third of the valves. Valves very flat, shining, the raised inner rims as high as the slightly convex median area but separated from it by a depression. Preanal scale large, about half as long as wide, broadly rounded at apex and with a macroseta on each side.

Gonopods well exposed, shaped as shown in figure 2, F-G, the terminal joints directed forward into a depression of the sterna between legs 6 and 7 ; bipedigerous sterna narrow, crossed in each direction by a median furrow.

Holotype.-Male, Cerro Azul, near "Goofy" Lake, Panama Province, Feb. 6, 1959, in log.

\section{TRICHODESMIELLA, new genus}

\section{Genotype.-Trichodesmiella multiloba, new species.}

Diagnosis.-Apparently related to Docodesmiella as indicated by size of body and similarly located pores, but the coarsely hispid dorsum, the lobation of the anterior margin of segment 1, and the sinus in the back margin of the keels of the other segments unmistakably distinguish it.

Description.-Body small, less than five times as long as broad, moderately convex, with 20 segments and normal pore formula.

Head with front and anterior half of vertex finely granular and minutely hispid, posterior half lacking granules, dull and with a very fine median furrow; labrum and clypeus together rather long, convex, smooth and shining; antennae separated by twice the diameter of a socket, incrassate, joints 5 and 6 largest, subequal in both dimensions.

Segment 1 short and broad, the short anterior margin indefinitely divided into 14-18 quadrate areas each of which usually has at least one small projecting marginal seta; inner surface with scattered low rounded tubercles, each supporting a prominent erect central seta. Ensuing segments with a sinus near the middle of the back margin of each keel, usually filled with organic matter in mature specimens but open in young ones; dorsum between the sinuses crossed by three rows of low rounded setose tubercles like those of segment 1 ; keels beyond the sinus not tubercular, the outer margin of the poreless ones 3-lobed, poriferous ones 4-lobed with the pore opening outward from the bottom of a small sinus in the lateral margin between lobes 3 and 4 ; all marginal lobes with a projecting median seta.

Last segment large and much exceeding the lobes of segment 19; preanal scale subtriangular. 


\section{Trichodesmiella multiloba, new species. Figure 2, H-K.}

Description.-Length $5.5 \mathrm{~mm}$., width $1.3 \mathrm{~mm}$. Dorsum moderately convex with rather broad keels descending more sharply on the basal half than beyond the slender lageniform sinus of the posterior margin. Labral-clypeal area of the head smooth and shining, rising convexly above the flat front, the area about half as long as the width of the clypeus at base; clypeus with an anterior row of six setae and a posterior row of about 12 smaller ones.

Segment 1 as shown in figure 2, $\mathrm{H}$, the anterior margin composed of 14-18 short, indefinitely marked quadrate areas, each with a marginal seta, infrequently with two or three; inner surface with 28-32 irregularly placed, very low, rounded, indefinite tubercles, each with an erect median seta. Ensuing segments, through segment 19, with similar tubercles in three transverse rows, about 16 tubercles in each row, all with an erect central seta; from segment 2 to near the posterior end of the body the keels have a deep, narrow, matter-filled sinus near the middle of the back margin as shown in figure 2 , I, which also shows the pore sinus, setose marginal lobes and thick anterior marginal rim. Last two segments and preanal scale shown in figure 2, J-K. Note. All drawings made from 19-segmented paratype, in which setae are not badly rubbed and the sinus in each keel is not filled with organic matter.

Holotype.-Female, Finca Lerida, near Boquete, Chiriquí Province, March 15, 1959, alt. $5650 \mathrm{ft.}$, (B-507) frass under nest in tree hole, 3 feet above ground.

Paratypes.-Chiriquí Province: Mature female, two 19-segmented females, one 18-segmented male, "Barca area," Finca Lerida, March 14, 1959, alt. $5650 \mathrm{ft}$., (B-487, 488, 491) concentrated floor litter and chips in logging area; one 19-segmented female, (B-489) concentrated litter and chips at base of stump. Eighteen-segmented male, Finca Lerida, March 15, 1959, alt. $7800 \mathrm{ft}$., (B-509) leaves and chips at base of stump.

\section{Family COMODESMIDAE}

It has been recognized that a number of groups of millipeds for which family status is justified have been lumped together for years under a single polymorphic family, the Vanhoeffeniidae. Related genera of one of the distinct groups have been associated under the family Comodesmidae Cook (1896a), where it appears the genus Hypsiloporus also should be placed. The distinctness of genera in the Comodesmidae from the other more Polydesmus-like groups seems obvious, but whether all of them can be maintained in the one family, founded on the Liberian Comodesmus lanatus, cannot be determined exactly until that species has been rediscovered or some of Cook's original specimens have been found. Until then the present disposition is thought not unreasonable. 
Of the two Panamanian genera of comodesmids, Hypsiloporus may be recognized as having the dorsal setae of the metazonites short, clavate and in three transverse rows, whereas in Inodesmus they are long, flexuous and thickly scattered over the surface.

\section{HYPSILOPORUS Loomis}

Hypsiloporus Loomis, 1961, Proc. U. S. Nat. Mus., (3454), 113, pp. 104-105, illus.

This genus was based on female specimens collected on Barro Colorado Island, Canal Zone. Although males from the genotype locality still are unknown, the present collection contains males of three species, probably none representing $H$. proclivis but congeneric with it, that allow mention of additional generic characters. The males are somewhat shorter, flatter, and with one less segment than the females; each gonopod is composed of a large hemispherical coxal joint within which most of the rather simple outer joint is contained and somewhat hidden in lateral view; anterior male legs and sterna without special modifications.

\section{KEY TO SPECIES OF HYPSILOPORUS OF PANAMA}

1. Lateral keels with outer margin rather thin, little rounded from front to back, with fine dentations................................

Lateral keels with outer margins thick, broadly rounded from front to back,

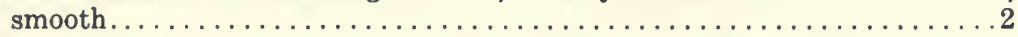

2. Metazonites flattened lengthwise; only lateral keels of segments $2-4$ produced

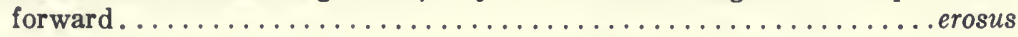

Metazonites longitudinally convex; lateral keels to middle of body produced

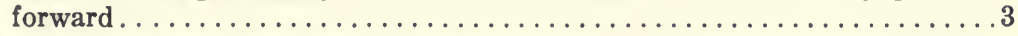

3. Size relatively large, $3-3.7 \mathrm{~mm}$. long. . . . . . . . . . . . montanus

Size smaller, about $2.5-3 \mathrm{~mm}$. long. . . . . . . . . . . . proclivis

Hypsiloporus erosus, new species. Figure 13, 0.

Diagnosis. - Although differing in the shape of the inner gonopods from the species of which males are known, the longitudinally flattened metazonites and less forwardly directed lateral keels associate this species most closely with $H$. serratus.

Description.-Body $2.7 \mathrm{~mm}$. to $3.3 \mathrm{~mm}$. long; colorless; keels thickened and lateral margins rounded as in montanus and proclivis but not as strongly or extensively produced forward and the metazonites are flatter lengthwise; sides beneath keels convex in both directions; posterior corner of keels from segments 2-14 or 15 rounded, continuing the outline of the outer margin; posterior margin not concave between the corners except on segments 16 and 17 where the corners are slightly 
produced but not on segment 18 , the margin there straight across and with 10 projecting setae. Seta at apex of joint 5 of last legs longer than joint 6 .

Gonopods with outer portion of each inner joint straight, slightly increasing in width to the truncate-erose tip (fig. 13, 0).

Holotype.-Male, El Valle, Cocle Province, Feb. 23, 1959, alt. $2400-2600 \mathrm{ft.}$., (B-348) thatch and log debris of nest of "snapping ant," trail to "Las Minas."

Paratypes.-Male, several females and many young, with holotype.

Hypsiloporus montanus, new species. Figure 2, L.

Diagnosis.-A larger species than any of the others but although males of $H$. proclivis are not known the convexity of the segments and strong forward bending of the anterior keels indicate closest relationship with that species.

Description.-Males $3 \mathrm{~mm}$. long with 19 segments; more slender and with dorsum a little flatter than females, which are 3.5-3.7 mm. long; body colorless. Segments with three series of thick curved setae as in proclivis, the surface completely reticulated and with minute spicules, giving it a slightly velvety appearance. Metazonites above and below strongly convex longitudinally with keels narrow, very thick at base, the outer margin thick; sides below keels inflated in both directions. Segment 2 with keels strongly bent forward, those thereafter less bent to mid-body where they project directly laterad; anterior corners of forward keels less than a right angle, the actual corner rounded; outer margin of keels broadly rounded; posterior corners broadly rounded on front half of body, thereafter becoming more acute on poreless keels; pores on usual segments, opening from a slightly elevated cone between bases of two small teeth near posterior corner as shown in illustration for $H$. serratus, the outer tooth small and slightly projecting, the inner one larger and projecting from the back margin.

Gonopods as shown in figure 2, L. Long seta on joint 5 of posterior legs as in proclivis.

Holotype.-Male, "Casita Alta," Finca Lerida, near Boquete, Chiriquí Province, March 17, 1959, alt. 7750 ft., (B-526) forest floor litter.

Paratypes.-Chiriquí Province: Two males, three females, with holotype. Two young, west of Finca Palo Santo, near Nueva California, March 9, 1959, alt. $4900 \mathrm{ft}$., (B-433) concentrated forest floor litter in damp ravine. "Barca area," Finca Lerida, female, March 12, 1959; two females, (B-488) concentrated forest floor litter and chips in logging area; three females, one young, (B-490) concentrated floor litter; 13 females and young, (B-491) concentrated floor litter, March 14, 1959; three young, March 15, 1959, alt. 5650 ft. Finca Lerida, March 17, 1959, male, 24 females and young, alt. $7800 \mathrm{ft.}$, 
(B-524) concentrated forest floor litter; two young, alt. 7750 ft., (B-525) concentrated forest floor litter under palms, etc. Three females, Cerro Punta, March 7, 1959, alt. 7000 ft., (B-425) forest floor debris on steep slope.

\section{Hypsiloporus proclivis Loomis}

Hypsiloporus proclivis Loomis, 1961, Proc. U. S. Nat. Mus., (3454), 113, pp. 105-107, illus.

Localities.-Canal Zone: Barro Colorado Island, two females, Jan. 1959, Berlese, log debris; numerous females and young, Jan. 22, 1959, Berlese, compost pile; one young, Jan. 25, 1959, (B-147) leaves and drift between rocks in stream bed.

Panama Province: Three young, Madden Lake Dam, Feb. 6, 1959, (B-211) crown debris of dead palm.

Males of this species still unknown.

Hypsiloporus serratus, new species. Figure 2, M; figure 13, P.

Diagnosis.-A smaller species than $H$. montanus, with outer margin of keels thinner, straighter and more irregular, being minutely toothed, but the gonopods show the relationship.

Description.-Male $2.7 \mathrm{~mm}$. long, .4 mm. wide, with 19 segments; body colorless; dorsal vestiture as in other species; metazonites above and below less convex longitudinally and flatter transversely than in montanus; lateral keels narrow, less thickened at base than in other species, the outer margin distinctly thinner, straighter and finely denticulate (fig. 13, P), lower sides not inflated, descending in a straight line. Keels of segments $2-4$ scarcely bent forward, those of segments 5 and 6 even less and thereafter they project laterad; anterior corners abruptly rounded; posterior corners more angular than in other species, being noticeably produced on posterior segments.

Gonopods with coxae much as in montanus, but each inner joint longer and more slender as shown in figure $2, \mathrm{M}$, although in another view seen to be slightly broader and inwardly concave, curving almost straight back from the anterior part of the coxa. In the single specimen in which the seta at the apex of joint 5 of the posterior legs is still present it is only about half as long as in the other species.

Holotype.-Male, Almirante, Bocas del Toro Province, March 27, 1959, (B-638) forest floor litter.

Paratypes.-Male, with holotype. Same locality: two young, March 27, 1959, (B-626) forest floor litter; fragment of female, March 30, 1959, (B-676) forest floor litter.

\section{INODESMUS Cook}

Inodesmus Cook, 1896, Brandtia, p. 25. 
Lasiodesmus Silvestri, 1908, Bull. Amer. Mus. Nat. Hist., 24, pp. 575-576, illus.

Inodesmus globulosus, new species. Figure 2, N.

Diagnosis.-Slightly smaller than $I$. peduncularis Loomis of Dutch Guiana and further distinguished by the more globular pore tubercle.

Description.-Body colorless in alcohol; 4.5-6 mm. long, .5-.6 mm. wide. Head with vertex medianly sulcate, the surface dull, finely and densely setose, a prominent elevation directly behind each socket; surface latero-caudad of each socket depressed; below lower limit of the sockets the front is depressed to the clypeus, the latter with the labrum convexly elevated; front, clypeus and labrum shining, much less setose than vertex.

Segments 1-5 essentially as in peduncularis except that pore tubercles of segment 5 are larger and more globose (fig. 2, N), ensuing pore tubercles smaller, slightly higher on the sides and gradually receding from front margin; on segments 18 and 19 at the posterior third. Prozonites finely reticulated; interzonal constriction more coarsely so; surface of segment 1 and ensuing metazonites scattered with numerous long, slender, erect but flexuous hairs, the surface between them dull, appearing granulated, but when it is dry, clean and observed with high magnification, it is seen to be very densely covered by minute velvety pubescence. Last segment much as in peduncularis; valves strongly inflated, lacking raised margins; surface and that of the preanal scale velvety pubescent; scale with two widely separated posterior tubercles, the intervening margin almost straight; surface quite convex.

Holotype.-Female, Las Cumbres, Panama Province, Feb. 15, 1959, (B-268) fibrous trunk in compost pile, at home of Dr. G. B. Fairchild.

Paratypes.-Two hundred and sixty-five mature and nearly mature females, with holotype.

Remarks.-It is most unusual, and inexplicable, that no males were in the large number of specimens of this species that was collected. Furthermore, none was reported among the specimens included in the three species previously forming this genus.

\section{Family GR YPTODESMIDAE}

After examination of the specimens Peters studied in establishing the genus Cryptodesmus, Cook (1896a) pointed out that $C$. alatus was founded on three specimens representing as many species, none of which was congeneric with C. (Polydesmus) olfersii (Brandt), which remained the only species of the genus. Thus Cook fixed olfersii as the genotype by monotypy. He also disposed of Peters' 
three specimens by designating one, alatus, as the genotype of Chonodesmus, where the second specimen was included as new, $C h$. regularis; the third specimen was described briefly as a new genus and species, Stictodesmus creper, and removed to the family Chytodesmidae. Cook (1911a) published additional notes and illustrations of the type specimens of Stictodesmus creper, Cryptodesmus olfersii and Chonodesmus alatus, and founded another genus, Apomus, on Cryptodesmus pusillus Attems (1900).

While Carl (1914) and Attems (1940) have not followed Cook in accepting Polydesmus olfersii as the genotype of Cryptodesmus, or in recognizing the validity of Chonodesmus, it would appear that no alternative remains, under the Rules.

Now another genus is here proposed to include the first member of the Cryptodesmidae to be found in North America.

\section{DIAPHANACME, new genus}

Genotype.-Diaphanacme latus, new species.

Diagnosis.-Most closely related to Chonodesmus but differing by being considerably broader; anterior margin of segment 1 and the keels transparent, thin and slightly reflexed; keels wider, with pronounced anterior shoulders where they join the body.

Description.-Body very broad, less than four times as long as wide, with 20 segments; keels projecting horizontally each side a distance equal to the diameter of the body itself and sharply shouldered in front where they join it. Segment 1 completely hiding head, subelliptical, outer angles equaling those of segment 2; anterior border expanded, thin, reflexed at margin, translucent, with 20 opaque, tongue-like intrusions from the central disk, each with an erect anterior seta; many additional setae scattered elsewhere over the smooth shining surface. Ensuing metazonites strongly shining, crossed by three transverse rows of about 20 seta-bearing elevations or tubercles, the elevations more distinct and tuberclelike on the body than on the keels; anterior margin of keels sharply upturned in front, thin, transparent; toothed lateral margin also transparent with an opaque projection from the inner surface in each tooth; lateral margin of segment 5 and all poreless keels 4-toothed, other poriferous keels 5-toothed; pores in normal sequence, opening obliquely outward from near the inner limit of the channel in front of the penultimate tooth of the margin; all lateral teeth and the quadrate areas of posterior margin each with a long seta.

Last segment subconical with two seta-bearing tubercles each side of the somewhat deflexed apex, the latter not exceeding the backwardly produced keels of segment 19. Preanal scale subelliptical with two well-separated seta-bearing tubercles behind. Coxal joint of gonopods with long setae; distal joint outwardly densely matted with fine short setae on basal half. 


\section{Diaphanacme latus, new species. Figure 2, O-R.}

Description.-Body $11 \mathrm{~mm}$. long, $3.2 \mathrm{~mm}$. wide, increasing in width to segment 5 or 6 ; color in alcohol light brown with transparent portion of margins colorless.

Head completely hidden beneath segment 1 (fig. 2, 0); anterior margin from directly laterad of each antenna broadly and evenly rounded except at the narrow emarginate labrum, the sides thin; surface of front evenly convex throughout and more setose than on vertex where the setae decrease in number but become longer; vertex coarsely reticulated, medianly sulcate on the posterior half, the sides with a fine roughened ridge extending backward and outward from each socket to segment 1 , the surface laterad of the ridge excavated to receive the basal joints of the rather short but not strongly crassate antennae.

Segment 1 subelliptic, only a third as long as wide, the acute outer angles reaching opposite the anterior corners of segment 2 , the latter broadening posteriorly to the posterior angles; anterior margin smooth and evenly rounded throughout, the border expanded, very thin, upturned along front and transparent with 20 opaque tongue-like intrusions from the central disk, each with an anterior seta; about 60 other erect setae scattered over the smooth shining surface elsewhere; posterior margin strongly concave at middle with the oblique sides faintly so.

Prozonites of ensuing segments coarsely reticulated to the broad, deep, and shining interzonal constriction; metazonites strongly shining and crossed by three rows of elevations or tubercles, about 20 in each row and each with a median seta, the elevations more sharply defined on the strongly convex dorsum of the body than on the keels. Keels horizontal, about twice as wide as long (fig. 2, P), equaling the diameter of the body and with a distinct antero-mesal shoulder; anterior border thin, transparent, with margin upturned and rim-like; outer toothed margin also transparent, with tongue-like intrusions from the inner surface. Segment 19 with keels directed straight back, their inner (posterior) margins parallel. Last segment large, subconic, the apex somewhat deflexed and not surpassing the angles of segment 19; each side with two seta-tipped conic tubercles; preanal scale as shown in figure $2, Q$, its surface and that of the moderately inflated valves and their prominent margins reticulated.

Gonopods as shown in figure 2, R. Male legs without modifications.

Holotype.-Male, El Valle, Cocle Province, alt. 2400 ft., Feb. 23, 1959, (B-349) floor debris from steep stream bed near trail to "Las Minas."

Paratypes.-Two very young specimens, with holotype.

Bocas del Toro Province: Male with 17 segments, Almirante, March 27, 1959, (B-638) forest floor litter.

\section{Family GYRTODESMIDAE}

It has been the practice of most recent European diplopodists to treat the oniscoid millipeds as belonging in a single family, Oniscodesmidae, or to separate from it a second family, Sphaeriodesmidae. 
Under this classification certain characters, including some of those enumerated by Cook (1898) for the division of the American oniscoids into five families, have been minimized and others substituted to have the effect of joining quite dissimilar groups in one or both of the above families. In the present state of knowledge of the oniscoids of this hemisphere, admittedly far from satisfactory, a return to some of Cook's concepts seems necessary in order to recognize a natural grouping of families, the outstanding diagnostic characters of which have been set forth in the foregoing key to families of the order Polydesmida. The first of these families, Cyrtodesmidae, shows the following characters.

Description.-Body relatively long and when rolled up generally more lenticular than spherical; vertex of head roughened, somewhat granular, tubercular, or ridged; segments with posterior margin of lateral keels deeply notched or incised, beginning with segment 2; posterior margin of the exposed last segment lobed or tuberculate whereas in the other oniscoid families the last segment is small, usually more or less hidden, and the posterior margin is smooth and continuous; segments with a distinct supplementary margin that is fimbriate or variously lobed.

Remarks.- Since the founding of Cyrtodesmus on Polydesmus velutinus Gervais and Goudot by Gervais in 1847, only one species, C. tomentosa Silvestri (1898a), has been added and this now appears to be at one of the extremes in the range of species suggested here as members of the genus so that its relationship to the genotype is rather remote and traces through a number of intermediate species. The only other reference to Cyrtodesmus through C. velutinus, based on examination of specimens, was by Cook, who studied the holotype in the British Museum and included observations on it in his 1898 paper. The description he gave, however, was very brief; it lacked mention of the gonopods, and the illustrations of the anterior end of the body and two lateral keels so far fail to show properly or correctly these features that they appear to be sketches rather than camera lucida drawings, which he usually made. Thus many questions as to the exact identity of the genus have arisen that could not be answered from existing references.

Early in 1960, Richard L. Hoffman visited the British Museum and examined the holotype of $C$. velutinus. From it he prepared an ample description with excellent drawings which included the gonopods. I am greatly indebted to him for allowing publication of this material which, for the first time, gives the species and genus a firm starting point and permits the relationship of several other genera to be established. 


\section{GYRTODESMUS Gervais}

Cyrtodesmus Gervais, 1847, Apteres, 4, p. 92.

Oncodesmus Cook, 1896, Brandtia, p. 28.

Cyliocyrtus Cook, 1898, (in part), Proc. U. S. Nat. Mus., (1154), 21, pp. 458459 , illus.

Trigonostylus Brolemann, 1898, (in part), Ann. Soc. Ent. France, 67, p. 273, illus.

Peltedo Chamberlin, 1940, Bull. Univ. Utah, (9), 30, p. 8.

Oncodesmoides Kraus, 1954, Senckenberg Biol., Frankfurt-am-Main, 35, p. 41, illus.

No new information on Oncodesmus has become available but with recognition of the great variation in size of the second segment, and in the dorsal sculpture and vestiture of the species here referred to Cyrtodesmus, the characters used by Cook for distinguishing Oncodesmus no longer are valid. Hoffman reported to me that the holotype of $O$. granosus (Gervais and Goudot) was not found on his visit to the British Museum and it seems likely that identification of that species may be impossible.

Doubt of the validity of Cyliocyrtus also is raised, as it is not known that the holotype of Cyrtodesmus asper Peters, made the genotype of Cyliocyrtus, remains in existence or has been studied since Cook mentioned it in 1898, when no characters or illustrations were given that would preclude its being placed as a synonym of Cyrtodesmus. Since 1898, however, two species of Cyliocyrtus have been described, C. ocreatus Loomis (1934) and C. ramosus Kraus (1955), the latter species here transferred to Cyrtodesmus and not congeneric with ocreatus or with Trigonostylus spinosus and T. crassisetis Brolemann (1898a), which were transferred to Cyliocyrtus by Loomis (1937). If that genus is not maintained the three last-named species must be placed in another genus.

The other synonyms proposed above, under Cyrtodesmus, were determined on the form of the gonopods.

Descriptive remarks. - As the genus Cyrtodesmus is now constituted, the principal distinguishing characters are the very distinctly dendritic seminal branch (telopodite) of the gonopod, and the coxal joint which usually is continued at its inner distal limit into a prominent lobe. Dorsal sculpture, vestiture, shape of segments at the extremities of the body and conspicuousness of the pores and pore tubercles are subject to great variation and constitute specific rather than generic characters. 


\section{Cyrtodesmus velutinus (Gervais and Goudot). Figures 2, S-U;} 3 , A.

Polydesmus velutinus Gervais and Goudot, 1844, Bull. Ent. Soc. France, (2nd ser.), 2, p. 28.

Cyrtodesmus velutinus Gervais, 1847, Apteres, 4, p. 93, illus.

Holotype. ${ }^{1-}$-Male, British Museum, 42-20, received from Goudot and preserved as a pinned dry specimen; it is now relaxed and has been placed in spirit.

Description.-Length ca. $21 \mathrm{~mm}$., width ca. $4 \mathrm{~mm}$. Vertex of head and metazonites dark brown; antennae and ends of legs distinctly pinkish; frons, prozonites, sternites and legs whitish.

Head small, enclosed by the paranota of segment 2; vertex roughened and pigmented; lower part of face smooth and testaceous; a distinct interantennal groove present; clypeus and labrum produced ventrad (à la Polydesmus), the latter broad and truncate; front of head sparsely setose, labrum tridentate. Antennae large, widely spaced, the interantennal isthmus equal to length of article 3 ; article 5 much the longest and largest, 6 and 7 smaller and quite short; 4 sensory cones; no other sensory areas detected; the antennae geniculate between articles 3 and 4 and 4 and 5 .

Body segments with metazonites arched, paranota depressed; surface of dorsum densely and finely granulate, each granule with a long erect white hair. Interzonal furrow very broad and deep, sloped abruptly down from the surface of the metazonite, rising more gradually up to the level of the prozonites; the latter smooth, white, finely shagreened. Collum small, about as wide as the head, included by paranota of segment 2, mostly quite flat except for the lateral ends, which are abruptly turned down; anterior edge straight and transverse. Paranota of segment 2 broadly flabellate (fig. $2, \mathrm{~S}$ ), rounded, the posterior margin with 3 deep incisions on each side. Paranota of segments 3-5 acutely triangular, the anterior edge cut back, the tip rounded, the posterior edge with two incisions, none of the edges rimmed. Ozopores (fig. $2, \mathrm{~T}$ ) on large erect tubercles in the center of each poriferous paranotum, opening through a clear bulbous tip of the tubercle. Pore formula normal. Tubercles smaller posteriorly and more depressed, those of segment 19 hardly evident. Lateral edge of mid-body segments bilobed. Paranota smaller and more depressed caudad, those of segment 19 very small acute lobes. Segment 20 small, the epiproct very blunt, with 2 large paramedian terminal tubercles and a large lateral tubercle on each side. Paraprocts large, flat, rectangular, without basal lobes, with very weak mesial marginal ridges; discal seta near the center of each valve, the marginal seta in the upper mesal corner. Hypoproct flat, broadly triangular, no median projection, the paramedian tubercles very small.

Legs long and moderately slender, all of the tarsus projecting beyond the sides of the paranota when extended laterally; all joints only sparingly setose; length in decreasing order, 6-3-2-5-4-1.

The following information and description of this species are by Richard L. Hoffman and are quoted verbatim. The above indicated illustrations also were drawn by him from the holotype. 
Sterna distinct, a different color and texture from the pleurotergites, very narrow, the coxae in contact medianly but the two pairs of legs slightly separated by a transverse space; sternal surface flat; stigmata small, the posterior stigma of each pair smaller and more rounded, the anterior more elongate oval, both set flush on the surface (not auriculate). Interzonal furrow very narrow across the ventrum. Prozonites as long as the metazonite at the mid-ventral line. Sides of body very minutely granular, no hairs or other modification present. Sterna glabrous, not elevated above the level of the prozonites; anterior sternites and legs without processes or modifications.

Gonopod aperture very large, oval, extending laterally beyond coxal sockets of 9 th legs, the anterior edge of the socket set off by a distinct groove (continuation of the interzonal furrow), preceded by a parallel elevated ridge. Coxae very large, in contact medially, with a large projection which extends beyond the gonopod aperture; distally produced into a long slender coxal process (fig. 2, U). Mesial face of coxae deeply concave, enveloping most of the telopodite; the latter with two distal branches; one long, slender, and distally bifid, the other subterminal, trifid, one of its branches carrying the seminal channel (fig. 3, A).

\section{KEY TO SPECIES OF CYRTODESMUS OF PANAMA}

1. Metazonites two distinct shades of brown; segment 1 fully exposed laterally, the keels of segment 2 not expanded forward or downward....... bicolor

Metazonites wholly dark; segment 1 usually partially hidden in lateral view by expanded keels of segment $2 \ldots \ldots \ldots \ldots \ldots \ldots \ldots \ldots \ldots \ldots \ldots \ldots \ldots \ldots \ldots \ldots \ldots \ldots$

2. Size small, males not over $4 \mathrm{~mm}$. long; segments without rows of primary tubercles; outer margin of keels not lobed ..............mundus

Size larger; dorsum with rows of primary tubercles on some segments; outer margin of keels with noticeable lobes....................

3. Primary tubercles with very conspicuous long macrosetae..... macrosetosus Macrosetae, if present, quite small and inconspicuous..............4

4. Segment 1 with six large and conspicuous tubercles immediately behind anterior margin; coxal joint of gonopod scarcely produced at distal limit.

depilis

Segment 1 with submarginal tubercles smaller or lacking; coxal joint of gonopod distally produced into a more or less prominent conic lobe.......5

5. Metazonites without dorsal hairs or spicules............... lyrapes

Metazonites with more or less evident dorsal vestiture ..........6

6. Primary tubercles of caudal segments confluent in high, thick ridges; metazonites heavily dirt-encrusted....................... confuentus

Primary tubercles of caudal segments separated; metazonites clean or lightly

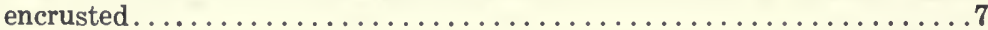

7. Posterior margin of segments with flattened, multispiculate, angular teeth. dentatus

Posterior margin of segments without conspicuous flattened teeth.......8

8. Segment 1 with 10 rounded tubercles along front margin......... coronatus Segment 1 with large tubercles fewer in number or lacking on front margin. .9

9. Last segment with a transparent hook each side of apex; telopodite of gonopod resembling a simple 2 -tined fork, tines nearly parallel, subequal in shape

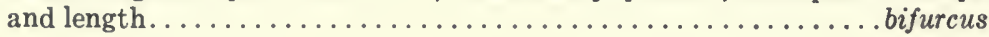


Last segment without terminal hooks; telopodite of gonopod with three or

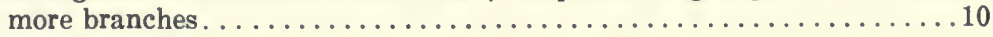

10. Segment 1 nearly semicircular; primary and secondary tubercles with an

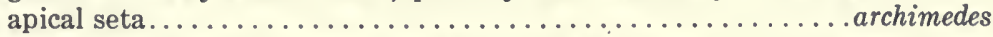

Segment 1 trapezoidal; dorsal surface of metazonites minutely hispidulous,

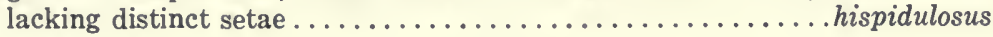

Cyrtodesmus archimedes (Chamberlin), new combination (=Oncodesmoides angulatus Loomis), new synonymy.

Peltedo archimedes Chamberlin, 1940, Bull. Univ. Utah, (9), 30, p. 9.

Oncodesmoides angulatus Loomis, 1961, Proc. U. S. Nat. Mus., (3454), 113, pp. 87-88, illus.

Localities.-Canal Zone: Several young, Barro Colorado Island, Jan. 1959, Berlese, from log debris.

Bocas del Toro Province: Almirante.

Cocle Province: El Valle.

Panama Province: Juan Dias.

Cyrtodesmus bicolor, new species. Figure 3, B-E.

Diagnosis.-Although this species shows a number of striking differences from other members of the genus it shares certain characters with them and, for the present, is placed here. Examination of males is needed to validate disposition. The species appears remotely related to $C$. lyrapes on the basis of dorsal sculpture and vestiture but is easily separated from it and other species by the coloration and form of segments 1 and 2 .

Description.-Body more loose-jointed and less capable of rolling compactly than other species; length $7 \mathrm{~mm}$., width $1.3 \mathrm{~mm}$.

Head in front of vertex, the prozonites and under surfaces uncolored; dorsum of metazonites bicolored with two tones of brown, darkest for a space including the lateral row of primary tubercles and a short distance below them and another area just beyond base of keels; color light brown at mid-dorsum, on the side adjacent to the keel, and on the outer portion of the keel itself.

Head with vertex medianly sulcate and coarsely granular, the anterior third less coarsely granular, lacking postantennal ridges, its anterior limit slightly higher than the front, which is depressed to the convexly raised clypeal area; side of head with a large conic elevation laterad of the socket, the two basal joints of the antennae lying in the depression behind it; antennae with joints 1-3 subequal in length and thickness, joint 4 as thick but shorter, joints 5 and 6 both broader and longer, the latter longest.

Segment 1 fully exposed from the side, the anterior margin reflexed (fig. 3, B), and with 10 prominent lobes as shown in figure $3, \mathrm{C}$; median surface behind the margin concave; posterior half of the segment with primary tubercles as shown; surface behind the raised margin coarsely granular. 
Segment 2 with lateral keels scarcely expanded, reaching only as low as the limits of segment 1 and with distinct anterior and posterior angles, the lateral margin 3-lobed; posterior margin with a prominent lobe set off on each side by a deep sinus; dorsum with four longitudinal rows of poorly defined primary tubercles, the two outer rows less conspicuous than the inner ones, scarcely more noticeable than adjacent granules; median rows separated by two rows of three or four granules each; similar primary and secondary tubercles continue to caudal end of body where the primary ones hardly increase in size. Prozonites considerably exposed, causing the loose-jointed appearance of the body, the surface of the anterior portion very minutely reticulated; interzonal constriction broad, deep, and much more coarsely reticulated. Metazonites raised sharply from the constriction; anterior margin across the dorsum with raised tubercles, the margin of the keel continuing as a raised rim; supplementary margin short, composed of sharply triangular serrations longer than their basal width; keels projecting from below middle of body (fig. $3, \mathrm{D}$ ); outer margin of segments $2-15$ or 16 with three lobes, segments 17,18 , and sometimes 16 , with four lobes; pores opening from the roughened midsurface of the outer portion of the keel, not on a special elevation.

Last segment as shown in figure $3, \mathrm{E}$; anal valves slightly convex, with broad, low inner margins; preanal scale broad, triangular.

Holotype.-Female, west of Finca Palo Santo, near Nueva California, Chiriquí Province, March 10, 1959, alt. 5000 ft., (B-457) concentrated forest floor litter in damp ravine.

Paratypes.-Three females, holotype locality, March 5, 1959, alt. $4750 \mathrm{ft}$. , (B-377) chips, etc., at base of cut stump; one young female, March 5, 1959, alt. $4700 \mathrm{ft}$. , (B-385) leaf debris in ravine; one female, March 9, 1959, alt. $4900 \mathrm{ft}$. , (B-433) forest floor debris in ravine.

Cyrtodesmus bifurcus, new species. Figure 3, F-I.

Diagnosis.-Obviously related to $C$. macrosetosus as shown by the shape and sculpturing of the body and the two translucent hooks at the end of the very short last segment. It differs in having the macro-

Fig. 3. A, Cyrtodesmus velutinus, left gonopod, mesal view.

B-E, Cyrtodesmus bicolor: B, segments 1-3, lateral view; C, segment 1, dorsal view; $\mathrm{D}$, segment 12 , posterior view; E, segments 19 and 20 , dorsal view.

F-I, Cyrtodesmus bifurcus: F, segment 1, dorsal view; G, segments 1-4, lateral view; $H$, keel of segment 5 , vertical view; $I$, distal portion of left gonopod, mesal view.

J-N, Cyrtodesmus confluentus: J, segment 1 , dorsal view; $K$, segments 2 and 3 , lateral view; $L$, segments $17-20$, lateral view; $M$, supplementary margin of metazonite; $N$, left gonopod, mesal view.

O-Q, Cyrtodesmus coronatus: $\mathrm{O}$, head and two segments, dorsal view; $\mathrm{P}$, segment 2, lateral view; $Q$, left gonopod, anterior view.

$\mathrm{R}-\mathrm{U}$, Cyrtodesmus dentatus. R, supplementary margin of metazonite; S, keel of segment 9 , vertical view; $T$, posterior end of body, ventral view; $U$, right gonopod, mesal view. 
setae reduced to short spicules; sides of segment 2 more expanded; keels more strongly shouldered in front where they join the dorsum; and in the bifurcate seminal branch of the gonopods.

Description.-Length of largest male (holotype) $5 \mathrm{~mm}$., width $1 \mathrm{~mm}$.; female slightly narrower because the lateral keels descend more sharply.

Head with vertex dark, evenly convex and finely roughened throughout, including the surface of a long narrow ridge, each side extending meso-caudally from the inner side of the antennal socket half way to segment 1 ; interval between the two ridges somewhat convex; vertex and front joined at same level but the clypeus convexly raised above the latter.

Segment 1 as shown in figure $3, F$, the anterior margin with six submedian crenations formed by large tubercles, each of which bears an apical spicule; margin laterad of outer tubercle broadly rounded; disk with a transverse row of four primary tubercles across middle and six similar ones in advance of posterior margin, each tubercle with a tiny apical spicule; surface elsewhere more or less distinctly granular, lacking any setae, spicules, or adherent deposit.

From segment 2-19 inclusive there are four distinct rows of three large conical, spicule-tipped, primary tubercles that become slightly larger on the posterior segments, the two median rows straight but on all but segments 2 and 3 the anterior tubercle of each outer row far below the other two (fig. 3, G); surface exclusive of primary tubercles more or less distinctly granular, lacking setae or any deposit. Segment 2 subequally convex across the dorsum, not angled or shouldered, the expanded keels continuous with it; segment widest between posterior corners of keels; anterior margin deeply and evenly concave from side to side, the posterior margin straight. On ensuing segments the keels of males wider and more outwardly flaring than those of females; keels strongly shouldered in front at junction with body (fig. 3, H); outer margin faintly bilobed on segments 3 and 4 but trilobed thereafter, a tiny spicule in each lobe; posterior margin with a large lobe at base, set off by open sinuses, the lobe strongly elevated behind; surface deeply depressed in front of outer sinus; pores evident on a small elevation near middle of outer half of keels. Penultimate segment with keels broad, not greatly produced backward, exceeded by the median pair of tubercles. Last segment very short, with a submedian pair of widely separated translucent hook-processes as in C. macrosetosus; margin laterad of each hook with a small seta-bearing tubercle and a still smaller one beyond. Anal valves flat with inner margins only slightly raised.

Gonopods as shown in figure 3, I.

Holotype.-Male, Almirante, Bocas del Toro Province, March 30, 1959, (B-676) forest floor litter.

Paratypes.-Two males, female, eight young, with holotype. Male with 18 segments, same locality, March 27, 1959, (B-635) forest floor litter.

Cyrtodesmus confluentus, new species. Figure 3, J-N.

Diagnosis.-Largest and most coarsely sculptured of the Panamanian species, with the tubercles of the submedian rows on the dor- 
sum of the posterior segments united into two high thick ridges; dorsum of segment 3 flat, the sides angularly shouldered; metazonites relatively more greatly raised above prozonites than in other species.

Description.-Diameter of body $3 \mathrm{~mm}$; color dark but mostly hidden by the very heavy deposit of dirt on the dorsal surface.

Head with vertex evenly convex, lacking a median depression, the surface strongly granular, anteriorly with two short ridges, very high and thick in front, narrowing and rapidly descending behind, the ridges close together, inwardly nearly parallel but tilting outward. Front slightly lower than vertex and separated from it by a slight depression; a sharp distinct tubercle on either side at the junction; surface laterad of each antenna raised into a large high prominence; front and clypeus not distinctly separated, both wrinkled-granular, evenly convex and rather finely hispid; clypeal area with eight macrosetae behind and six in front; lateral margin of head indentate at junction of clypeus and front.

Segment 1 (fig. 3, J) twice as wide as long; front margin smooth and continuous but tubercles of dorsum projecting above it, causing a crenate appearance; lateral and posterior margins together almost evenly rounded, crenate; dorsal surface swollen on either side of a rather sharp, narrow, median depression; surface sculpturing consisting of small to medium-sized tubercles, the larger ones on the two convex areas, surface of tubercles and intervening spaces, on all segments, with fine, short, dirt-retaining setae.

Segment 2 (fig. 3, K) with sides greatly expanded, hiding head and first segment in lateral view; sides almost vertical, flaring outward a little at lower posterior corners, a broad general concavity anterior to the upper sinus of the posterior margin; in vertical view the expanded sides are seen to be wider in front than where they meet the dorsum; lateral surface with small uniform tubercles partially hidden by dirt; dorsum between lateral shoulders nearly flat, swollen on either side near front.

Segment 3 also with square shoulders, the dorsum broad between them and quite flat, with two well-separated rows of large indefinite tubercles, three in each row; smaller indistinct tubercles scattered elsewhere; sides of dorsum nearly vertical to keels, which flare outward; outer limit of keels sharply rounded, becoming more rounded to segment 7 where three lobes begin to be evident and are more distinct thereafter; all keels thicker than in other Panamanian species, granular; pores indistinct, apparently borne on one of the central granules. After segment 3 the primary tubercles in the usual arrangement of three in a submedian row, two laterad of these, and one still farther laterad, the tubercles high and broadly rounded on most segments but becoming confluent and forming high thick ridges in the submedian rows of posterior segments (fig. $3, \mathrm{~L}$ ); in addition to primary tubercles, smaller distinct ones of variable size are present instead of the usual numerous granules of other species; surface of all tubercles apparently with tiny setae holding the organic incrustation; each primary tubercle also with an apical scar, possibly indicating where a macroseta had been; metazonites rising higher above prozonites than usual; supplementary margin of segments as shown in figure $3, \mathrm{M}$.

Last segment short, rather narrow and with three small marginal lobes each side of the small median one; lower lateral margin with a very small seta-bearing tubercle opposite the outer dorsal angle of each valve; valves slightly inflated, 
margins thinly raised; preanal scale triangular, the two seta-bearing tubercles contiguous, forming the apex of the scale.

Gonopods as shown in figure $3, \mathrm{~N}$.

Holotype.-Male, badly broken, Changuinola District, Bocas del Toro Province, May 21, 1924, J. C. Bradley, leg., "Cornell Univ. Lot 100." This specimen was received from U. S. National Museum and is deposited there as holotype No. 2801, in the myriapod collection.

Paratype.-Bocas del Toro Province: One female, Almirante, March 30, 1959, (B-676) forest floor litter.

Cyrtodesmus coronatus, new species. Figure 3, O-Q.

Diagnosis.-In the small group of species having a translucent bimucronate last segment and most closely resembling $C$. bifurcus, from which it differs in the slightly larger size; in the shape of segment 1 and its tuberculation; and in details of the gonopods.

Description.-Length of holotype male 4.5-5 mm., width 1.1-1.2 mm.; a mature female is slightly larger but an 18 -segmented female is $6.5 \mathrm{~mm}$. long.

Head with vertex finely roughened behind and slightly sulcate at middle; postantennal crests short, slightly converging behind, high, prominent and inclined outward in front but decreasing in size caudally; interval between crests narrow, flattened and rougher than surface elsewhere; space between antennae less than width of a socket; vertex and front meeting at same level, the clypeal area convexly raised.

Segment 1 semicircular (fig. 3, O), with 10 distinct rounded tubercles along front margin, a median row of four and a posterior row of six similar tubercles, all with an apical spicule; secondary tubercles small, distinct and quite uniform in size; disk not noticeably depressed at middle or especially convex on either side.

Segment 2 (fig. 3, P) with anterior margin deeply concave, posterior margin almost straight, a little concave; primary tubercles distinct, in two rows of three each on either side, four submarginal tubercles on the keels and one in front of the large outer posterior lobe, all primary tubercles on this and ensuing segments spicule-tipped; secondary tubercles less than half as large, distinct, and of quite uniform size; surface of all tubercles roughened but free of adhering matter; in one female tiny spicules present on some of the small tubercles, especially along the posterior margin; dorsum of segment 2 flattened between inner primary rows, and rather sharply angled along the outer primary row; the expanded keels subvertical, flaring outward slightly and widest between posterior corners. Ensuing segments with primary rows of tubercles well defined, those of the posterior segments hardly increased in size, the posterior four tubercles of segment 18 erect, but those of segment 19 strongly inclined backward beyond the margin; keels broad and rather narrow, flaring outward sharply from below the middle of the body, strongly shouldered at the body, the outer margin of all keels with three lobes; pores on small sharply elevated tubercles about equidistant from front, back and outer margins; keels of segment 19 small and hardly produced backward, much exceeded 
by the four primary tubercles; supplementary margin of segments composed of very closely placed, parallel-sided, apically rounded projections about twice as long as wide.

Last segment very short, little exceeding the tubercles of segment 19 ; surface rough but without prominent tubercles; posterior margin on either side of the rather broad median lobe with two broad lobes having apical setae as long as the two translucent hooks of the median lobe. Anal valves flattened, with tiny, slightly raised margins. Preanal scale triangular, over twice as wide as long and with two long subapical setae.

Gonopods as shown in figure $3, \mathbf{Q}$.

Holotype.-Male, Almirante, Bocas del Toro Province, March 27, 1959, (B-638) forest floor litter.

Paratypes.-Female and ten young of various ages, with holotype. Female, same locality, Apr. 1, 1959, (B-703) forest floor litter.

\section{Cyrtodesmus dentatus, new species. Figure 3, R-U.}

Diagnosis.-The sharply dentate posterior margin of the metazonites and restriction of primary tubercles to the posterior segments, in addition to peculiarities of the gonopods, mark this species.

Description.--Largest specimen (female) $2.6 \mathrm{~mm}$. wide and about $12 \mathrm{~mm}$. long; males a little smaller. Surface of body clean, without adherent material; color nearly black.

Holotype with head scarcely depressed at middle of vertex, lacking a distinct sulcus, anteriorly with the usual two strong ridges converging behind the antennae; surface between ridges flat, lacking tubercles as does median surface behind ridges; sides of vertex with small tubercles; vertex and front on same level but joined in a faint depression; front wrinkled and setose, surface laterad of each antenna raised into a thin transverse ridge; clypeus noticeably convex, smnoth, shining, crossed by a row of six large setae.

Segment 1 subtrapezoidal, anterior margin straight across, less than twice the median length; lateral margins strongly converging to the posterior margin, which is slightly convex and shorter than median length; dorsal surface convex on either side of a very shallow median depression, densely covered with small distinct subconical tubercles, the largest of which (4) are at the front margin with one or two near each anterior corner.

Segment 2 with keels shaped much as in other species but flaring outward strongly, especially at back corners, instead of being almost vertical, the distance between them being much greater than where the anterior lobes are separated by the posterior margin of segment 1; sides of segment with typical radiating nontubercular lines, the surface elsewhere with variable small tubercles; posterior margin of dorsum not noticeably emarginate, with six small projecting tubercles at middle, laterad of which larger ones extend to the base of the keels.

Surface of ensuing segments evenly scattered with small uniform conic tubercles each with one to three or four stiff erect setae near apex, setae longer than height of supporting tubercle; general surface, including tubercles, very finely 
granular and without large primary tubercles evident on anterior two-thirds of body but the position of such tubercles marked by a rather large seta, as in some related species; beginning on segment 15 , six primary tubercles of the two inner rows are weakly evident and increase in size thereafter, becoming quite conspicuous on segment 19, where each of the tubercles has three to nine short subapical setae and a somewhat longer macroseta; metazonites with posterior tubercles projecting beyond posterior margin as conspicuous flattened angular teeth; supplementary margin as shown in figure $3, \mathrm{R}$. Lateral keels broad (fig. $3, \mathrm{~S}$ ), with a single deep sinus in the back margin well away from the side of the body; pores small and very inconspicuous, opening from the surface.

Last segment broad and long (fig. 3, T), considerably exceeding the keels of segment 19; surface with medium and small tubercles, the largest near the middle of the dorsum anteriorly; marginal setose lobes and tubercles as shown; anal valves quite convex, with strong raised margins.

Gonopod as shown in figure $3, \mathrm{U}$; in situ the coxal joints more noticeably flattened than in other species.

Holotype.-Male, Finca Lerida, near Boquete, Chiriquí Province, March 17, 1959, alt. $7800 \mathrm{ft.}$, (B-524) forest litter.

Paratypes.-Bocas del Toro Province: Male, two females, Almirante, March 27, 1959, (B-638) forest floor litter; female, March 30, 1959, (B-676) forest floor litter.

Chiriquí Province: Male, female, three young, Finca Lerida, El Velo Forest area, March 12, 1959, alt. 5600-5650 ft., H. S. Dybas and A. Solem, leg.

Cyrtodesmus depilis, new species. Figure 4, A-D.

Diagnosis.-Distinguished by the lack of dorsal vestiture, the large tubercles at front of segment 1 , the lack of primary rows of tubercles on anterior segments, and various features of the gonopods.

Description.-Length of male about $8 \mathrm{~mm}$., width $1.7 \mathrm{~mm}$.; female very little larger; body segments lacking setae or spicules, except on last one, the surface of tubercles and intervening spaces minutely shagreened and free of dirt.

Fig. 4. A-D, Cyrtodesmus depilis: A, segment 1, dorsal view; B, segment 2, lateral view; C, last segment, dorsal view; $D$, right gonopod, lateral view.

E-H, Cyrtodesmus hispidulosus: E, segments 1-4, lateral view; F, caudal end of body, ventral view; $G$, left gonopod, mesal view; $H$, sternum and coxae of eighth legs of male, posterior view.

I, Cyrtodesmus lyrapes: gonopods.

$\mathrm{J}-\mathrm{N}$, Cyrtodesmus macrosetosus: J, segment 1 , dorsal view; $\mathrm{K}$, segments 2 and 3 , lateral view; L, supplementary margin of metazonite; M, segments 19 and 20 , dorsal view; $\mathrm{N}$, left gonopod, mesal view.

$\mathrm{O}-\mathrm{U}$, Cyrtodesmus mundus: $\mathrm{O}$, segment 1, dorsal view; $\mathrm{P}$, segments 1 and 2 , lateral view; $Q$, segment 6, posterior view; $R$, outer portion of segment 15 , vertical view; $\mathrm{S}$, supplementary margin of metazonite; $\mathrm{T}$, segments 19 and 20 , dorsal view; U, left gonopod, mesal view. 

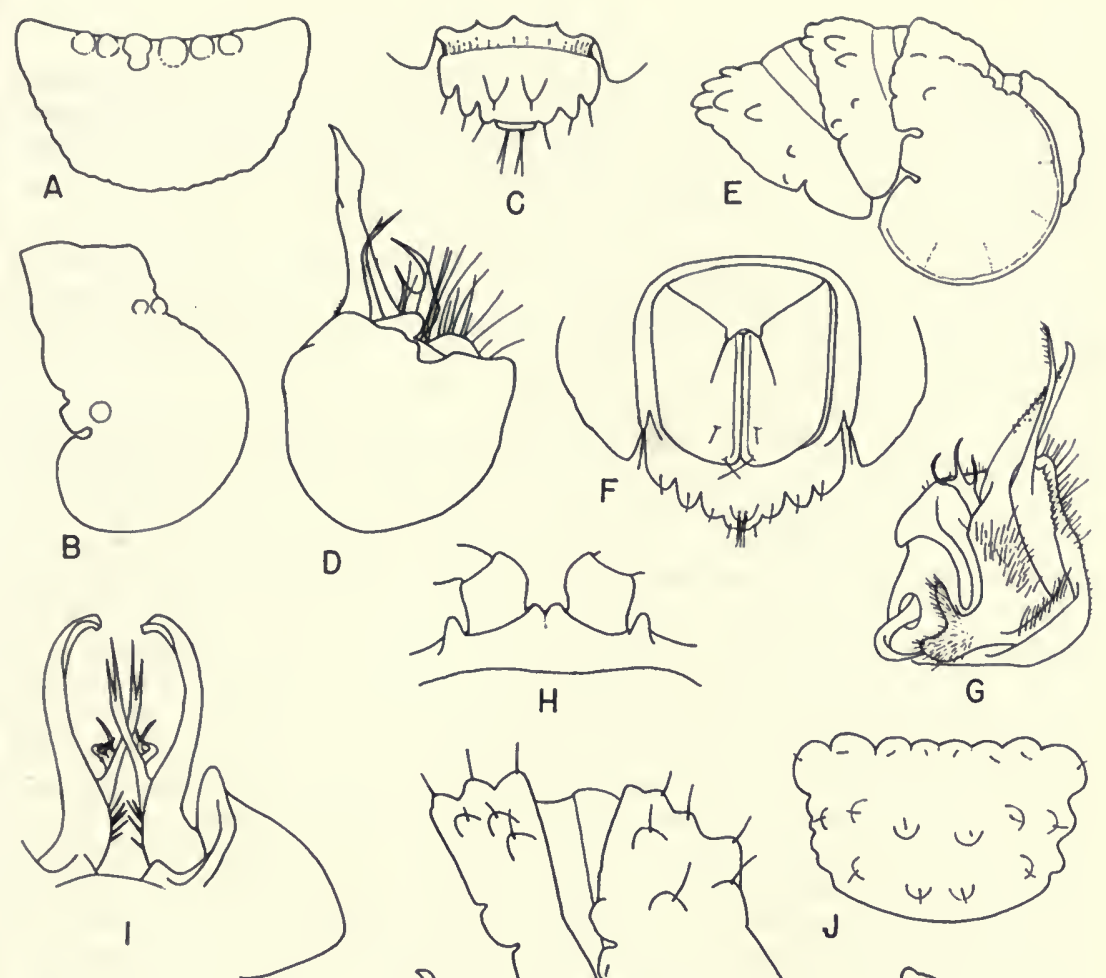

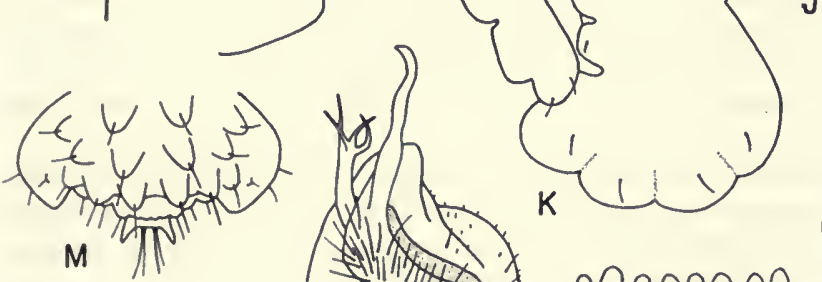

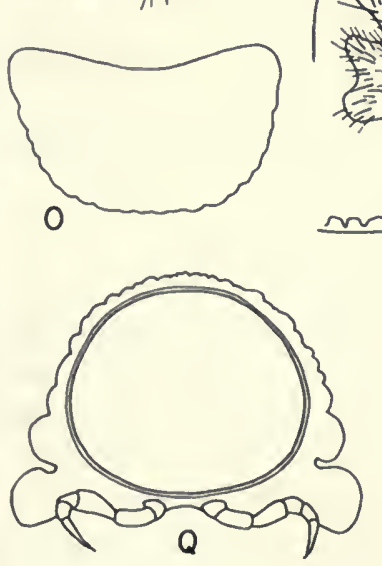
$\frac{\mathrm{n} n \mathrm{nnman}}{\mathrm{L}} \mathrm{P}$
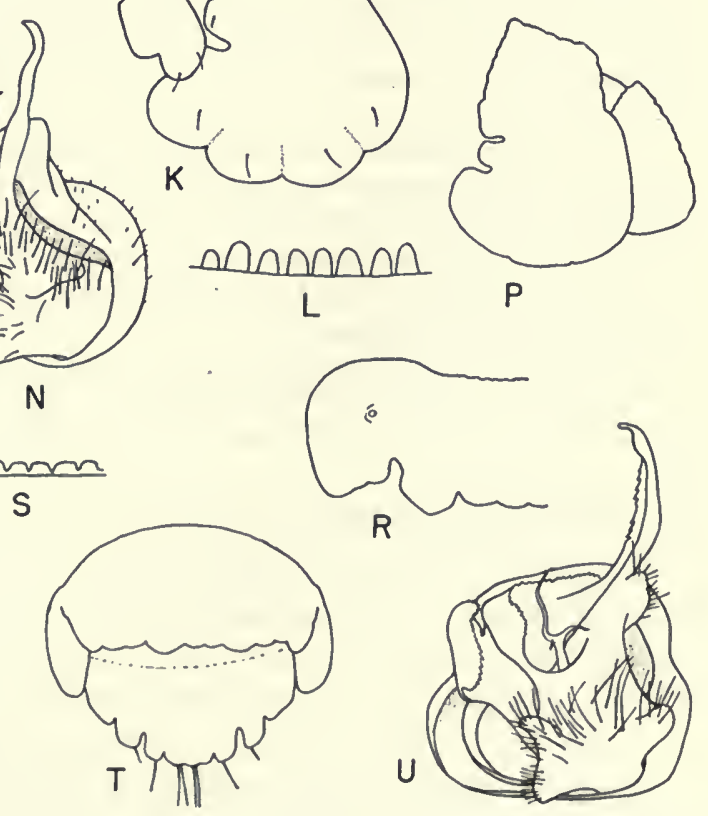
Head lightly sulcate on crest of vertex, the two postantennal ridges small, inconspicuous, extending scarcely more than a fourth of the way to segment 1 and barely convergent, the space between them slightly concave; surface and that of remainder of vertex very finely granular; vertex descending abruptly between the antennae to the front; clypeal area moderately convex.

Segment 1 (fig. 4, A) with six prominent rounded tubercles, several times as large as any behind them, along anterior margin; other tubercles strongly conic, of various sizes intermixed, with none of the larger ones in transverse rows; disk convexly raised on either side of median line.

Segment 2 with sides considerably expanded (fig. 4, B), front margin strongly concave to keel on either side; upper edge of keel extending forward and outward in a nearly straight line, as seen from above; posterior margin broadly convex; dorsum flattened, a little depressed in front of middle, sides rather angular above keels, which descend almost vertically but are slightly wider between posterior corners; mid-dorsum with uniform small distinct granules or tubercles, the angular sides scattered with considerably larger ones of different sizes; tubercles on keels smaller except for two at the anterior base and one in front of the large posterior lobe. On ensuing segments the anterior half of prozonite white, the posterior half dark as is the rather short, abruptly concave constriction and the metazonite; tubercles on dorsum of metazonite sharply defined, of different sizes, none in rows until after segment 13 or 14 where a submedian pair of rows of three tubercles each is discernible, their size increasing slightly on last segments; no outer row of primary tubercles evident on any segment, although one or two large tubercles may be found in that location; keels strongly shouldered anteriorly at body, those of segments 3 and 4 short, with outer margin 2-lobed; segments thereafter with keels longer, rather narrow, outer margin 3-lobed; keels projecting sharply outward and downward from below middle of body; pores opening from a rather large, sharply rounded tubercle at posterior third, just distolaterad of the outer sinus in the back margin.

Last segment (fig. 4, C) rather short, broad and only slightly convex transversely, the dorsum with two large conical seta-tipped tubercles. Anal valves moderately convex, the inner margins narrowly raised. Preanal scale elongatetriangular, two small marginal seta-tipped tubercles near apex.

Gonopod (fig. 4, D) with coxal joint scarcely produced at inner apex, not forming the usual pronounced lobe.

Holotype.-Male, Finca Lerida, near Boquete, Chiriquí Province, March 16, 1959, alt. 7200 ft., G. A. Solem, leg.

\section{Cyrtodesmus hispidulosus, new species. Figure 4, E-H.}

Diagnosis.-The very finely hispidulous surface of the dorsal tubercles and the lack of macrosetae; the broad first segment; and the strongly emarginate posterior median margin of segment 2 , in addition to differences of the gonopods, readily distinguish this species.

Description.-Holotype $13 \mathrm{~mm}$. long, $3 \mathrm{~mm}$. wide; color almost black.

Head with vertex very finely granular, a fine shallow median sulcus in its crest; a granular ridge, highest in front, extends mesocaudad above each antenna; sur- 
face between the two ridges rather sharply raised at middle; surface laterad of each antenna raised into an oblique ridge; front joining vertex at a lower level, irregularly wrinkled crosswise and setose with the shortest setae behind; clypeus crossed by a row of six strong setae; sides of head strongly divergent in front.

Segment 1 broadly trapezoidal, nearly twice as wide as long across the front but only half as wide behind; lateral margins converging sharply backward; surface densely covered by well-defined high rounded tubercles of various sizes, the largest on the back portion of the convex surface each side of the posterior twothirds of disk, the intervening median depression broadly concave; dorsal tubercles projecting slightly over all margins except at anterior corners where the margin is smooth and continuous for a short distance laterally and a longer distance in front.

Segments 1-4 as shown in figure 4, E, the secondary tubercles not drawn; dorsally the posterior margin of segment 2 strongly emarginate, that of segments 3 and 4 decreasingly so and that of segment 5 straight. Each segment from 4 to 19 with a submedian row of three large primary tubercles on each side; somewhat laterad of the last two of these tubercles is a pair of smaller ones with another tubercle still farther laterad, closer to the anterior margin. Segment 3 with only the three outer tubercles strongly developed. All segments with numerous small secondary tubercles, and the surface, including primary tubercles, minutely hispidulous, almost to be classed as shagreened, but matted with dirt; no macrosetae present; supplementary margin much as in C. dentatus. Lateral keels flaring outward abruptly from sides of dorsum; outer margins distinctly 3-lobed; surface with secondary tubercles dense and distinct on outer half but smaller and reduced in number basally; pores opening from a rather large tubercle near middle of outer portion of keels. Segment 19 with keels strongly produced backward (fig. 4, F). Segment 20 broad and much exposed; dorsal surface finely granular-tubercular with an anterior row of large tubercles and two still larger ones farther back; ventrally a slender conic tubercle, with a long seta, located near outer apical angle of each valve; posterior margin each side of papillate apex with three distinct lobes, each with a ventral seta; anal valves and preanal scale as shown.

Coxae of gonopods touching at apex but their inner margins emarginate, exposing part of basal portion of outer joints, the two slender divisions of which project beyond each coxa; a small triangular lobe on posterior margin of gonopodial opening extends forward and separates the coxae at base. Inner view of gonopod shown in figure 4, G. Sternum of pair of legs behind the gonopods elevated and with a pair of tubercles separating the coxae; another tubercle laterad of each coxa (fig. $4, \mathrm{H}$ ).

Holotype.-Male, Finca Palo Santo, near Nueva California, Chiriquí Province, March 9, 1959, alt. 4900 ft., G. A. Solem, leg.

Paratypes.-Chiriquí Province: Young male and female, 9.7 road miles south of El Volcan, March 10, 1959, alt. 2750 ft., G. A. Solem, leg.; three 19-segmented young, Finca Lerida, near Boquete, March 17, 1959, alt. $7800 \mathrm{ft} .$, (B-524) forest litter.

Cyrtodesmus lyrapes, new species. Figure 4, I.

Diagnosis.-Related to $C$. bifurcus as shown by the gonopods and many features of the body but differing in the smaller primary tuber- 
cles, lack of dorsal vestiture, and less strongly shouldered lateral keels.

Description.-Body $5 \mathrm{~mm}$. long, $1 \mathrm{~mm}$. wide; dorsum without macrosetae, pubescence or spicules.

Head similar to that of bifurcus except that the two postantennal ridges are each composed of three or four more or less confluent tubercles, are shorter, and meet at a point less than half way to segment 1, the interval between them flat and finely roughened as is the remainder of the vertex.

Segment 1 shaped as in bifurcus and with six large tubercles along the midmargin; remainder of surface quite coarsely granular with no larger primary tubercles present. Segment 2 with mid-dorsum somewhat flattened, more strongly convex each side but not definitely shouldered; primary tubercles of the four rows small, rounded and rather inconspicuous, the surface elsewhere rather coarsely granular; anterior margin convex between the keels, the posterior margin straight; keels shaped much as in bifurcus but the margin more continuous, the posterior lobe less evident, and posterior corners not as widely separated. Ensuing segments with primary tubercles a little more evident, and on the caudal segments they become larger and more conical; surface of segments elsewhere rather coarsely granular, especially on the keels; keels narrower, longer and somewhat more descending than in bifurcus, the anterior shoulders less pronounced and the outer margins less strongly lobed; sub-basal posterior lobes not conspicuously elevated behind, the surface in front of the outer sinus not strongly depressed; pores as in bifurcus. Penultimate segment much as in bifurcus, the lateral keels not greatly produced backward, considerably exceeded by the median margin with its four strongly projecting conic primary tubercles.

Last segment a little larger than in bifurcus but with similar apical hooks, the margin on either side with two subequal tubercles. Anal valves slightly convex, the margins raised and shining.

Gonopods as shown in figure $4, \mathrm{I}$.

Holotype.-Male, Almirante, Bocas del Toro Province, Apr. 1, 1959, (B-703) forest floor litter.

Paratypes.-Five very young, with holotype.

Chiriquí Province: Female with 19 segments, road west of Finca Palo Santo, near Nueva California, March 5, 1959, alt. $4700 \mathrm{ft}$., (B-385) leaf debris in ravine.

Cyrtodesmus macrosetosus, new species. Figure 4, J-N.

Diagnosis.- The large macrosetae of the segments and the moderate expansion of the sides of segment 2 , and the very short last segment with bilobed papillate apex outwardly distinguish this species from all others.

Description.-Size medium, males smaller than females; holotype $6.5 \mathrm{~mm}$. long, $1.7 \mathrm{~mm}$. wide; female $8 \mathrm{~mm}$. long, $2 \mathrm{~mm}$. wide; color dark as in other species.

Head with a broad shallow median depression on crest of vertex; two low slightly converging ridges behind the antennae, the surface between them flat, 
finely granular as is the surface elsewhere, including the ridges; vertex and front joined at same level, the front slightly wrinkled and finely setose; each side of head with a ridge laterad of the antenna; clypeus a little raised above the front, convex, with 6-8 long setae behind and six in front.

Segment 1 (fig. 4, J) with rounded seta-bearing tubercles forming crenations on the anterior margin between the large rounded outer corners; lateral margins converging backward a little and with 3-5 crenations that are less evident in females; posterior margin broadly rounded, smooth; surface swollen on either side of a broad indefinite median depression, each side with five large seta-bearing tubercles; entire surface finely granular, including tubercles.

Segment 2 (fig. $4, \mathrm{~K}$ ) with keels less expanded than in other species but widely spreading anteriorly; lower sides flaring outward, the segment much wider between lower posterior corners than in front; anterior margin between keels with four deeply but narrowly separated crenations, each with a central tubercle; posterior margin straight and continuous; lateral margin with four crenations, a long seta in the center of each; dorsal surface each side with three large tubercles near the middle, two laterad of them and another still farther laterad, each with a strong macroseta; median area of keels strongly depressed; entire surface of this and ensuing segments with granules as on segment 1 . Segments 3 and 4 with outer margin of keels bilobed, succeeding keels usually trilobed, at times bilobed without reference to pores, the lobes containing a large seta; keels somewhat narrower and not as greatly depressed as in other Panama species, the large sinus of the posterior margin near the body; pores large, in front and slightly ectad of sinus, opening from the surface with a small seta-bearing tubercle well laterad of pore; dorsum of segments with six large tubercles, each surmounted by a strong seta, the tubercles somewhat larger on caudal segments; posterior margin of segments irregular but not definitely crenate; supplementary margin (fig. 4, L) short, elements apically rounded. Segment 19 (fig. 4, M) with posterior tubercles projecting over back margin between the short, widely separated keels. Last segment wide but very short and almost hidden by segment 19 , three small lobes on either side of the broad median one covering the papillate apex, on either side of which is a sharply conical, translucent and slightly deflexed mucro; each side of segment with a small marginal seta-bearing tubercle below, nearly opposite middle of valve; anal valves slightly inflated, the margins narrowly raised; preanal scale broadly triangular, the tubercle each side small and close to apex.

Gonopods as shown in figure $4, \mathrm{~N}$.

Holotype.-Male, Finca Lerida, near Boquete, Chiriquí Province, March 17, 1959, alt. 7800 ft., (B-524) forest litter.

Paratypes.-Chiriquí Province: Male, female, with holotype. Female, three young, March 17, 1959, alt. $7750 \mathrm{ft}$., (B-526) forest floor litter; male, two young, March 18, 1959, alt. $6900 \mathrm{ft}$. , (B-543) floor debris in deep ravine, "Casita Alta," Finca Lerida.

Cyrtodesmus mundus, new species. Figure 4, O-U.

Diagnosis.-The smallest member of the genus, with lower and narrower keels, the outer margins lacking obvious lobes; segments 
without large tubercles but with uniform small ones; surface clean, without adhering dirt.

Description.-Holotype $4 \mathrm{~mm}$. long, .7 mm. wide.

Head with vertex very finely granular, a slight median depression on crest, front of vertex with two short, thin, slightly divergent ridges close together, each ridge caudoectad of an antenna, the surface laterad of each antenna not specially raised; side margin of head broadly emarginate where clypeus and front join; front meeting vertex at a lower level between antennae, its surface transversely wrinkled and hispid; clypeus more convex than the front, shining, with a row of 6-8 macrosetae behind and about six in front. Antennae considerably closer together than the diameter of a socket.

Segment 1 (fig. 4, O) large, anterior margin broadly concave, smooth, with tubercles rising immediately above it but not projecting as faint crenations like those along the lateral and posterior margins; dorsum quite evenly convex from side to side with almost no indication of a median depression; surface evenly scattered with small, distinct, subequal, conic tubercles bearing very tiny setae, a few tubercles with a slightly larger central seta.

Segment 2 (fig. $4, \mathrm{P}$ ) with anterior lateral margin expanded forward only a little, exposing much of segment 1 from the side; keels almost vertical and nearly parallel, scarcely wider behind, the lower angles not flaring outward; dorsum convex from side to side and without a ridge along either side at junction of the keel; surface with small, distinct tubercles as on segment 1 and the other segments, and not incrusted with dirt. Segment 3 with outer margin of keels rather broadly rounded, becoming more so on succeeding segments, none of which has outer lobes visible in holotype but slightly so in some other specimens; all keels low on the sides of the very convex dorsum (fig. 4, Q), narrower than their length, projecting obliquely outward, the posterior margin separated from the body by a deep, wide sinus, mesad of which there is a large projecting lobe (fig. $4, R$ ); supplementary margin of segments as shown in figure 4, S; pore near center of keel on a slight elevation. Dorsal sculpturing of segments 19 and 20 a little coarser than on other segments but with no indication of primary tubercles in distinct rows; segment 19 with keels narrow, rather sharply rounded behind; segment 20 (fig. 4, T) large, exposed and much exceeding segment 19 , strongly convex, broadly rounded behind with three lobes laterad of the wide apical one.

Gonopods as shown in figure $4, \mathrm{U}$.

Holotype.-Male, Finca Lerida, near Boquete, Chiriquí Province, March 17, 1959, alt. 7800 ft., (B-524) forest litter.

Paratypes.-Chiriquí Province: Male, female, with holotype. Male, March 14, 1959, (B-488) floor litter and chips, logging area; female, March 14, 1959, (B-489) litter and chips at base of cut stump; male, female, March 15, 1959, "Barca area," Finca Lerida, alt. $5650 \mathrm{ft}$. Male, several young, "Casita Alta," Finca Lerida, March 18, 1959 , alt. $6900 \mathrm{ft}$. , (B-543) floor debris in deep ravine.

In addition to the foregoing species, the genus Cyrtodesmus appears to include the following; none is native to Panama and all are presented as new combinations. 
Cyrtodesmus (Oncodesmus) tomentosus, C. (O.) festae, C. (O.) laciniatus (Silvestri, 1898a); C. (O.) promaculatus (Silvestri, 1898b); $C$. (Trigonostylus) niger (Carl, 1914); C. (Oncodesmoides) rectus, C. (O.) uncinatus (Kraus, 1954); C. (Cyliocyrtus) ramosus (Kraus, 1955); C. (Oncodesmoides) weyrauchi (Kraus, 1957); C. (Oncodesmoides) bicarinatus, C. (O.) yamaquizu, C. (O.) pustuliferus (Kraus, 1960).

\section{Family DORSOPORIDAE}

\section{DORSOPORUS Loomis}

Dorsoporus Loomis, 1958, Jour. Washington Acad. Sci., 48, p. 236, illus.

\section{Dorsoporus barroensis Loomis}

Dorsoporus barroensis Loomis, 1958, Jour. Washington Acad. Sci., 48, p. 237, illus.

Locality.-Canal Zone: Barro Colorado Island.

Known only from three original specimens and a female collected on the island by C. W. and M. E. Rettenmeyer, in 1956.

\section{Family EURYURIDAE}

\section{KEY TO GENERA OF EURYURIDAE OF PANAMA}

1. Outer branch of gonopod expanded and twisted on base, the seminal canal shielded by the expanded portion................... phelidesmus

Outer branch of gonopod not greatly twisted, seldom broadened, the seminal

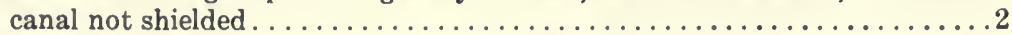

2. Head without prominent subantennal swellings............. Pycnotropis Head with prominent subantennal swellings............ Seminellogon

\section{APHELIDESMUS Brolemann}

Aphelidesmus Brolemann, 1898, Ann. Soc. Ent. France, 67, p. 266, illus. Trachelorachis Silvestri, 1898, Boll. Mus. Zool. Torino, (324), 13, p. 5, illus. Trachelacanthe Berg, 1899, Comun. Mus. Nat. Buenos Aires, (3), 1, p. 77.

Aphelidesmus taurinus, new species. Figure 5, A-B.

Diagnosis.-Size of body, coloration, and proportions as in the Costa Rican $A$. calverti Chamberlin (1914) but obviously differing in the ventral sculpturing of the metazonites, shape of last segment, and gonopods. 
Description.-Male $29 \mathrm{~mm}$. long, $4 \mathrm{~mm}$. wide; largest female $31 \mathrm{~mm}$. long, $4.2 \mathrm{~mm}$. wide; basal joints of antennae, legs and first segment colorless, the segments thereafter with interzonal constriction dark brown and more extensive on prozonites than metazonites where only a third of the dorsum between the keels is brown; keels and posterior two-thirds of metazonites uncolored; head with vertex and front dark, clypeal area lighter.

Head smooth and shining, median furrow of vertex strong; front with a round convex area extending half way up between antennae, a pair of setae at its upper third, another more widely separated pair in front of swelling; six setae on clypeus and 16-20 smaller ones on labrum.

Segment 1 as wide as segment 2 , with a raised rim continuous along anterior margin, narrowly rounded sides and half way up posterior margin. Ensuing segments with dorsum very strongly convex, smooth and shining, the interzonal constriction deep, sharply defined, crossed by numerous faint striations; lateral keels continuous with dorsum, narrow, those of segments 2-4 and sometimes segment 5 with a blunt projection at anterior corner; posterior corners of segments 4-18 moderately and equally produced backward, the corners of segment 19 half as large; outer margin of poriferous keels with posterior half thickened, double that of poreless keels. Sides of metazonites below keels densely and finely tuberculate, the tubercles more concentrated near posterior margin, all tubercles less abundant on caudal half of body. Last segment with produced portion large, its sides converging caudally; apex broadly rounded, medianly indented (fig. 5, A). Anal valves strongly convex; inner margins thickened, shining. Preanal scale large, less than twice as wide as long; apex broadly rounded.

Gonopods as shown in figure 5, B. Both sexes with a small rounded-conic tubercle caudomesad of each coxa on sternum.

Holotype.-Male, Almirante, Bocas del Toro Province, March 30, 1959.

Paratypes.-Two females, with holotype.

\section{PYGNOTROPIS Carl}

Pycnotropis Carl, 1914, Mem. Soc. Sci. Nat. Neuchatel, 5, p. 932, illus.

Amydrinus Chamberlin, 1941, Bull. American Mus. Nat. Hist., 78, p. 500, illus.

Frg. 5. A-B, Aphelidesmus taurinus: A, last segment, dorsal view; B, left gonopod, ventral view.

C-E, Seminellogon magnus: C, lateral keels of segments 14 and 15, dorsal view; D, left gonopod, mesal view; E, left gonopod, posterior view.

F-K, Lignydesmus projectus: F, head and first two segments, anterior view; G, segments 1 and 2, lateral view; $H$, segments 19 and 20 , vertical view; $I$, caudal end of body, ventral view; $J$, outer joint of right gonopod, ventral view; $K$, apex of outer joint of left gonopod of paratype, ventral view.

L-N, Nyssodesmus concolor: L, keel of segment 15, dorsal view; M, left gonopod, lateral view; $\mathrm{N}$, left gonopod, mesal view.

O-R, Platyrhacus gracilipes: $\mathrm{O}$, segment 1 , dorsal view; $\mathrm{P}$, keel of segment 10 , dorsal view; $Q$, preanal scale; $R$, right gonopod, ventral view. 

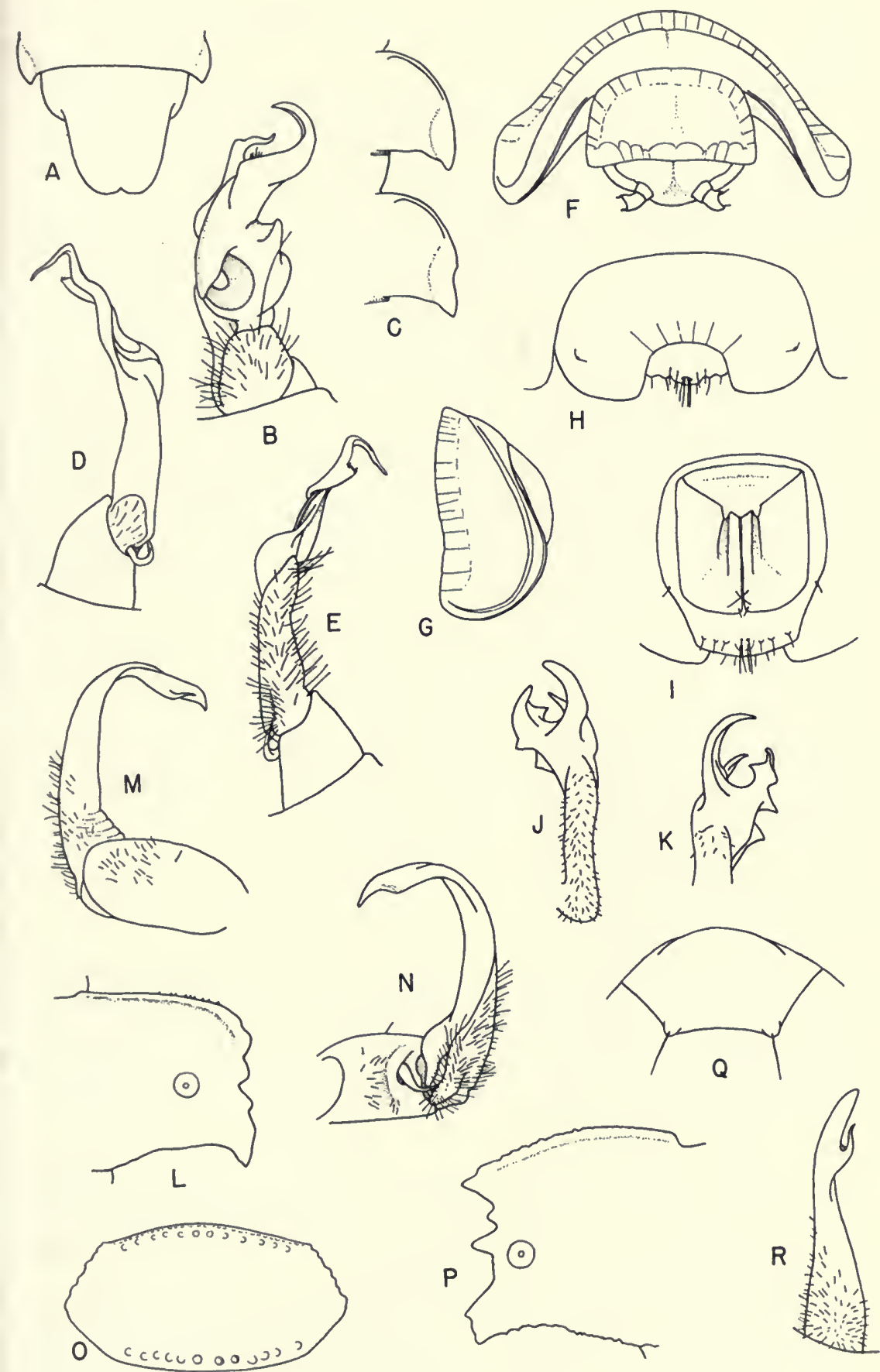


\section{Pycnotropis latzeli Attems}

Pycnotropis latzeli Attems, 1931, Zoologica, (Lief. 3-4), 30, p. 79, illus.

Locality.-Panama.

\section{SEMINELLOGON Chamberlin}

Seminellogon Chamberlin, 1923, Pan-Pacific Ent., 9, p. 13, illus.

Sigmogonotropis Hoffman, 1951, Proc. U. S. Nat. Mus., 102, p. 240, illus.

\section{KEY TO SPECIES OF SEMINELLOGON OF PANAMA}

1. Size large, body about $65 \mathrm{~mm}$. long. . . . . . . . . . . . magnus Body considerably less than $65 \mathrm{~mm}$. long. . . . . . . . . . . . . .

2. Longest branch of gonopods tridentate on edge just below apex...... serratus Longest branch of gonopods with edges smooth just below apex ........3

3. Longest branch of gonopods slenderly acuminate at apex.......cerroazulensis Longest branch of gonopods broader at apex with two or three terminal

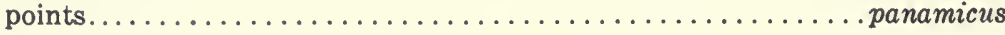

\section{Seminellogon cerroazulensis Hoffman}

Seminellogon cerroazulensis Hoff man, 1954, Jour. Washington Acad. Sci., (2), 44, pp. 54-55, illus.

Localities.-Cocle Province: Female, El Valle, Las Minas trail, alt. 2750 ft., Feb. 23, 1959, A. Solem, leg.

Panama Province: Two males, three females, Cerro Azul, near "Goofy" Lake, Feb. 6, 1959, A. Solem, leg.

Seminellogon magnus, new species. Figure 5, C-E.

Diagnosis. - The serrate subterminal flange on the outer side of the principal branch of the gonopod indicates relationship with S. serratus (Hoffman,) but the species is distinguished by other features of the gonopods. It differs from all other species in the larger size, the somewhat roughened dorsum and the prominent tubercles near the back margin of the metazonites below the keels.

Description.-Male $65 \mathrm{~mm}$. long, $9 \mathrm{~mm}$. wide. Head dark brown throughout; segment 1 brown except at outer angles and along mid-dorsum which is narrowly lighter in front but much wider behind; on following segments the basal half of the keels and the sides of dorsum narrowly dark brown, the median portion of both zones colorless but with a narrow light brown line.

Head smooth and shining, vertex with a sharply impressed median sulcus, the surface on either side of its front half strongly and evenly inflated; front medianly convex beginning between the antennae, a pair of widely separated setae at lower level of antennal sockets; six large setae on clypeus, and 12-16 small ones at front 
of labrum; in front and outside of each antenna the surface raised obliquely. Antennae with joints 2-6 about equally long and thick.

Segment 1 smooth and shining except for a few very fine lines; segments thereafter gradually rougher and from segment 5-19 the surface evenly but sharply impressed with fine short crooked lines but somewhat shining; anterior metazonites coarsely tuberculate below keels with rounded to sharply conical tubercles, the largest low on the sides near the back margin; on posterior segments the tubercles present only near the back margin.

Segment 1 with a complete anterior raised rim terminating at the posterior margin behind the sharply rounded outer limits; anterior margin concave mesad of each outer angle, the posterior margin strongly triarcuate, with median portion broadly concave, either side convex. Segments 2-4 with anterior corners slightly projecting laterad, broadly rounded and with no tooth indicated. Dorsum of all segments strongly convex; keels broad, projecting almost horizontally from near middle of body, those behind segment 6 or 7 somewhat caudally bent, the anterior corners increasingly more broadly rounded, the posterior ones acute and subequally exceeding the mid-dorsal margin; margin of keels rimmed along front and anterior half of lateral margin, the posterior half thickened, doubly so in lateral view on those with pores; pores opening laterally from an impressed area (fig. 5, C). Last segment large, broader near the truncate-rounded apex than across base; anal scale almost semicircular, surface evenly convex; inner margins of valves thick, shining.

Coxae of gonopods separated by a thick sternite, twice as wide as long and broader in front, rounded behind; surface irregularly coarsely wrinkled; coxae slender, the outer joints rising straight from their distal ends, each outer joint slender with the seminal style closely applied to the anterior face and wrapped around it distally on the posterior side where it is sheathed by the subapical dentate flange (fig. 5, D-E). Surface of raised rim surrounding gonopodial opening very coarsely wrinkled outwardly. Sterna of bipedate segments separated by a broad transverse depression, each sternum broadly concave from side to side and without an elevation near coxa.

Holotype.-Male, El Valle, Cocle Province, alt. 2200-2400 ft., Feb. 23, 1959.

\section{Seminellogon panamicus (Chamberlin)}

Aphelidesmus panamicus Chamberlin, 1925, Proc. Biol. Soc. Washington, 38, p. 41.

Seminellogon panamicus Loomis, 1961, Proc. U. S. Nat. Mus., (3454), 113, p. 86.

Localities.-Canal Zone.

Panama Province: Cerro Campana.

\section{Seminellogon serratus (Hoffman)}

Sigmogonotropis serratus Hoffman, 1951, Proc. U. S. Nat. Mus., (3300), 102, pp. 240-243, illus.

Seminellogon serratus Loomis, 1961, Proc. U. S. Nat. Mus., (3454), 113, p. 86.

Locality.-Darien Province: Cana. 


\section{Family ONISCODESMIDAE}

\section{BARRODESMUS Chamberlin}

Barrodesmus Chamberlin, 1940, Bull. Univ. Utah, (9), 30, p. 7.

\section{Barrodesmus isolatus Chamberlin}

Barrodesmus isolatus Chamberlin, 1940, Bull. Univ. Utah, (9), 30, pp. 7-8.

The identity of this species remains in doubt. The sex of the holotype was not given and it is only by inference from the statement, "A number of specimens, mostly immature," that it may be supposed to have been mature. The species has not been reported since it was originally described and there are no specimens in the present collection referable to it. The only generic character mentioned is the lack of an areate posterior border on the segments, which would separate it from Lignydesmus and other members of the family.

LIGNYDESMUS Cook (=Mesesmus Chamberlin, Panamadesmus Loomis, Huanucodesmus Loomis), new synonymy.

Lignydesmus Cook, 1896, Brandtia, p. 28.

Mesesmus Chamberlin, 1941, Pomona Coll., Jour. Ent. Zool., 33, pp. 57-58, illus.

Panamadesmus Loomis, 1961, Proc. U. S. Nat. Mus., (3454), 113, p. 89, illus. Huanucodesmus Loomis, 1961, loc. cit., 113, p. 91.

Several characters of Lignydesmus, as here constituted, previously have been used in erecting new genera but now appear to be only of specific value. These include differences in the size and sculpture of segment 2 , and the size of the opening between the keels of the penultimate segment and the amount of exposure of the last segment. Thus the species show certain outward dissimilarities but a continuity in the structure of their gonopods, where males are known, that is thought to unite them in the present genus.

In addition to the genotype, $L$. rubriceps (Peters), and the Panamanian species, the genus appears to contain the following members:

Lignydesmus (Oniscodesmus) fuhrmanni (Carl, 1914), L. (Detodesmus) tingo (Chamberlin, 1955), and $L$. (Oniscodesmus) tarmanus (Kraus, 1959).

\section{KEY TO SPECIES OF LIGNYDESMUS OF PANAMA}

1. Posterior keels of penultimate segment very close together, hiding the last segment in dorsal view................................. 
Posterior keels of penultimate segment more widely spread, the last segment

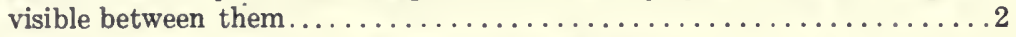

2. Keels of segment 19 projecting well behind segment $20 \ldots \ldots \ldots \ldots$ projectus

Keels of segment 19 not exceeding the last segment..............

3. Size small, $5 \mathrm{~mm}$. long or a little more..................

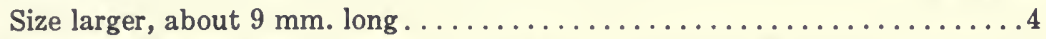

4. Segment 2 not greatly expanded forward in lateral view; sinus in posterior margin of segment 19 narrow in front................ insulanus

Segment 2 considerably expanded forward in lateral view; sinus in posterior margin of segment 19 broad in front................ panamanus

Lignydesmus eutypus (Chamberlin) (=Mesesmus eutypus Chamberlin), new combination.

Oniscodesmus eutypus Chamberlin, 1940, Bull. Univ. Utah, (9), 30, p. 7.

Mesesmus eutypus Chamberlin, 1941, Pomona Coll., Jour. Ent. Zool., 33, pp. 57-58, illus.

Locality.-Canal Zone: Barro Colorado Island.

Lignydesmus insulanus (Chamberlin) (=Mesesmus insulanus Chamberlin), new combination.

Mesesmus insulanus Chamberlin, 1941, Pomona Coll., Jour. Ent. Zool., 33, p. 57 , illus.

Locality.-Canal Zone: Barro Colorado Island.

\section{Lignydesmus panamanus Loomis}

Lignydesmus panamanus Loomis, 1961, Proc. U. S. Nat. Mus., (3454), 113, pp. 88-89, illus.

Locality.-Bocas del Toro Province: Almirante.

Lignydesmus projectus, new species. Figure 5, F-K.

Diagnosis.-More nearly resembling $L$. rubriceps, in extension of segment 2 below segment 3 , than it does $L$. panamanus. From both species it differs in the shape and proportions of segments 1 and 20, and in having the keels of segment 19 projecting farther behind segment 20.

Description.-Holotype $9.5 \mathrm{~mm}$. long, $3.5 \mathrm{~mm}$. wide; largest female $11 \mathrm{~mm}$. long, $4.1 \mathrm{~mm}$. wide; color light brown.

Head rather deeply sulcate on crest of vertex, the sulcus widening rapidly half way to the antennae, the broadened portion containing short erect setae similar to those on front but fewer; surface each side of sulcus convex, glabrous, finely reticulated, quite dull; clypeus smooth and shining, raised rather sharply above the transversely wrinkled setose front, more strongly so on sides, which also are noticeably constricted at junction of front, the clypeus being narrower here than farther 
forward, where its sides are convex; surface with an irregular row of fine setae at the posterior edge, and eight larger ones in front.

Segment 1 (fig. 5, F) more nearly quadrate than in either rubriceps or panamanus, the anterior portion with distinct areas, the sides and back areate; median portion with a strong depression widening in front, the surface each side convex. Segment 2 shown in lateral view in figure $5, G$; ensuing segments with areate portion and that in front of it not strongly convex, the areate markings extending through segment 19; pores borne on the usual swellings. Posterior end of body shown in figure $5, \mathrm{H}-\mathrm{I}$; segment 19 with the broad keels considerably exceeding segment 20 , which is broad, thickened, little rounded behind and with four dorsal subapical setae and three others below on each side of the papillate cluster of four; anal valves flattened, the low raised margins extending only two-thirds of distance dorsad; preanal scale broadly triangular, having a rather pronounced anterior ridge followed by a much lesser one; a strong conic seta-bearing tubercle on margin each side of apex.

Gonopods of holotype shown in figure 5 , $\mathrm{J}$, with variation exhibited in paratype shown in figure $5, \mathrm{~K}$. Third male legs with joint 3 swollen beneath.

Holotype.-Male, Finca Lerida, near Boquete, Chiriquí Province, March 17, 1959, alt. $7800 \mathrm{ft} .,(\mathrm{B}-524)$ forest litter.

Paratypes.-Chiriquí Province, Finca Lerida: female, El Velo forest area, March 12, 1959, alt. 5650 ft., G. A. Solem, leg.; male, female, March 12, 1959, alt. 5650 ft.; female, "Barca area," March 12, 1959, alt. 5650 ft.; one young, "Barca area," March 14, 1959, alt. $5650 \mathrm{ft}$. , (B-490) forest floor litter; male, "Barca area," March 15, 1959, alt. 5650 ft., G. A. Solem, leg.; two young, "Barca area," March 17, 1959, alt. $7750 \mathrm{ft}$., (B-525) forest floor litter under palms; female, "Casita Alta," March 17, 1959, alt. 7750 ft., (B-526) forest floor litter; female, March 18, 1959, alt. $6900 \mathrm{ft}$.

Lignydesmus sculptilis (Loomis), new combination

Panamadesmus sculptilis Loomis, 1961, Proc. U. S. Nat. Mus., (3454), 113, p. 90 , illus.

Locality.-Canal Zone: Piña area.

\section{Family PERIDONTODESMIDAE}

\section{PERIDONTODESMUS Silvestri}

Peridontodesmus Silvestri, 1896, Ann. Mus. Civ. Stor. Nat. Genova, 36, p. 197.

\section{Peridontodesmus sp.}

Locality.-Cocle Province: Two very young, El Valle, Feb. 23, 1959 , alt. $2400 \mathrm{ft}$., trail to Las Minas, (B-349) floor debris from steep stream bed. 


\section{Family PLATYRHACIDAE}

\section{KEY TO GENERA OF PLATYRHACIDAE OF PANAMA}

1. Gonopod in mesal view with seminal channel ascending the mesoanterior face to the seminal branch, which is on the forward side of the gonopod.

Psammodesmus

Gonopod with seminal channel obliquely crossing the inner face to the seminal branch, which is on the mesoposterior side of the gonopod.........2

2. Distal third of gonopod bent at nearly a right angle to the lower portion.

Nyssodesmus

Distal third of gonopod nearly straight or bent at considerably less than a right angle to lower portion........................... Plathacus

\section{NYSSODESMUS Cook}

Nyssodesmus Cook, 1896, Brandtia, p. 53.

\section{Nyssodesmus attemsi Hoffman}

Nyssodesmus attemsi Hoffman, 1960, Proc. U. S. Nat. Mus., (3423), 111, pp. 27-28, illus.

Locality.-Chiriquí Province: Puerto Armuelles.

Nyssodesmus concolor, new species. Figure 5, L-N.

Diagnosis.-While the tuberculation and possibly the color appear characteristic of $N$. attemsi, the gonopods indicate closer relationship with $N$. tristani (Pocock), in which the apex of each gonopod is slenderly and acutely spoon-like, not truncated, with seminal style hidden in mesal view; but in no species is the curved outer portion of the gonopod as long as in this one.

Description.-Body relatively broad, about five times as long as wide, $96 \mathrm{~mm}$. long, $18 \mathrm{~mm}$. wide in male; the largest specimen, a female, $100 \mathrm{~mm}$. long, $20 \mathrm{~mm}$. wide with dorsum more convex, keels narrower and more obliquely descending; those of male not horizontal. Animals without apparent pigmentation, concolorous throughout, very light yellowish-gray, probably off-white in life.

Head with a prominent shining tubercle on either side of crest of vertex bearing two closely placed setae; surface behind tubercles cross-wrinkled; granulartuberculate in front of them, behind antennae, and on the somewhat swollen sides; vertex medianly sulcate, deepest in front; a pair of close-placed setae between antennae, another pair farther forward and two more widely separated ones near middle of clypeus, each on a broad shining convexity, a pair of setae in each outer angle; 20-22 small setae on labrum. Antennal sockets strongly rimmed mesally, the rim increasing in height and thickness to its upper limit behind the antenna where it ends abruptly, rim cross-wrinkled above; anterolateral edge of each socket also rimmed and cross-wrinkled.

Segment 1 with anterior margin straight to the outer third, each side slightly oblique to the outer angle, which is opposite the anterior quarter of the segment; 
posterior margin very broadly rounded; surface densely beset with small, greatly flattened tubercles, a few slightly larger ones irregularly placed near front and back margins. Ensuing segments with similar small tubercles that are nearly obliterated on the caudal segments, where three transverse rows of slightly larger tubercles may be evident. Ventral surface of metazonites dull but not granular; prozonites densely minutely granular. Keels usually with five or six broadly rounded tubercles on the outer margin, on poriferous keels the median ones usually more separated than on poreless keels; anterior raised rim smooth on front segments but on those behind the middle becoming increasingly beset with tiny sharp teeth (fig. 5, L); posterior margins somewhat irregular but usually not distinctly toothed; basal surface of keels sculptured like dorsum but beyond the pores the surface more distinctly tuberculate than on any other part of dorsum; peritreme large, elevated, strongly shining, removed from outer margin by no more than twice its diameter; pore in depressed median area. Keels of segment 19 directed straight back, the inner margins parallel. Last segment broader than long, constricted near the base, widest just in front of constriction, from which the posterior margin is almost evenly rounded behind. Anal valves, except the margins, and preanal scale finely granular; anterior surface of latter strongly convex with midmargin overlapping segment 19; posterior pair of tubercles large, widely separated, the margin between them thin and slightly convex.

Gonopods as shown in figure 5, M-N. Rim around gonopodial opening scarcely raised in front, thin but moderately raised behind. All sterna of both sexes from the third legs caudad with a conic elevation mesad of each coxa, those in front of gonopods noticeably higher and more acute than the others.

Holotype.-Male, "in large old log," Almirante, Bocas del Toro Province, March 30, 1959.

Paratypes.-Male, female and fragment, with holotype.

\section{PLATYRHAGUS Koch}

Platyrhacus Koch, 1847, in Herrich-Schaffer, Kritische Rev. Insectenfaune Deutschlands, 3, p. 58.

Barydesmus Cook, 1896, Brandtia, p. 53.

\section{Platyrhacus chapini Hoffman}

Platyrhacus chapini Hoffman, 1953, Proc. Ent. Soc. Washington, 55, pp. 254255 , illus.

Locality.-Chiriquí Province: Las Siguas.

Platyrhacus gracilipes, new species. Figure 5, O-R.

Diagnosis. - Not only is this a diminutive species, perhaps the smallest of the genus, but it is peculiar in having gonopods closely resembling those of Tirodesmus, although the form of the lateral keels excludes it there. 
Description.-Length of holotype $52 \mathrm{~mm}$., width $8 \mathrm{~mm}$; female paratype $63 \mathrm{~mm}$. long, $11 \mathrm{~mm}$. wide; males a little less convex and with broader keels than females, the keels higher on sides of body, near its dorsal fourth; color of dorsum, including base of keels, dark brown, outer two-thirds of keels yellow (in alcohol); clypeal area, basal five joints of antennae, apex of last segment, anal valves, preanal scale, legs and sterna light-colored.

Head with a sharp median sulcus in vertex, deepest in front, continuing between antennae where it divides and each division broadens in passing around in front of each antenna to side of head; each side of vertex with an oblique longitudinal row of stiff setae, three on one side and two on the other in the male holotype, three on each side in females, the rows converging caudally; surface coarsely granular, the granules less numerous in the anterior part of the sulcus. Front with a pair of setae on a line with bottom of sockets. Clypeus slightly wrinkled but not granular, shining, with six widely separated setae posteriorly and a similar anterior row; labrum with a row of 18-22 setae less than half as long as those of clypeus; antennae separated by about the diameter of a socket; each socket surrounded by a granular ridge except on the outer side; joint 6 of antennae longer than any other, joints 2-6 subequal in width.

Segment 1 (fig. 5,0 ) with surface generally granular; anterior margin with a slightly raised semigranular rim immediately behind which are 12 rather inconspicuous low rounded tubercles a little smaller than those of a similar row near posterior margin, three median tubercles in latter row in holotype replaced by pits of the same diameter; anterior lateral margin on each side with about six faint rounded marginal undulations; posterior lateral margin smooth.

Body segments with a row of about 12 small, shining, rather indistinct tubercles at anterior third; a very indefinite and somewhat irregular submedian row of 8-10 smaller tubercles and a submarginal posterior row of 12-14 larger, more definite ones than those of the first row; remainder of surface granulate, the granules more distinct on the lateral keels; keels shaped as in figure $5, \mathrm{P}$, with three to five outer teeth, including the posterior corner which frequently has one or two supplemental teeth on the outer side; anterior and posterior margins serrate-granulate; pore callus large, flat, and close to the outer margin. Last segment large, a little constricted near the base, rounded behind; four low seta-bearing tubercles in a median row with four others behind, the outermost on each side in the margin. Anal valves each with a large seta on a smooth rounded tubercle near the basal third, removed from the thickened margin, and another similar tubercle on the outer side of the margin near apical third; in holotype this seta is directly in the thickened margin; preanal scale shown in figure $5, \mathrm{Q}$, a basal swelling slightly overlapping the margin of segment 19.

Gonopods (fig. 5, R) greatly resembling those of Tirodesmus biolleyi, as illustrated by Pocock (1903-1910). Gonopodial opening with margin raised, the posterior rim thickened and rolled backward. Sterna of both sexes lacking a special elevation near each coxa.

Holotype.-Male, Cerro Punta, Chiriquí Province, alt. $6600 \mathrm{ft}$., March 7, 1959, under log.

Paratypes.-Chiriquí Province: Female with 19 segments, with holotype. Female, Cerro Punta, alt. 5600 ft., March 8, 1959. Male, Finca Lerida, near Boquete, alt. 5650 ft., March 14, 1959. 
Male, "Barca area," Finca Lerida, alt. 5650 ft., March 15, 1959, G. A. Solem, leg.

\section{PSAMMODESMUS Cook}

Psammodesmus Cook, 1896, Brandtia, p. 53.

\section{Psammodesmus remotus, new species. Figure 6, A-D.}

Diagnosis.-Associated with the genotype, $P . \cos$ Cook, on the basis of pore location but they are even more remote from the margin than in that species.

Description.-Length $60 \mathrm{~mm}$., width $11 \mathrm{~mm}$.; dorsum strongly convex, the broad keels projecting horizontally from mid-body. Head brownish-black as is segment 1 except at its outer limits; ensuing segments with middle of dorsum, its outer sides, and narrow basal portion of keels brownish-black; intermediate sides of dorsum and outer four-fifths of keels light.

Head with vertex moderately impressed at middle, the surface each side finely granular-tuberculate and with several larger, greatly flattened and coalesced, shining tubercles forming an irregular row on the crest, the two rows converging behind; sides of head laterad of antennae also finely tuberculate; front and clypeal areas dull but not tuberculate; from each corner of the clypeus the surface is evenly raised to form a straight oblique ridge meeting the opposite one just in front of a pair of setae on line with the bottom of the antennal sockets, a seta at the outer end of each ridge and another in its middle; six setae at front of clypeus; about 12 smaller ones projecting from labrum. Antennae separated by the width of a socket; joint 2 widest but joint 6 longest.

Segment 1 a little wider than head, shaped and sculptured as in figure 6, A, the anterior row of large tubercles on a distinct ridge; posterior sides of the inner portion very convex, rising abruptly from each outer angle; mid-dorsum moderately and broadly depressed. Prozonites of ensuing segments minutely decorated with rather indefinite elevations, two to five times as long as broad; metazonites granular-tuberculate, with three transverse rows of large rounded shining tubercles, 6-8 in first row and 10-12 in second and third rows, the largest in the latter;

FIG. 6. A-D, Psammodesmus remotus: A, right half of segments 1 and 2, dorsal view; B, keel of segment 13, vertical view; C, right gonopod, ventral view; $D$, right gonopod, mesal view.

E-H, Airocaulon humerosum: E, segment 5, vertical view; F, keel of segment 5, end view; $G$, segments 18 and 19 , dorsal view; $H$, left gonopod, lateral view.

I, Botrydesmus biramosus, right gonopod, mesal view.

$\mathrm{J}-\mathrm{K}$, Botrydesmus conifera: J, segment 1 , dorsal view; $\mathrm{K}$, right gonopod, lateral view.

L-Q, Catapleuradesmus diadematus: L, antenna, showing interantennal space; $M$, segment 1 , dorsal view; $N$, keel of segment 5 , vertical view; 0 , side of segments $16-18$, showing location of pores, vertical view; $P$, left gonopod, lateral view; $Q$, right gonopod, ventrocaudal view.

R-U, Poratia fossata: R, antenna; S, segment 1, dorsal view; T, keels of segments 14-16, vertical view; U, right gonopod, mesal view. 
no polygonal areas evident. Segment 2 much wider than 1 , its keels greatly pro duced forward, those of following segments rapidly less so; most keels as show in figure $6, \mathrm{~B}$, the tiny pores in small, circular, inconspicuous pads no more elevate or obvious than adjacent tubercles but removed from the lateral margin by six $t$ eight times the diameter of the pad; keels of segment 18 with posterior corners no as acute as foregoing ones; keels of segment 19 directed nearly straight back bu very broadly rounded; segment 20 broader than long, its greatest width acros middle, the sides convex. Preanal scale with a pair of large conical tubercles ex ceeding the apex, which is very slightly rounded between them; surface finel tuberculate as is that of the valves except the thick shining margins.

Gonopods shown in figure 6, C-D, the terminal expansion of each horizont: to the basal portion, the seminal style unusually long. Sternum between sixt legs elevated near each coxa; sternum of seventh legs wider, strongly convex an not raised near coxae; behind the gonopods all coxae, including those of last leg; have an adjacent sternal swelling; sterna in front of gonopods with surface smoot but those behind with small tubercles.

Holotype.-Male, El Valle, Cocle Province, alt. 2200-2400 ft Feb. 23, 1959.

\section{Psammodesmus schmitti Loomis and Hoffman}

Psammodesmus schmitti Loomis and Hoffman, in Hoffman, 1953, Jour. Wash ington Acad. Sci., 43, p. 301, illus.

Localities.-Darien Province: Cana.

Panama Province: Pequeni River.

\section{Family RHACHODESMIDAE}

In the following genera, Teinorhachis differs from Aceratophallu in having the anterior poreless segments narrower than the adjacen poriferous ones.

\section{ACERATOPHALLUS Carl}

Aceratophallus Carl, 1902, Rev. Suisse Zool., 10, p. 608, illus.

\section{Acera tophallus quadratus Loomis}

Aceratophallus quadratus Loomis, 1961, Proc. U. S. Nat. Mus., (3454), 113 pp. 92-94, illus.

Locality.-Probably Canal Zone.

\section{TEINORHACHIS Loomis}

Teinorhachis Loomis, 1961, Proc. U. S. Nat. Mus., (3454), 113, p. 94, illus 


\section{Teinorhachis tenuis Loomis}

Teinorhachis tenuis Loomis, 1961, Proc. U. S. Nat. Mus., (3454), 113, p. 95, illus.

Locality.-Probably Canal Zone.

\section{Family SPHAERIODESMIDAE}

\section{SPHAERIODESMUS Peters}

Sphaeriodesmus Peters, 1864, Monats. Preuss. Akad. Wiss. Berlin, p. 529.

\section{Sphaeriodesmus conformans Chamberlin}

Sphaeriodesmus conformans Chamberlin, 1925, Proc. Biol. Soc. Washington, 38, p. 44.

Localities.-Canal Zone and adjacent Panama Province.

This species apparently is smaller than the following and has the second segment shorter than the third; the gonopods also show specific differences.

Sphaeriodesmus isolatus Chamberlin

Sphaeriodesmus isolatus Chamberlin, 1940, Bull. Univ. Utah, (9), 30, pp. 13-14.

Locality.-Canal Zone: Barro Colorado Island.

\section{Family STYLODESMIDAE}

\section{KEY TO GENERA OF STYLODESMIDAE OF PANAMA \\ Body Composed of 19 Segments}

1. Outer margin of keels behind second segment 2 -lobed..........Botrydesmus

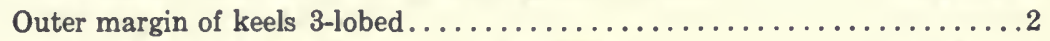

2. Outer lobes of keels not separated by sinuses................. Airocaulon

Outer lobes of keels separated by definite sinuses..................

3. Sinuses deep; outer margins of lobes and crests of tubercles strongly spiculate; anal scale tufted at apex...................................

Sinuses much less extensive; spicules of lobes and tubercles fewer and smaller;

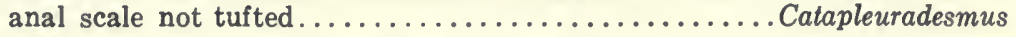

Body Composed of 20 Segments

1. Dorsal tubercles in transverse rows; pores continuous on segments 7-18.

Prosopodesmus

Dorsal tubercles in lengthwise rows; some pores lacking between segments

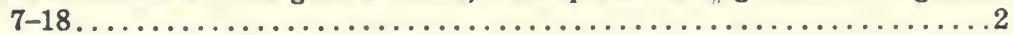

2. Pores not extending beyond segment $15 \ldots \ldots \ldots \ldots \ldots$. . . . . . . . . . . . 
Pores present on segment $16 \ldots \ldots \ldots \ldots \ldots \ldots \ldots \ldots \ldots \ldots \ldots \ldots \ldots \ldots \ldots \ldots$

3. Anterior tubercle of each row on segment 2 transversely oval; pore tubercles projecting from beneath one of the outer lobes............ Tracheloaspis

Anterior tubercles of each row on segment 2 round; pore tubercle not partially

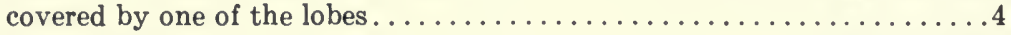

4. Keels of segments $6-19$ outwardly 4 -lobed............ Calymmodesmus Some or all of the keels of segments $6-19$ 3-lobed..............

5. Beginning with segment 7 poriferous keels 4 -lobed.........Rettenmeyeria Poriferous keels all 3 -lobed............................ 6

6. Segment 1 about as wide as head and with 10 distinctly separated anterior

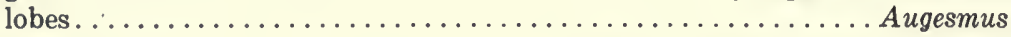

Segment 1 much wider than head, with 12 anterior quadrate areas.......7

7. Keels of segments 2-16 3-lobed, segments 17-19 4-lobed......... Gasatomus

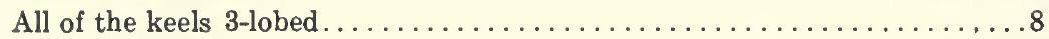

8. Pores opening from near middle of upper side of pore tubercle...... Xenoporus Pores probably opening from outer end of pore tubercle........ Nabatomus

\section{AIROCAULON, new genus}

Genotype.-Airocaulon humerosum, new species.

Diagnosis.-Having the general appearance of Poratia and Psochodesmus but easily separated by the reduced number of segments, position of the pores, and lobation of lateral keels. The straight outer branch of the gonopod suggests closest affinity with the latter genus.

Description.-Body small and about six times as long as wide, composed of 19 segments. Vertex of head medianly sulcate throughout, the anterior surface coarsely granular. Segment 1 with shape, lobation, and sculpture as in Psochodesmus. Ensuing segments with four lengthwise rows of three large tubercles each, the surface elsewhere coarsely granular, the rows scarcely increasing in height on the caudal segments, the posterior tubercles not or but faintly projecting behind the margin; keels narrow, strongly shouldered in front at body and with three distinct outer lobes from segments 2-18 inclusive; pores borne on a tubercle of the dorsal surface mesad of the middle lobe of segments $5,7,9,10,12,13,15-17$ and possibly 18; last segment greatly exceeding segment 18 , with two dorsal tubercles and six marginal lobes.

Gonopods with coxal joints depressed-galeate, the apical joint of each a thin straight blade. Anterior legs and sterna not specially modified.

\section{Airocaulon humerosum, new species. Figure 6, E-H.}

Description.-Body $4 \mathrm{~mm}$. long, .6 mm. wide.

Head coarsely granular from between antennae two-thirds of way to segment 1 , posterior third minutely granular; median sulcus extending completely across vertex but most conspicuous in front; vertex descending abruptly to front, which, with clypeus and labrum, bears erect setae of varying length; space between antennae less than diameter of a socket; antennae subclavate, joints 2-4 of equal length but increasing in diameter, joint 5 longest and thickest, joint 6 next in these dimensions. 
Segment 1 with 10 thick, subequal, separated, anterior marginal lobes; median surface with an anterior row of four large rounded tubercles and six similar ones adjacent to posterior margin, surface elsewhere coarsely granular. Ensuing segments with prozonites strongly convex, coarsely and evenly reticulated; interzonal constriction descending rapidly, long and concave, the metazonite suddenly raised behind it; metazonites with four longitudinal rows of large rounded tubercles, three in each row, the rows not much enlarged on caudal segments and their posterior tubercles, at most, but faintly projecting behind the margin; surface elsewhere coarsely granular; lateral keels (fig. 6, E) obliquely descending from low on the sides, about as narrow as long, those from segments $5-15$ or 16 with a prominent shoulder in front at junction with body; outer margin on segments 2-18 distinctly 3-lobed; pores opening from a tubercle on dorsal surface, mesad of the median lobe, which is depressed considerably below the other two (fig. 6, F), the pore tubercle lower on segments 16 and 17, lacking on segment 18 where no pore could be seen; outer posterior marginal lobe of keels large; keels of segment 18 reduced in size and very little produced backward.

Last segment large, much exposed behind segment 18, with two conspicuous conic dorsal tubercles and six distinct marginal lobes shown in figure 6, G; anal valves flattened, margins scarcely raised; preanal scale large, half as long as wide; subtriangular, the sides broadly emarginate, the apex flanked each side by a setabearing tubercle.

Gonopod as in figure 6, $\mathrm{H}$.

Holotype.-Broken male, Almirante, Bocas del Toro Province, Apr. 1, 1959, (B-703) forest floor litter.

\section{AUGESMUS Chamberlin}

Augesmus Chamberlin, 1951, Pub. Cult. Comp. Diam. Angola, Mus. de Dondo, Sept. 10, pp. 76-77, illus.

Augesmus trinus (Loomis) (=Cynedesmus trinus Loomis), new combination.

Cynedesmus trinus Loomis, 1959, Jour. Kansas Ent. Soc., 32, pp. 5-6, illus.

Localities.-Canal Zone. Panama Province: Cerro Campana.

BOTR YDESMUS Loomis (=Prionodesmus Loomis), new synonymy.

Botrydesmus Loomis, 1934, Smithsonian Misc. Coll., (14), 89, pp. 62-64, illus. Prionodesmus Loomis, 1959, Jour. Kansas Ent. Soc., 32, p. 7, illus.

Without restudying the holotype of Prionodesmus fulgens, now in the U. S. National Museum, I am convinced that the illustration of a gonopod of that species is incorrect in showing a third branch on the posterior arm, this branch actually being the main (anterior) one of the opposite gonopod. Without the third branch it will be seen that the gonopod conforms, in general characteristics, to that of 
the genotype and furthermore is sufficiently similar to that of $B$. coronatus, also from Barro Colorado Island, to justify consideration of this species as a synonym of fulgens.

\section{KEY TO SPECIES OF BOTRYDESMUS OF PANAMA}

1. Segment 1 with lobes of front margin in four groups, $2-3-3-2 \ldots$ biramosus

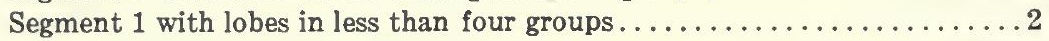

2. Segment 1 with lobes in two groups, $5-5 \ldots \ldots \ldots \ldots \ldots \ldots \ldots \ldots$ cryptus

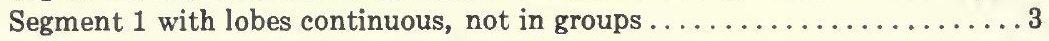

3. Segment 1 with median tubercles raised into high cones........... conifer Segment 1 with median tubercles lower, not strikingly conical ........ fulgens

Botrydesmus biramosus, new species. Figure 6, I.

Diagnosis.-Most closely related to the genotype, $B$. lutosus, as indicated by the shape of segment 1 and details of the gonopods but differing in having both arms of the latter with two branches; body also somewhat broader and less convex, especially in comparison with the other Panamanian species.

Description.-Body $4.1 \mathrm{~mm}$. long, .7 mm. wide; a little less convex than other species; keels relatively narrow, longer than broad.

Head crossed by a row of tubercles at middle of vertex, the median pair distinct, the outer ones low and indefinite; surface behind the row very finely granular, more coarsely granular in front on either side of a deep and conspicuous median depression; antennae separated by a little more than the width of a socket.

Segment 1 with marginal lobes separated by wide sinuses into four groups, 2-3-3-2, much as in lutosus except that the lobes are more pointed than rounded at apex; disk with the 10 tubercles rather small and not especially prominent, arranged about as in fulgens, the anterior one on each side the largest.

On ensuing segments the dorsal ridges are lower and a little thicker than in the other species and the tubercles are less confluent, especially those of each outer row; tubercles small and elongate-oval to round; ridges of segments 15-17 somewhat more elevated than those in front but not as prominent as in other species; dorsal surface heavily dirt-encrusted except on crest of ridges or tubercles; keels of segments 3-18 inclusive 2-lobed, the keels of segment 18 reduced in size and slightly produced backward. Last segment with the two dorsal tubercles small otherwise much as in the other species.

Gonopods as shown in figure $6, \mathrm{I}$, each outer joint only slightly protruding from the coxal joint in holotype. Third male legs with joints 3-5 definitely swollen.

Holotype.-Male, Almirante, Bocas del Toro Province, March 30, 1959 (B-676) forest floor litter.

Botrydesmus conifer, new species. Figure 6, J-K.

Diagnosis.-Closely related to $B$. fulgens, as shown by body size, vertigial tubercles and lobation of segment 1 but differing from all 
known species in the striking conic tubercles of that segment and features of the gonopods.

Description.-Male $3 \mathrm{~mm}$. long, .4 mm. wide; female $4 \mathrm{~mm}$. long, .5 mm. wide.

Head crossed by a low ridge on vertex surmounted by a row of about ten oval tubercles, the six inner ones largest and most distinct; surface behind ridge very minutely granular, coarsely granular in front to where it descends to front, a sharp median sulcus present; front between and below antennae finely short hispid, the clypeal-labral area less hispid but the setae longer; antennae separated by less than the width of a socket.

Segment 1 short and broad (fig. $6, \mathrm{~J}$ ), with ten distinct lobes, the six inner ones separated by sinuses, the outer two on each side adnate, with the outer one smaller and the inner one larger than the inner six; disk with ten conspicuous high conic tubercles arranged as in the other species.

Ensuing segments with the tubercles of the four rows confluent, forming high thin ridges; on segments $16-18$ the outer ridge on each side gradually reduced in size and represented by only a small tubercle on segment 18; tubercles of inner rows more or less separated on segments 17 and 18 and more elevated than on foregoing ones; keels with lobes as in fulgens, those of segment 18 much reduced in size; last segment also similar in shape and sculpture to that in fulgens.

Gonopods as shown in figure $6, \mathrm{~K}$. No joints of third male legs swollen.

Holotype.-Male, road west of Finca Palo Santo, near Nueva California, Chiriquí Province, March 5, 1959, alt. 4700 ft., (B-385) leaf debris in ravine.

Paratypes.-Female, six young, with holotype. Female with 18 segments, same locality and date, alt. $4750 \mathrm{ft} .,(\mathrm{B}-376)$ in chips, etc., at base of cut stump.

\section{Botrydesmus cryptus Chamberlin}

Botrydesmus cryptus Chamberlin, 1940, Bull. Univ. Utah, (9), 30, pp. 6-7.

Locality.-Canal Zone: Barro Colorado Island.

The lobation of segment 1 and presence of a small third ridge on either side of body are the outstanding differences attributed to this species, which has not been reported since its original publication.

Botrydesmus fulgens (Loomis) (=Botrydesmus coronatus Loomis), new combination and new synonymy.

Prionodesmus fulgens Loomis, 1959, Jour. Kansas Ent. Soc., 32, p. 7, illus.

Botrydesmus coronatus Loomis, 1961, Proc. U. S. Nat. Mus., (3454), 113, pp. 96-97, illus.

Localities.-Canal Zone, Barro Colorado Island: Male, female, Jan. 25, 1959, (B-147) leaves and drift between rocks in stream bed; six females and young, Jan. 1959, Berlese, log debris. 
Chiriquí Province: Two females apparently this species, "Casita Alta," Finca Lerida, near Boquete, March 17, 1959, alt. 7750 ft., (B-526) forest floor litter.

Panama Province: Young female, Chilibrillo Cave, near Chilibre, Feb. 7, 1959, (B-222) from drift along stream in cave.

\section{CAL YMMODESMUS Carl}

Calymmodesmus Carl, 1914, Mem. Soc. Sci. Nat. Neuchatel, 5, pp. 959-961, illus.

The members of this genus appear to be true myrmecophiles, seldom found except in association with army ants.

\section{KEY TO SPECIES OF CALYMMODESMUS OF PANAMA}

1. Dorsum strongly convex; primary tubercles of two submedian rows nearly twice as large as those of outer row; terminal joint of gonopod with both branches slender and of same general shape, the lower half as long as upper.

gracilis

Dorsum less convex; primary tubercles of inner and outer rows subequal; terminal joint of gonopod with upper and lower branches differing in shape.. 2

2. Marginal lobes of last segment well separated from each other; terminal joint of gonopod with lower branch close to apical portion .......... formicatus

Inner pair of lobes of last segment poorly separated; lower branch of gonopod

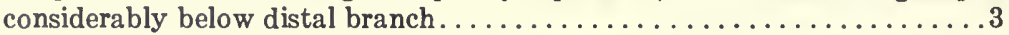

3. Tubercles of four primary rows subequal throughout body; outer joint of gonopod ending in an acute deflexed branch..............falcatus

Tubercles of inner primary rows larger than those of outer rows on posterior segments; outer joint of gonopod ending in a distinctly blunt branch.

rettenmeyeri

\section{Calymmodesmus falcatus Loomis}

Calymmodesmus falcatus Loomis, 1959, Jour. Kansas Ent. Soc., 32, p. 2, illus. Locality.-Canal Zone: Barro Colorado Island.

\section{Calymmodesmus formicatus Loomis}

Calymmodesmus formicatus Loomis, 1959, Jour. Kansas Ent. Soc., 32, p. 2, illus.

Localities.-Canal Zone, Ancon, Barro Colorado Island: ten males, females and young, Madden Forest Reserve, "Cruces Trail," in column of Nomamyrmex esenbecki crassicornis, Sept. 21 and Oct. 26, 1959, W. J. Hanson, leg.

\section{Calymmodesmus gracilis Loomis}

Calymmodesmus gracilis Loomis, 1959, Jour. Kansas Ent. Soc., 32, p. 4, illus. 
Localities.-Canal Zone, Barro Colorado Island and Madden Dam: twelve males, females and young, Madden Forest Reserve, "Cruces Trail," in column of Nomamyrmex esenbecki crassicornis, Sept. 21 and Oct. 26, 1959, W. J. Hanson, leg.

\section{Calymmodesmus rettenmeyeri Loomis}

Calymmodesmus rettenmeyeri Loomis, 1959, Jour. Kansas Ent. Soc., 32, pp. 2-4, illus.

Localities.-Canal Zone, Barro Colorado Island and Madden Dam: 29 males, females and young, Madden Forest Reserve, "Cruces Trail," in column of Nomamyrmex esenbecki crassicornis, Sept. 21 and Oct. 26, 1959, W. J. Hanson, leg.

The specimens of the above three species, collected by W. J. Hanson, were sent to me by Dr. Carl W. Rettenmeyer, Kansas State University, for identification.

\section{CATAPLEURADESMUS, new genus}

Genotype.-Catapleuradesmus diadematus, new species.

Diagnosis.-Most closely related to Sarolepis but with keels more descending, lobes separated by much smaller sinuses, dorsal spicules reduced in size and number, preanal scale not tufted at apex, and gonopods simpler.

Description.-Body very small, composed of 19 segments; surface moderately incrusted with dirt which usually fills the sinuses in margins of keels.

Head with a sharply angular, tubercular, transverse crest on vertex; antennae short, stout and very close together.

Segment 1 with ten anterior marginal lobes, the inner six deeply separated; inner surface with an anterior row of four large tubercles and a posterior one of six tubercles, the inner pair at the back margin, which outwardly bears several elevated lobes or tubercles. Ensuing segments extending considerably below limits of segment 1; dorsum strongly convex, the tubercles of the four rows lower than in Sarolepis but projecting farther over the back margin on caudal segments, the apical spicules much fewer and smaller; surface between the rows appearing less depressed but more roughened than in that genus; anterior and posterior margins with smaller and lower raised lobes, arranged as in Sarolepis; keels low on the sides and sharply descending, their outer margin 3-lobed, the lobes separated by less extensive sinuses than in Sarolepis, with pores similar in number and position but those in advance of the last two poriferous keels on more definite dorsal swellings.

Last segment rather coarsely granular above; margin 6-lobed, the median pair largest, deeply separated and widely diverging.

Gonopods with rather swollen coxal joints; apical joint of each composed of two closely applied, straight, acuminate divisions. 
Catapleuradesmus diadematus, new species. Figure 6, L-Q.

Description.-Body $2.3 \mathrm{~mm}$. long, .4 mm. wide, with 19 segments in the male; margins of segments and tops of elevations sparsely beset with very short spicules to which some dirt usually adheres.

Head sharply angled transversely across crest of vertex and bearing a row of 12-14 tubercles, the outer pair on each side large and distinct, followed by three or four smaller indistinct ones and a submedian one, the latter largest of all; vertex in front of crest convex, granular, and rather deeply sulcate half way to antennae, the surface behind crest flat longitudinally and finely roughened; vertex and front meeting at same level, the latter flat, a slight depression separating it from the somewhat convex clypeus, which has a row of eight short setae in front; antennae short and stout as shown in figure 6, L, separated by about a third the diameter of a socket.

Segment 1 (fig. 6, M) about as wide as head, granular between the large tubercles; posterior margin with four or five small oval tubercles laterad of the median pair of large ones, which are at the margin. Segment 2 and ensuing segments extending well below the outer angle of segment 1, the keels almost continuing the descent of the sides of body and flaring outward very little; outer margin of keels of segment 2 longer than those of segments 3 or 4 but not as long as those thereafter, the margins 3-lobed through segment 16, indefinite on segments 17 and 18. Dorsum of segments with three tubercles in each of four rows but they are lower than in Sarolepis and increase little in height on posterior segments although the posterior tubercle of each row is more projecting on posterior segments; spaces between tubercles in the rows, those between anterior lobes of segment 1, and on either side of the large lobe of the back margin of the keels seldom filled with dirt. Pores opening from slight convexities on the surface of the third lobe of keels on segments $5,7,9,10,12,13,15$ and 16 and from a definite tubercle of the posterior margin on segments 17 and 18 (fig. 6, N-0); keels of segments 3-5 with decreasing shoulders anteriorly at junction with body.

Gonopods as shown in figure 6, P-Q.

Holotype.-Male, Almirante, Bocas del Toro Province, March 30, 1959, (B-676) forest floor litter.

Paratype.-Fragment of posterior end of body, with holotype.

\section{GASATOMUS Chamberlin}

Gasatomus Chamberlin, 1923, Zoologica, New York Zool. Soc., 3, p. 417, illus.

\section{Gasatomus dubius Chamberlin}

Gasatomus dubius Chamberlin, 1940, Bull. Univ. Utah, (9), 30, pp. 5-6.

This species was based on four young specimens from Barro Colorado Island and it is assumed that the eldest was selected as the holotype although it lacked three moults of maturity. Since no specimen of the genus has since been discovered in the Panamanian fauna extreme doubt attaches to the correctness of the original disposition 
of the specimens in Gasatomus. As G. dubius was described as having a 12-lobed first segment and pores on the middle lobe of the keels of segment 5, at least, it well may belong in Calymmodesmus but it is almost hopeless to expect that these young specimens ever can be assigned to one of the four species known from the island.

\section{NABATOMUS Chamberlin}

Nabatomus Chamberlin, 1940, Bull. Univ. Utah, (9), 30, p. 5.

\section{Nabatomus delus Chamberlin}

Nabatomus delus Chamberlin, 1940, Bull. Univ. Utah, (9), 30, p. 5.

This species from Barro Colorado Island has not been reported since discovery but there appear to be many points of similarity with Xenoporus carinaceps. Chamberlin did not mention the location of the pore on keels of $N$. delus; hence I have assumed it to be at the outer end of the pore tubercle, as is common in the family. The opening on the side of the tubercle, exemplified in Xenoporus, is most unusual and it seems unlikely that this condition, had it existed in delus, would have been overlooked by a careful worker.

\section{PORATIA Cook and Cook}

Poratia Cook and Cook, 1894, Ann. New York Acad. Sci., 8, p. 238.

Dominicodesmus Chamberlin, 1923, Proc. Biol. Soc. Washington, 36, p. 189.

Tidopterus Chamberlin, 1923, Zoologica, New York Zool. Soc., 3, p. 420, illus.

\section{KEY TO SPECIES OF PORATIA OF PANAMA}

1. Head crossed by a deep channel at upper level of antennal sockets; large tubercles of the four rows on metazonites distinctly compressed laterally. . fossata

Head not crossed by a channel at level of antennal sockets; tubercles of the four

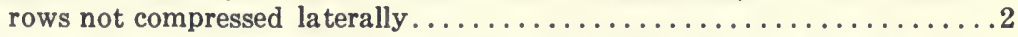

2 . Segment 1 short in relation to width; tubercles of the four rows large and distinct throughout body, scarcely increasing in size on caudal segments; secondary tubercles very poorly defined .............. granulofrons

Segment 1 longer in relation to width; four rows of primary tubercles poorly defined except on caudal segments where they increase in size considerably; secondary tubercles sharply defined, many nearly as large as primary ones.

digitata

\section{Poratia digitata (Porat)}

Scytonotus digitatus Porat, 1889, Ent. Tidskr., p. 24.

Poratia digitata Cook and Cook, 1894, Ann. New York Acad. Sci., 8, p. 238. Poratia heterotuberculata Carl, 1902, Rev. Suisse Zool., 10, p. 667, illus.

Dominicodesmus panamicus Chamberlin, 1940, Bull. Univ. Utah, (9), 30, p. 6. 
Localities.-Canal Zone, Barro Colorado Island: three young, Jan. 14, 1959, Berlese, wood frass at base of dead stump; female, six young, Jan. 22, 1959, Berlese, compost pile; 19-segmented female, Jan. 28, 1959, (B-180) fibrous center of old palm crown on ground.

Poratia fossata, new species. Figure 6, R-U.

Diagnosis.-Related to $P$. digitata but distinguished by the strong channel between vertex and front of head, the lateral compression of the tubercles in the four dorsal rows, and features of the gonopods. brown.

Description.-Body $4.5 \mathrm{~mm}$. long, .6 mm. wide; color in alcohol very light

Head with vertex medianly deeply but narrowly sulcate, the surface either side with 20 or more coarse granules or small tubercles; vertex separated from front by a deep, sharply impressed channel crossing just above the upper level of the antennal socket; side of head raised into a large rounded swelling latero-cephalad of each socket, basal joints of the antennae lying in a groove formed behind it; antennae as shown in figure $6, R$.

Segment 1 as shown in figure 6, S, the surface granular between the large rounded tubercles. Ensuing segments with four longitudinal rows of large, sharply elevated, laterally compressed tubercles, three distinctly separated tubercles in each row, those of the inner rows a little enlarged on segment 19 but those of the outer rows no larger than on other segments; two quite definite rows of small granules between the large inner rows of tubercles, a single row of granules between the outer and inner rows; surface laterad of the outer row scarcely granular; poreless keels of segments 2-14 3-lobed, those of segments 16-19 4-lobed; poriferous keels with an anterior outer lobe, the pore tubercle more or less replacing the other two lobes (fig. 6, T); posterior margin of keel with the outer lobe from segments $2-16$ or 17 large and obliquely raised.

Last segment with two large tubercles on the dorsum; posterior margin with three rounded lobes on each side of the apical one; anal valves but slightly convex, the inner margins not especially raised; preanal scale large, triangular, with two long, rather widely separated, subapical setae.

Gonopods with hemispherical coxae from the forward part of which the outer joint of one extends mesad across the outer joint of the other; a gonopod is shown in mesal view in figure $6, \mathrm{U}$.

Holotype.-Male, Almirante, Bocas del Toro Province, March 22, 1959, under bark.

Paratypes.-Mature male and 18-segmented one, same locality, March 30, 1959, (B-676) forest floor litter.

\section{Poratia granulofrons (Chamberlin)}

Treseolobus granulofrons Chamberlin, 1918, Bull. Mus. Comp. Zool., (5), 62, p. 221. 
Dominicodesmus geophilus Chamberlin, 1923, Proc. Biol. Soc. Washington, 36, p. 189.

Psochodesmus granulofrons Loomis, 1934, Smithsonian Misc. Coll., (14), 89, p. 54.

Poratia granulofrons Loomis, 1961, Proc. U. S. Nat. Mus., (3454), 113, p. 98.

Localities.—Canal Zone: Barro Colorado Island; Piña area.

Panama Province: Taboga Island; seven young, Chilibrillo Cave, near Chilibre, Feb. 7, 1959, (B-222) from drift along stream in cave.

Males of this species appear not to have been seen by Chamberlin, nor have any been reported since the original description and none was found in the present collection.

\section{PROSOPODESMUS Silvestri}

Prosopodesmus Silvestri, 1910, Zool. Anz., 35, p. 362, illus.

Homodesmus Chamberlin, 1918, Bull. Mus. Comp. Zool., (5), 62, pp. 222-223.

\section{Prosopodesmus jacobsoni Silvestri}

Prosopodesmus jacobsoni Silvestri, 1910, Zool. Anz., 35, p. 362, illus.

Homodesmus parous Chamberlin, 1918, Bull. Mus. Comp. Zool., (5), 62, p. 223.

Localities.-Canal Zone: male, female, Barro Colorado Island, Jan. 22, 1959, Berlese, compost pile; female, Madden Forest Preserve, Feb. 15, 1959.

Panama Province: male, Chilibrillo Cave, near Chilibre, Feb. 7, 1959, (B-222) from drift along stream in cave.

This introduced species from the Orient also has been found in several West Indian islands.

\section{RETTENMEYERIA Loomis}

Rettenmeyeria Loomis, 1959, Jour. Kansas Ent. Soc., 32, p. 6, illus.

\section{Rettenmeyeria parvipes Loomis}

Rettenmeyeria parvipes Loomis, 1959, Jour. Kansas Ent. Soc., 32, pp. 6-7, illus.

Locality.-Canal Zone: Known only from original collection in association with army ants on Barro Colorado Island.

\section{SAROLEPIS, new genus}

Genotype.-Sarolepis spiculatus, new species.

Diagnosis.-Obviously related to Botrydesmus which it resembles in many respects, having strongly lobed keels indented by deep 
sinuses, the margins of the metazonites elevated, and the spaces between the rows of tubercles depressed and lacking granules. It differs in having the tubercles of the four rows rounded and separated, outer margins of the keels 3-lobed, pores of segments 17 and 18 on tubercles projecting from the back margins of the keels, and the preanal scale tufted at apex.

Description.-Body small, composed of 19 segments, the dorsum strongly convex, keels low on the sides and projecting obliquely outward, dorsal surface mostly with a thin adhering incrustation of dirt held by short, stout spicules of the margins and elevations, the sinuses separating the marginal lobes usually dirt-filled.

Head with front of vertex granular and medianly sulcate; antennae short and strongly crassate, separated by less than the diameter of a socket.

Segment 1 with ten anterior lobes, the inner six separated by deep, narrow sinuses, the outer two each side united; inner surface with ten prominent tubercles; posterior margin with five elevated lobes laterad of each inner tubercle.

Ensuing segments with four longitudinal rows of three high tubercles each; surface between the rows slightly roughened but not granular, shining; anterior and posterior margins, including all margins of keels, distinctly lobed, the lobes separated by sinuses of different sizes; outer margins of keels from segments 2-16 distinctly 3-lobed; pores on dorsal swellings on the third lobe of segments $5,7,9$, $10,12,13,15,16$ and on definite marginal tubercles of segments 17 and 18.

Last segment large and much exposed, the posterior margin with six lobes separated by narrow, somewhat dirt-filled sinuses; anal valves moderately convex, with thick raised margins; preanal scale subelliptic to subtriangular and with a dense tuft of spicules, similar to the dorsal ones, at apex.

Gonopods with the galeate coxal joints prominently lobed at base in front; outer joint of each consisting of a lateral plate, slightly exceeding apex of coxa, and a higher mesal arm with three apical branches. Anterior male legs and sterna without modifications.

\section{Sarolepis spiculatus, new species. Figure 7, A-F.}

Description.-Male $3.3 \mathrm{~mm}$. long, .5 mm. wide; female $4 \mathrm{~mm}$. long, .6 $\mathrm{mm}$. wide; body colorless but with a brown incrustation of dirt.

Fig. 7. A-F, Sarolepis spiculatus: A, segment 5 of female from inner row of tubercles outward; B, keel of segment 17, vertical view; C, keel of segment 18 , vertical view; $D$, preanal scale; $E$, left gonopod, lateral view; $F$, left gonopod, anterior view.

G-L, Cyclopsodesmus scaurus: G, head of male, anterior view; $\mathrm{H}$, head and first segments, dorsal view; I, keels of segments 5 and 6 , male paratype, dorsal view; J, left gonopod, paratype, anterior view; K, gonopods, posterior view; L, first leg of paratype male, anteromesal view.

M-P, Cyclopsodesmus geniculatus: M, antenna; N, preanal scale; O, left gonopod, mesal view; $P$, apical portion of left gonopod, anterior view.

Q-S, Cyclopsodesmus octosetosus: Q, segment 1, dorsal view; R, right gonopod, lateral view; $\mathrm{S}$, terminal joint of left gonopod, mesoposterior view. 

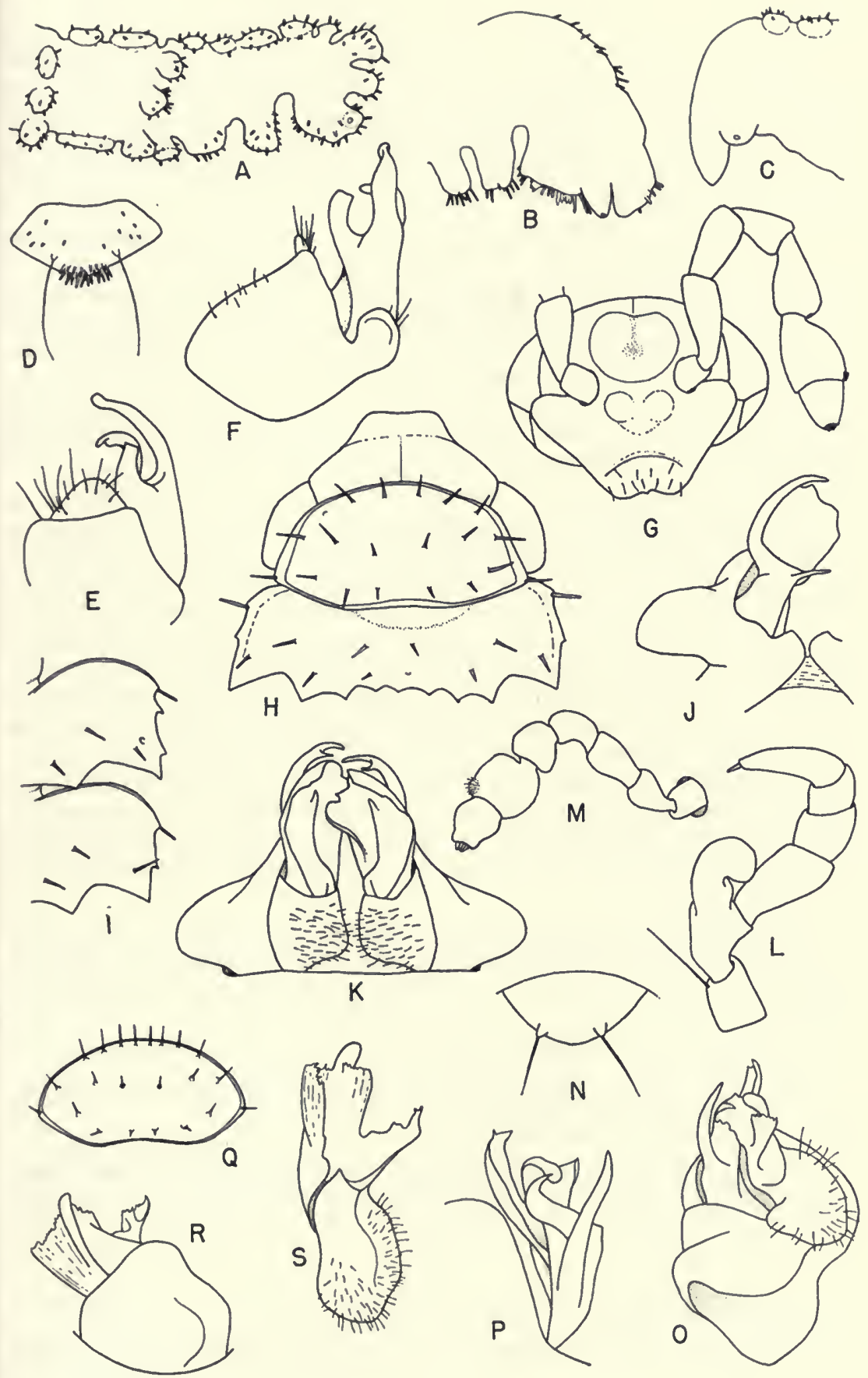
Head with anterior portion of vertex granular, the posterior portion much more finely so; a median sulcus present and most prominent in its middle section; front separated from vertex and similarly from clypeus by a faint channel; clypeus and labrum shining; antennae strongly crassate, joints 2 and 5 subequal in length, longer than any other joint, but joint 5 widest of all; antennal separation less than the diameter of a socket.

Segment 1 with ten anterior lobes, the six inner ones subequal in size and separated by deep, slender sinuses, the two outer lobes on each side united and together larger than the inner ones; anterior margin of lobes hispid or spiculate with stout rather blunt spicules, sides of lobes glabrous; inner surface with an anterior row of four high, rather slender tubercles, rounded and spiculate at apex; a posterior row of six similar ones, the inner pair at the posterior margin, the others increasingly removed from it; posterior margin with two raised apically spiculate lobes between the median pair of tubercles, five similar lobes between these and the outer corner of the segment.

Ensuing segments with four longitudinal rows containing three high, slender, well-separated and somewhat caudally inclined tubercles, spiculate at apex, the tubercles a little higher on segments $15-17$, lower on 18 , with none projecting beyond posterior margin; anterior margin of metazonites with two raised, oval, apically spiculate lobes between each pair of anterior rows of tubercles and between the posterior median pair but only one lobe between the inner and outer tubercles (fig. 7, A), other details of metazonite shown in the figure; surface between rows of tubercles and both margins appearing depressed, shining, with minor roughness but no spicules, although a little dirt may be present, the surface similar laterad of outer row of tubercles. Lateral keels about as wide as long, projecting outward and slightly downward from low on the sides; outer margin 3-lobed from segment $2-16$, the lobes separated by deep, more or less dirt-filled sinuses; pores opening from a slight swelling on the dorsal surface of the third lobe of usual segments, and from a distinct tubercle on the posterior edge of segments 17 and 18, as shown in figure $7, \mathrm{~B}-\mathrm{C}$.

Last segment with six marginal lobes separated by deep sinuses, the median pair of lobes largest, the outermost smallest; dorsal surface with a broad rounded swelling or tubercle at the base of each median lobe; preanal scale as shown in figure 7, D.

Gonopods as shown in figure 7, E-F.

Holotype.-Male, Almirante, Bocas del Toro Province, March 27, 1959, (B-638) forest floor litter.

Paratypes.-Male, female, one young, with holotype. Two males, two females, three young, holotype locality, March 30, 1959, (B-676) forest floor litter.

\section{TRACHELOASPIS Loomis}

Tracheloaspis Loomis, 1961, Proc. U. S. Nat. Mus., (3454), 113, pp. 98-99, illus. 


\section{Tracheloaspis tumida Loomis}

Tracheloaspis tumida Loomis, 1961, Proc. U. S. Nat. Mus., (3454), 113, pp. 99100 , illus.

Localities.-Canal Zone and adjacent Panama Province.

Bocas del Toro Province: Almirante, female, March 27, 1959, (B-635) forest floor litter.

\section{XENOPORUS Loomis}

Xenoporus Loomis, 1961, Proc. U. S. Nat. Mus., (3454), 113, pp. 100-101, illus.

\section{Xenoporus carinaceps Loomis}

Xenoporus carinaceps Loomis, 1961, Proc. U. S. Nat. Mus., (3454), 113, pp. 101-103, illus.

Localities.-Bocas del Toro Province: Two young, Almirante, March 30, 1959, (B-676) forest floor litter.

Cocle Province: El Valle.

\section{Family TRICHOPOL YDESMIDAE \\ (=Eutynellidae Chamberlin), new synonymy}

Eutynellidae Chamberlin, Bull. Univ. Utah, (9), 30, pp. 30-39.

Considering the characters given by Chamberlin for the genus Eutynellus, and his inclusion of Agenodesmus Loomis (1934) in the family Eutynellidae, there is little doubt of the above synonymy.

\section{KEY TO GENERA OF TRICHOPOLYDESMIDAE OF PANAMA}

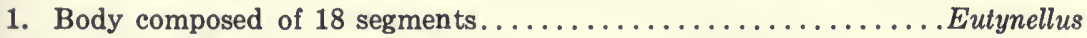

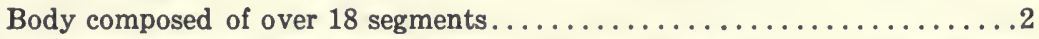

2. Body composed of 20 segments; segment 14 with pores......... Tichodesmus Males with 19 segments, females with 20 ; segment 14 poreless..........

3. Head of males with a large swelling above antennae........ Cyclopsodesmus

Head of males not prominently swollen above antennae. ............

4. Gonopods composed of a large depressed basal joint supporting a semiglobular joint from which a third element consisting of a simple curved blade projects.

Enantiogonus

Gonopods composed of a large coxal joint and a second joint of variable

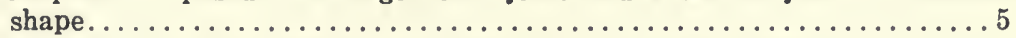

5. Coxal joint of gonopod large and solid, not excavated within, the terminal joint protruding from its oblique mesal face............ Cylindrogonus

Coxal joint of gonopod large but more or less hollowed, capable of enclosing

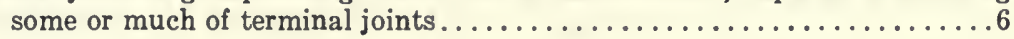


6. Coxal joints of gonopods flattened ventrally, almost wholly concealing terminal joints, which are directed caudally; dorsum with very prominent

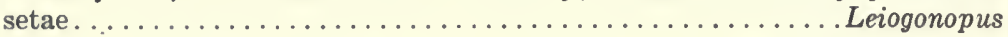

Coxal joints of gonopods strongly convex below, the inner joints projecting vertically or anteriorly from them; dorsal setae much less prominent....7

7. Pores near apex of back corner of keels; inner joints of gonopods short, stout, rather simple........................................

Pores farther forward, on dorsal surface of keels; inner joints of gonopods more

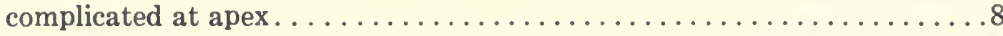

8. Gonopods with each inner joint much enclosed in coxa but ending in a projecting slender branch of varying length that crosses its opposite counterpart.

Irazunus

Gonopods with each inner joint stouter, more exposed distally and without a branch that crosses its opposite counterpart.............. Irogonus

An unidentified species, assigned to Cryptogonodesmus by Loomis (1961), cannot now be associated with this genus, which is not known to be represented in Panama.

\section{CYCLOPSODESMUS, new genus}

Genotype.-Cyclopsodesmus scaurus, new species.

Diagnosis.-Outwardly resembling Cryptogonodesmus Silvestri but broader; males with only 19 segments and with a large round swelling on the head above the antennae; inner gonopods more or less expanded distally; first pair of male legs with lobed second joints.

Description.-Body about six times as long as broad, composed of 19 segments in the male, 20 in the female; dorsal surface finely reticulated; males with large erect setae on metazonites, smaller ones in females; lateral keels broad, those of the male elevated from high on sides of dorsum, their posterior corners higher than mid-dorsum but only equaling it or lower in the female.

Head of male with a large inflated boss above antennae, which are rather slender, with joint 5 or joints 5 and 6 having sensory area near distal end.

Segment 1 definitely angled on each side, encircled by a raised margin and crossed by three transverse series of erect setae. Ensuing segments in male with faint transverse median depression, a row of four setae in front of it, a similar row behind, removed from posterior marg in except on caudal segments; setae each arising from a small nodule near the center of a broad convex area; outer margin of keels toothed with only the anterior tooth bearing a seta; posterior angles large, acute, higher than middle of dorsum, which is weakly convex, the posterior margin of each keel with an angular lobe adjacent to the dorsum; pores small, opening obliquely backward and upward from a swelling of the surface near the posterior corner; penultimate segment with posterior corners small, usually exceeded by the six setae projecting from the straight edentate margin between them; last segment with six setae across the middle, and four subapical ones, with the outer on each side marginal; preanal scale with two subapical seta-bearing tubercles.

Gonopods with coxae broad, rather widely open behind and within; inner gonopods each with apical portion more or less expanded, the basal portion short, 
thick, posteriorly hispid. Sterna of male segment 6 with larger and more abundant setae than other sterna, one or both of the sterna with a rounded tubercle on each side; some joints of pregenital legs with special tubercles.

\section{Cyclopsodesmus scaurus, new species. Figure 7, G-L.}

Description.-Body of male $9 \mathrm{~mm}$. long, $1.7 \mathrm{~mm}$. wide; female $12 \mathrm{~mm}$. long, $2 \mathrm{~mm}$. wide.

Head peculiarly sculptured (fig. 7, G), a large, abruptly raised, nearly circular swelling between the antennae, extending half way back across the vertex, its surface strongly shining and very shortly sparse-setose, slightly depressed medianly and behind; vertex with fine median sulcus, surface and that of sides of head dull, with somewhat more and slightly longer setae than the large swelling; two much smaller, adjacent, moderately roughened, less distinct swellings in front and mesad of the antennae; front rougher than other parts of the head, its anterior portion swollen, almost ridge-like, with the clypeus sharply descending from it and strongly concave; antennae as shown, a large pit at the apex of joint 5 on the outer side, a sensory setose area similarly placed on joint 6 .

Segment 1 (fig. 7, H) squarely angled on the sides, completely encircled by a raised rim; surface slightly convex on either side of middle, an anterior row of ten large erect setae, the outermost on each side in the angle; a median row of four, and a posterior row of six similar setae well in front of posterior margin; all setae rising from tiny granules as do those on ensuing segments; surface, and that of other segments, finely but distinctly reticulated.

Ensuing segments with dorsum slightly convex, crossed by a faint transverse median depression and two rows of large setae centered in slightly convex areas, four setae in each row, the first row in front of the depression, the other row in advance of the posterior margin, which has six projecting teeth that lack setae except on caudal segments. Lateral keels high on sides of body, outwardly raised, their posterior corners as high as or higher than middle of dorsum except on last segments; outer margin of poreless keels with two teeth; poriferous keels with three teeth in front of produced posterior corner (fig. 7, I), the anterior tooth with projecting seta; pores small, well in front of posterior angle; segment 16 with teeth of posterior margin reduced in size, each tipped with a seta several times as long as thick; segment 17 with teeth still smaller but ending in slightly longer setae; segment 18 with six still longer setae in the straight, edentate, posterior margin between the small acute angles, which are shorter than the setae; last segment with four long submedian setae and another on each side; two small subapical setae with another on each side, and the usual four terminal ones. Preanal scale with two well-developed marginal tubercles; apex between them narrow, slightly rounded.

Gonopods (fig. 7, J-K) with basal joint of each inner gonopod obliquely flattened inward, the surface with inwardly directed setae. First pair of male legs (fig. $7, \mathrm{~L}$ ) with a large thin spoon-like process mesodistally, curving sharply outward; second joint of seventh legs continued ventrodistally into a large finger-like lobe extending at least opposite the middle of the next joint; sterna of sixth segment with long dense setae, the seventh sternum somewhat raised into a tubercle on each side. 
Females without modifications of the head, the surface more setose; back of vertex glabrous; dorsum of segments more convex, with the raised areas more noticeable but the setae shorter; posterior margin of segments much less toothed between the smaller posterior corners; keels less elevated, posterior corners not higher than mid-dorsum, outer margin of keels less strongly toothed.

Holotype.-Male, "Barca area," Finca Lerida, near Boquete, Chiriquí Province, March 14, 1959, alt. 5650 ft., (B-491) concentrated floor litter.

Paratypes.-Chiriquí Province: Female, with holotype. One young, Cerro Punta, March 6, 1959, alt. $6250 \mathrm{ft}$.; two males, two females, one young, "Barca area," Finca Lerida, March 14, 1959, alt. $5650 \mathrm{ft}$., (B-490) concentrated floor litter; female, eight young, Finca Lerida, March 17, 1959, alt. 7750 ft., (B-525) concentrated forest floor litter under palms, etc.

\section{Cyclopsodesmus geniculatus, new species. Figure 7, M-P.}

Diagnosis.-Smallest of the three species with the dorsal swellings more prominent and the setae less conspicuous; the geniculate fourth joint of the antennae is distinctive; the gonopods indicate closer relationship with $C$. octosetosus.

Description.-Male $5 \mathrm{~mm}$. long, $.8 \mathrm{~mm}$. wide; largest female $6 \mathrm{~mm}$. long, $1.2 \mathrm{~mm}$. wide; males with dorsum almost flat transversely; keels elevated as in other species; females considerably more convex, the keels somewhat descending; color in alcohol light brown.

Head swollen above but even less distinctly than in octosetosus, the swelling faintly depressed along the middle, the setae shorter than elsewhere on the head; vertex medianly finely sulcate; clypeus slightly convex, two macrosetae on each side; antennae (fig. 7, M) with joint 4 sharply bent; joint 6 only with sensory area near distal end; antennae separated by about one and a half times the diameter of a socket; surface between them slightly concave.

Segment 1 shaped and margined as in other species; an anterior submarginal row of ten setae, a middle row of four, and a posterior row of six near margin. Ensuing segments with prozonites reticulated as in other species, but the metazonites less conspicuously so and somewhat shining above and below, and more convex longitudinally than in other species; setae similar in number and arrangement but shorter, arising from the center of more pronounced swellings, the outer swelling of each anterior row largest and most elevated, half on keel and half on body, the two outer swellings next in size but not as high as the outer one on each side of posterior row, in which the two inner ones are smallest but well defined; lateral keels not noticeably different from other species, an angular lobe projecting from the back margin, the intervening dorsal margin smooth except on segment 18, which has six stout setae projecting less than the posterior angles of keels, which are relatively larger than in other species. Last segment with setae as in other species; preanal scale large, shaped as in figure $7, \mathrm{~N}$.

Gonopods as shown in figure 7, O-P. 
Males with second joint of first legs a little swollen below near outer end but not definitely lobed; sterna and coxae of segment 6 hirsute and lobed as in octosetosus but second joint of legs not swollen.

Holotype.-Male, Cerro Punta, Chiriquí Province, March 7, 1959, alt. $7000 \mathrm{ft}$., (B-425) forest floor debris on steep slope.

Paratype.-Male, two females, five young, with holotype.

Cyclopsodesmus octosetosus, new species. Figure 7, Q-S.

Diagnosis.-Differing from the genotype in the slightly smaller size, less evident median boss above the antennae, and the lack of specializations below them; posterior mid-dorsal margin of segments without teeth; the gonopods also show obvious differences.

Description.-Male $7.5 \mathrm{~mm}$. long, $1.3 \mathrm{~mm}$. wide; color in alcohol light brown; surface of segments reticulated above and below as is head with the exception of the clypeal area, which is smooth and shining; dorsum slightly convex with the keels rising somewhat from the sides, their posterior corners higher than middorsum on most segments.

Head with swelling above antennae as broad as or broader than in genotype but not as sharply defined or medianly depressed, evenly short setose as is rest of head except the clypeus, which is slightly convex; front without special swellings; vertex finely but sharply sulcate at middle; antennae rather long and slender, joints 2-5 increasing in length and thickness, joint 6 no longer than 5 but thicker, both joints with a sensory area at outer distal end.

Segment 1 (fig. 7, Q) shaped much as in genotype but with eight rather closely placed setae in anterior row, the other setae arranged as in that species. Ensuing segments with dorsal setae smaller but arranged as in scaurus; outer dentition of keels also similar, the angular lobe on the posterior margin adjacent to body large; mid-body margin smooth between lobes except on segment 17 where the lobes are reduced in size and equaled by four intervening teeth, which are without apical setae; segment 18 with six projecting setae arising from tubercles which do not exceed the margin; last segment, anal valves and preanal scale as in scaurus.

Gonopods as shown in figure $7, \mathrm{R}-\mathrm{S}$.

Males with second joint of first pair of legs slightly lobed near mesocaudal apex, each lobe distally finely short setose; sterna of sixth segment each with a pair of rounded tubercles, a similar tubercle on each coxa, all the tubercles woollysetose, the second joint of both pairs of legs more thickened than those of adjacent legs.

Holotype.-Male, Cerro Punta, Chiriquí Province, March 6, 1959, alt. $6900 \mathrm{ft.}$, (B-406) dirt under log in pasture (army ants present).

\section{CYLINDROGONUS, new genus}

Genotype.-Cylindrogonus copiosus, new species.

Diagnosis.-Distinguished by having the coxal joints of gonopods large and solid, not galeate, although inwardly obliquely flattened, 


\section{with the short stout subcylindrical terminal joint of each issuing from near the middle of the inner face of the coxa.}

Description.-Body small, about six times as long as wide; males with 19 segments, females with 20 segments.

Head very finely short setose; clypeal area slightly inflated; vertex with median furrow; antennae moderately crassate, a sensory area near distal end of joint 6 . Segment 1 subreniform, completely rimmed, crossed by three transverse rows of erect setae; median surface somewhat depressed. Anterior segments gradually widening to segment 5 after which they are parallel-sided to the caudal end of the body where the last three segments narrow rapidly; dorsum slightly convex, finely but distinctly reticulated; segments with three transverse rows of small setae, those of the two anterior rows each arising near the center of a rather distinct convex area; setae of row 3 very small, inconspicuous, at posterior margin; lateral keels rather broad, high on the sides, almost horizontal and at nearly same level as dorsum; outer margins with distinct serrations; pores opening backward and upward from the posterior portion of a large swelling; preanal scale twice as wide as long, the apex broad and rounded between the two prominent seta-bearing tubercles.

Gonopods with each coxal joint large and solid but obliquely truncated inward toward body; the short, thick, subcylindric terminal joint protruding from near the center, with two slender branches from its anterior side exceeding the apex. First male legs each with a prominent mesodistal lobe or tubercle on joint 2; sternum of sixth legs bilobed.

\section{Cylindrogonus copiosus, new species. Figure 8, A-F.}

Description.-Males from 5 to $6.2 \mathrm{~mm}$. long, .9 to $1 \mathrm{~mm}$. wide; largest female $7 \mathrm{~mm}$. long, $1.2 \mathrm{~mm}$. wide; body quite flat above, much resembling a tiny Polydesmus, dorsal setae short, inconspicuous, especially behind middle of body; color in alcohol light brown, probably lighter in life.

Head with clypeal area smooth and strongly shining; convexly raised above front, which, with the vertex, is slightly roughened and very finely short setose; vertex with a fine but distinct median furrow on its crest and posterior portion. Antennae (fig. 8, A) separated by twice the diameter of a socket, a sensitive area at apex of joint 6 .

FIG. 8. A-F, Cylindrogonus copiosus: A, antenna; B, segments 1 and 2, dorsal view; C, segments $17-19$, dorsal view; $D$, right gonopod, mesal view; E, right gonopod, lateral view; $F$, first male leg, anterior view.

G-L, Irazunus chiriquensis: G, anterior end of body, dorsal view; H, antenna; $I$, keels of segments 10 and 11 , dorsal view; J, segments $17-19$, dorsal view; $K$, preanal scale; L, gonopods, ventral view.

M-N, Irazunus ovatus: M, segment 1, dorsal view; N, gonopods, ventral view.

O-Q, Irazunus penicillatus: $\mathrm{O}$, anterior end of body, dorsal view; $\mathrm{P}$, right gonopod, ventral view; $Q$, second joint of left first leg of male, posterior view.

R-S, Irazunus uncus: R, right gonopod, ventromesal view; S, apex of same gonopod, enlarged.

$\mathrm{T}-\mathrm{V}$, Irazunus velaripes: T, antenna; U, segments 1 and 2, dorsal view; V, gonopods, ventral view. 

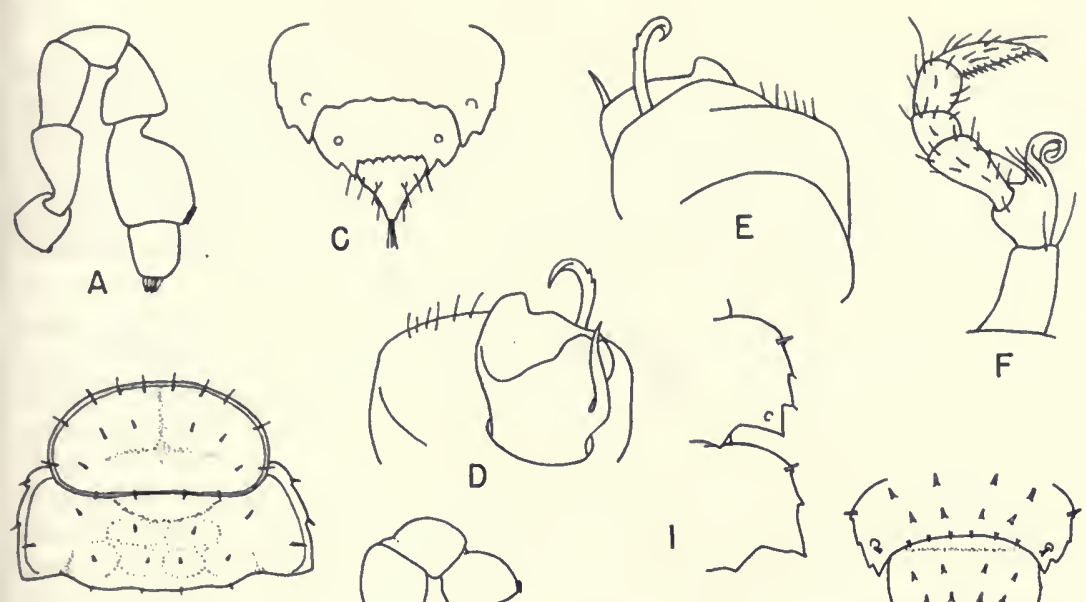

B
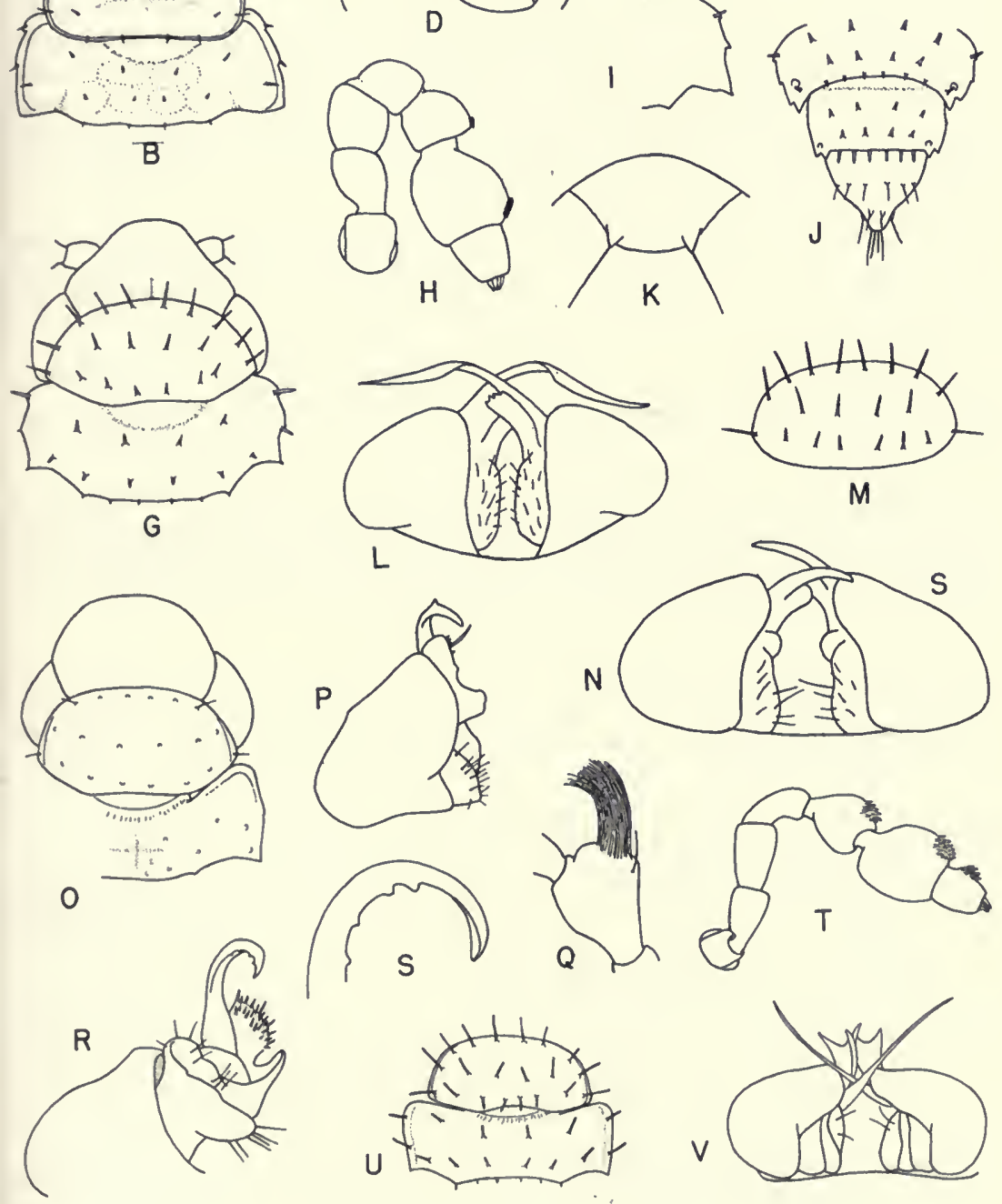
Segment 1 (fig. 8, B) broadly oval or subreniform; encircled by a raised rim that is thin along the posterior mid-margin but uniformly heavier elsewhere; surface strongly inflated but with a narrow impression extending from middle of front margin two-thirds of distance to back margin, a similar narrow transverse impression crossing it behind middle of segment; surface also with a row of ten rather long fine setae behind the anterior rim, six smaller ones in a strong arc across the middle portion and four tiny setae adjacent to the posterior rim.

Segment 2 as shown in figure $8, \mathrm{~B}$, the setae on it and succeeding segments decreasing in size, scarcely evident behind middle of body; lateral keels moderately broad, high on sides of body, outer margin strongly serrate, two serrations on poreless keels in front of posterior corner, three on those with pores; pores quite large, opening obliquely upward and backward from a strong convexity occupying the back corner of the keel. Posterior end of body narrowing rapidly (fig. 8, C), keels of penultimate segment reduced in size, the posterior corner each side being directly mesad of the large third marginal serration; posterior margin with six projecting setae. Last segment broadly conic, crossed by a median row of six setae, four long ones in the apex; preanal scale with two large seta-bearing tubercles widely separated by the broadly rounded apex.

Gonopods as shown in figure 8, D-E. First male legs (fig. 8, F) with a large curved and twisted process or lobe at the inner distal end of joint 2 ; a comb of setae beneath the last joint; sternum of sixth legs raised into two thin transverse rounded lobes.

Holotype.-Male, "Casita Alta," Finca Lerida, near Boquete, Chiriquí Province, March 17, 1959, alt. 7750 ft., (B-526) forest floor litter.

Paratypes.-Chiriquí Province: About 50 males, females and young, with holotype. Over 150 males, females and young from different locations and habitats, March 14-17, 1959, Finca Lerida, (B-489, 490, 491, 509, 524, 525, 543).

\section{ENANTIOGONUS Loomis}

Enantiogonus Loomis, 1961, Proc. U. S. Nat.-Mus., (3454), 113, pp. 103-104, illus.

\section{Enantiogonus fragilis Loomis}

Enantiogonus fragilis Loomis, 1961, Proc. U.S. Nat. Mus., (3454), 113, p. 104, illus.

Locality.-Canal Zone: Piña area.

EUTYNELLUS Chamberlin

Eutynellus Chamberlin, 1940, Bull. Univ. Utah, (9), 30, p. 9.

\section{Eutynellus flavior Chamberlin}

Eutynellus flavior Chamberlin, 1940, Bull. Univ. Utah, (9), 30, p. 10. 
It is remarkable that the extensive milliped collections made on Barro Colorado Island by Henry S. Dybas, C. W. and M. E. Rettenmeyer, and myself did not include this species, of which Chamberlin said "numerous specimens" were collected there. It is regrettable that he gave neither illustrations nor description of the gonopods, although the reduced number of segments coupled with the laterally opening pores will simplify identification of specimens from the holotype locality or adjacent parts of the surrounding country.

\section{IRAZUNUS Attems}

Irazunus Attems, 1933, Ann. Naturhist. Mus. Wien, 46, p. 260, illus.

\section{KEY TO SPECIES OF IRAZUNUS OF PANAMA}

1. Antennae with a distinct sensory area on each of last three joints; inner gonopods with sail-like element arising from base of each of crossed branches.

velaripes

Antennae with indistinct or no sensory area on joint 7; elements from base of

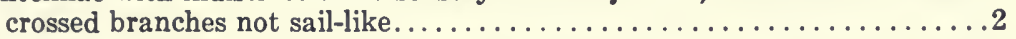

2. Males with prominent brush of densely grouped hairs on second joint of first

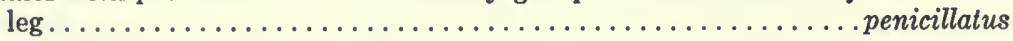

Males with unmodified first legs...........................

3. Segment 1 strongly oval; crossed branches of gonopods short and scarcely

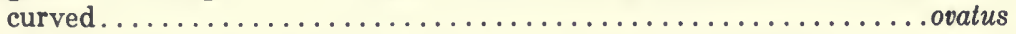

Segment 1 at most suboval with lateral angles abruptly rounded or subacute; crossed branches of gonopods long or strongly bent..............

4. Slightly larger species than next; lateral angles of segment 1 subacute; element at base of each crossed arm of gonopods small and not hispid... chiriquensis

Lateral angles of segment 1 sharply rounded; element at base of each of the strongly hooked and crossed arms large and coarsely hispid......... uncus

\section{Irazunus chiriquensis, new species. Figure 8, G-L.}

Diagnosis. - The form of the inner gonopods, although specifically different, associates this species with $I$. reimoseri Attems (1933) as does the shape of segment 1 and the ensuing keels.

Description.-Largest male (holotype) $4.5 \mathrm{~mm}$. long, .6 mm. wide; female $6 \mathrm{~mm}$. long, . $8 \mathrm{~mm}$. wide; color in life probably light brown; dorsum moderately convex, the narrow keels continuous with it; entire dorsal surface coarsely reticulated.

Head of male densely and rather conspicuously setose; clypeal and frontal areas confluent, faintly convex; vertex elongate, inflated at crest (fig. 8, G), not inflated in female; a faint median furrow extending forward a short distance from segment 1 ; antennae as in figure $8, \mathrm{H}$.

Segment 1 sublenticular with rather acute outer limits; margins not rimmed, a submarginal anterior row of ten large setae, a median row of four almost as large, and a posterior submarginal row of six still shorter ones, all setae borne on tiny shining granules. 
Segment 2 strongly convex from front to back, much more so than ensuing segments, with three transverse rows of setae, 4-6-6, as on following segments also, those of the two anterior rows rising from shining granules in the center of faintly convex areas, the last row of setae in the posterior margin and very small except on the penultimate segment; transverse median depression faintly evident on segment 3 but becoming stronger thereafter. Lateral keels (fig. 8, I) with three teeth on poreless ones, four on those with pores; anterior tooth or angle with a stout seta, the other teeth usually with much smaller ones; margins of keels not definitely rimmed but the margin near the anterior corner elevated a little; pores opening obliquely outward and backward. Posterior end of body narrowed (fig. 8, J); keels of penultimate segment with posterior angles small, only half as long as the setae between them; anal valves with rather thick, strongly raised margins; preanal scale shown in figure $8, \mathrm{~K}$.

Holotype.-Male, west of Finca Palo Santo, near Nueva California, Chiriquí Province, March 10, 1959, alt. 5000 ft., (B-457) concentrated floor litter at base of log and cut stump.

Paratypes.-Chiriquí Province: Male, three females, with holotype. From same general locality: 40 males, females, young, March 5, 1959, alt. $4750 \mathrm{ft} .,(\mathrm{B}-377$ ) chips, etc., at base of cut stump; male, female and several young, March 5, 1959, alt. 4700 ft., (B-385) leaf debris in ravine; male, many females and young, March 6, 1959, alt. $4900 \mathrm{ft} .,(\mathrm{B}-393)$ floor debris in ravine.

Irazunus ovatus, new species. Figure $8, \mathrm{M}-\mathrm{N}$.

Diagnosis.-Distinguished by the oval first segment and shape of the inner gonopods, although the latter associate it with I. minusculus Attems (1933).

Description.-Holotype $4.5 \mathrm{~mm}$. long, $.6 \mathrm{~mm}$. wide; color in life probably light brown; dorsum flatter than in chiriquensis, the surface coarsely reticulated; keels about as narrow but most of the outer margin turned upward; setae of same number and arrangement and on similar shining granules, the setae of rows 1 and 2 mostly directed upward and forward.

Head densely setose but the setae longer than in chiriquensis; vertex more evenly rounded, not specially inflated as in males of that species; antennae a little more slender, the five basal joints not as uniform in length, joints 2 and 3 subequal, considerably longer than joints 1,4 or 5 .

Segment 1 (fig. 8, M) almost a symmetrical broad oval with outer limits rounded, a very faint margining rim present; setae disposed much as in chiriquensis except that the outer two of the anterior row are much more separated than the others.

Segment 2 flatter longitudinally than in chiriquensis, its keels and those that follow with outer margin more rounded, teeth in similar position but less strongly developed, a seta only at each anterior corner, except on segments 17 and 18 , those on keels of segment 2 projecting outward, those on segments 3-5 becoming more upright, and from segment 6 caudad the setae nearly erect; on segment 17 an addi- 
tional seta on the fourth tooth, and on segment 18 one on the third and fourth tooth, the latter, forming the posterior corner, very small and scarcely evident; posterior margin with six long heavy projecting setae; metazonites with transverse depression beginning faintly on segment 3 and increasing somewhat thereafter; segments at caudal end of body shaped as in chiriquensis except for above details; preanal scale narrower at apex between the two setiferous tubercles.

Gonopods as shown in figure $8, \mathrm{~N}$. Anterior male legs lacking modifications.

Holotype.-Male, Finca Lerida, near Boquete, Chiriquí Province, March 17, 1959, alt. 7800 ft., (B-524) concentrated forest floor litter.

Paratype.-Male with 18 segments, with holotype.

\section{Irazunus penicillatus, new species. Figure $8, \mathrm{O}-\mathrm{Q}$.}

Diagnosis.- The brush of hairs on the second joint of the first pair of male legs is found in no other species. The gonopods, although showing distinctive differences, associate this species with $I$. minusculus Attems.

Description.-Males 4.5-6.3 mm. long, $1 \mathrm{~mm}$. wide: largest female, with but 19 segments, $7.5 \mathrm{~mm}$. long, $1.2 \mathrm{~mm}$. wide; dorsum quite flat in both sexes; keels high on sides of body with posterior corners slightly elevated but not as high as middle of dorsum; surface of segments strongly shining but under high magnification seen to be finely reticulated, the prozonites more definitely so.

Head with a fine median sulcus on vertex; clypeal area slightly convex, more shining and more densely short setose than on front or vertex where the setae may be mostly rubbed off; antennae separated by about twice the diameter of a socket, joint 6 thickest and slightly longest, followed in length by subequal joints 3 and 5 and subequal joints $2,4,7$, with joint 1 shortest.

Segment 1 (fig. 8,0 ) with most setae lost as on remainder of body but appearing to have been in usual locations; the six posterior marginal setae of segment 18 present, projecting straight back with tips equaling apex of small acute posterior corners of keels, corners about a fourth as long as those of segment 17, where they are larger than on foregoing segments; keels with a raised rim along anterior margin, extending around corner and lateral margin to base of posterior angle, outer margin of poreless keels with a minute denticle at anterior corner and one at midmargin, the poriferous keels with an additional marginal denticle; posterior margin of keels emarginate to a slight angulation at junction with body, the margin across dorsum straight and smooth; pores opening outward, backward and upward from a moderately inflated swelling considerably in front of angle.

Last segment with a median row of four setae, two subapical ones, and the usual terminal four; anal valves slightly convex, roughened, margins strongly raised and thickened; preanal scale large, broad, apically truncated; a seta-bearing tubercle at each corner.

Gonopods as shown in figure $8, \mathrm{P}$.

First pair of male legs with second joint enlarged and supporting a densely grouped cluster of long golden setae (fig. 8, Q). Sternum of segment 6 setose, a 
transverse lobe opposite each leg, the posterior pair largest; ventral face of the two basal leg joints also more setose than on preceding legs.

Holotype.-Male, "Barca area," Finca Lerida, near Boquete, Chiriquí Province, March 15, 1959, alt. 5600 ft., from sawed slabs.

Paratypes.-Four males, three females, three young, near type locality, March 14, 1959, alt. $5650 \mathrm{ft}$., (B-488) concentrated floor litter and chips in logging area. Female with 19 segments, Finca Lerida, March 16, 1959, alt. 6000-7000 ft.

Irazunus uncus, new species. Figure 8, R-S.

Diagnosis.-Most closely related to $I$. minusculus Attems, but readily separated by the shape of the posterior margin of the segments as well as by the strongly hooked arm of each inner gonopod.

Description.-Males $3.5 \mathrm{~mm}$. long, $.5 \mathrm{~mm}$. wide, with 19 segments; female $5 \mathrm{~mm}$. long, .6 mm. wide; colorless to light brown in alcohol; surface of segments evenly reticulated.

Head finely sulcate on posterior portion of vertex, which is not more prominently swollen than in female; surface finely and evenly short-setose except on the clypeus, which is without short setae and smooth, shining and slightly convex; antennae with small sensory areas on joints 5-7, but much less evident than those of $I$. velaripes.

Segment 1 not encircled by a raised rim, suboval, anterior margin more rounded than posterior margin; lateral limits abruptly rounded rather than angular; setae as in other species; segment 2 definitely widest across anterior angles, which are acute and each bearing a long thick seta directed forward and outward; lateral margin converging caudally, with a small seta-tipped tooth at middle; posterior corner broadly rounded but with a small seta-tipped tooth marking the corner; posterior margin almost evenly rounded and extending behind angles of keels. Ensuing segments with setae about as in chiriquensis except that the swollen areas that support them are more elevated and better defined, the outer swelling of median row smaller than those of other two rows except on segments 17 and 18 where they increase in length, those of 18 as long as any elsewhere on body except the median row on last segment; posterior margin of segments smooth or a little irregular but not toothed; lateral keels much as in chiriquensis, the anterior corners with margin raised; three outer setiferous teeth on poreless segments, four on those with pores, the foremost seta largest; posterior corners acute but little produced backward until after segment 11 or 12; posterior margin of keels emarginate to the slight undulation at junction with body, the margin straight across body; pores opening outward and backward from posterior portion of a strong swelling in front of back angle; keels and posterior angles of segment 18 much reduced in size; last segment crossed by a median row of four setae considerably larger than posterior ones of segment 18; anal valves with margins strongly raised; preanal scale broadly truncate at apex, a seta-bearing tubercle at each posterior angle.

Gonopods (fig. 8, R-S) with coxae shining, meeting distally but open mesally before and behind at base, the two serrate branches of the inner elements issuing 
from the anterior opening and crossing each other, the serrations easily visible in posterior view. Legs in front of gonopods not modified.

Holotype.-Male, Almirante, Bocas del Toro Province, March 27, 1959, (B-638) forest floor litter.

Paratypes.-Bocas del Toro Province: Twenty-four males, females and young, with holotype; four males, four females, four young, March 30, 1959, (B-676) forest floor litter on hill; two males, female, young, Apr. 1, 1959, (B-703) forest floor litter, holotype locality.

Irazunus velaripes, new species. Figure $8, \mathrm{~T}-\mathrm{V}$.

Diagnosis.-The long and slender but straight crossed branches of the gonopods indicate relationship with $I$. reimoseri Attems, but the expanded elements at their base are unusual. The conspicuous sensory area of antennal joint 7 further distinguishes this species.

Description.-Males $4.5-5 \mathrm{~mm}$. long, $.5 \mathrm{~mm}$. wide; females a little longer and wider; surface of segments finely and evenly reticulated, somewhat shining; dorsum of males rather flat, more so than that of females; keels slightly elevated with posterior corners highest, equaling but not exceeding middle of dorsum; color in alcohol light brown.

Head quite evenly beset with moderately short fine setae; vertex finely sulcate behind; clypeal and labral area continuous with front, not separately convex; antennae separated by slightly more than diameter of a socket, of moderate length, joints 5 and 6 thicker than others, a sensory area of short thick setae at outer distal end of each and a similar prominent area on the last joint (fig. 8, T).

Segment 1 semicircular (fig. 8, U) with nearly quadrate lateral angles, an anterior series of ten long submarginal setae, a median row of four, and a posterior row of six, as in other species; raised margin conspicuous at lateral angles and for a distance in front of them. Segment 2 notably wider than 1, widest anteriorly, the sides faintly converging caudally; dorsal setae disposed as shown in figure $8, \mathrm{U}$, the setae of the two anterior series quite long, almost uniformly thickened throughout their length, not acuminate; posterior series much smaller but increasing in length on posterior segments, setae of the penultimate one extending well behind the angles of the keels; dorsal setae borne on convex swellings, those at middle of dorsum less pronounced than the outer one in each of the two rows; posterior corners of anterior keels acute but hardly produced until after middle of body, those on segment 17 much smaller than those on 16 , corners of segment 18 scarcely evident, only half or less as long as the intervening marginal setae; pore swelling large, immediately in front of the posterior angle, pore opening obliquely backward and more outward than upward. Last segment with a median row of four dorsal setae, a little longer than the posterior setae of segment 18; preanal scale with the apex broadly truncated between the pair of marginal setae.

Gonopods as shown in figure $8, \mathrm{~V}$, the coxal joints hemispherical and widely separated, especially behind at base. Anterior male legs without obvious modifications. 
Holotype.-Male, El Valle, Cocle Province, Feb. 23, 1959, alt. $2400 \mathrm{ft.}$, (B-349) floor debris from steep stream bed, trail to Las Minas.

Paratypes.-Cocle Province: Three males, female, three young, with holotype; male, one young, same locality, Feb. 23, 1959, (B-332) bivouac debris of Echiton sp.; male, El Valle, Feb. 23, 1959, alt. 2200-2400 ft., (B-348) ground debris.

\section{IROGONUS, new genus}

Genotype.-Irogonus reniformis, new species.

Diagnosis.-Distinguished from Cylindrogonus by having each inner gonopod larger and rising within the coxa rather than from its oblique face; body broader; keels wider, obliquely elevated, the large posterior corners higher than mid-dorsum; segment 4 narrower and about half as long as segment 5 .

Description.--Size small, length slightly exceeding six times the width; surface of body finely reticulated; dorsum between the keels with a faint transverse median depression but no well-defined convex areas although apparently provided with setae rising from tiny granules in unrubbed specimens; lateral keels with two subbasal convexities and a larger one occupying the posterior corner.

Head with anterior surface, at least, setose, the vertex possibly so and with a median sulcus; antennae rather long, not strongly crassate, separated by about twice the diameter of a socket.

Segment 1 subreniform, the rounded outer limits slightly elevated; setae lacking but indicated by granules in usual arrangement of ten in front, four median, and six behind. Ensuing segments with dorsum moderately convex, keels rather wide, thin, outwardly elevated, especially at posterior corners, which are higher than mid-dorsum along middle of body, the outer margin with teeth very weakly developed, three on poreless keels, four on those with pores, a short thick seta projecting from each anterior tooth. Segment 4 narrower and conspicuously shorter than segment 5. Penultimate segment shorter than the last, the posterior angles small, not as long as the six setae projecting from the margin between them. Anal scale long, broadly rounded-truncate at apex between the two setabearing tubercles.

Gonopods with each coxal joint large, partly enclosing the stout inner projecting element which terminates in a tridentate arm with two slender, evenly curved hooks near the base, the mesal hook longest and directed outward; mesal face of inner gonopod with short thickened setae or conic tubercles. Anterior male legs and sterna not modified.

Irogonus reniformis, new species. Figure 9, A-E.

Description.-Length $6.3 \mathrm{~mm}$., width $1 \mathrm{~mm}$.; dorsum having appearance of flatness because the broad keels are obliquely elevated, highest at the posterior corners, where they exceed the middle of the moderately convex dorsum; dorsal surface finely reticulated. 
Head quite setose between and below the antennae; vertex almost without setae, possibly rubbed off, median sulcus present; antennae rather slender, geniculate at joint 4 , joint 6 with sensory area near outer distal end.

Segment 1 subreniform (fig. 9, A), the rounded outer limits slightly elevated; anterior margin medianly narrowly rimmed; ten tiny granules behind the anterior margin, four others just behind the middle, and six in advance of the posterior margin, the granules probably having borne setae.

Segments 2-4 shorter and with keels narrower than those that follow, the difference between segments 4 and 5 striking (fig. 9, B). Ensuing segments with shallow transverse depression crossing dorsum to base of keels, the surface without evident convex areas but with granules, as in figure $9, \mathrm{~B}$, which probably indicate where setae were lost, as the three caudal segments have similar granules supporting setae. Lateral keels with two convex areas near base, each with a median granule; a larger swelling extends forward from the posterior corner and has a submedian seta; anterior corner of keels with a short stout projecting seta; outer margin of keels very weakly serrate, with three teeth on poreless ones and four on poriferous ones, the pores large and distinct. Posterior end of body shown in figure $9, \mathrm{C}$, the penultimate segment very short, the tiny posterior corners only approximating those of the preceding segment, the back margin with six long thick setae projecting behind it. Last segment conic, four setiferous granules across basal third, two others at apical third, and the usual four terminal ones; preanal scale rather long, broadly rounded-truncate at apex between the two setiferous tubercles.

Gonopods shown in figure 9, D-E. Anterior male legs without modifications.

Holotype.-Male, Cerro Punta, Chiriquí Province, March 7, 1959, alt. $6900 \mathrm{ft}$.

\section{LEIOGONOPUS, new genus}

\section{Genotype.-Leiogonopus echinus, new species.}

Diagnosis.-The greatly flattened, mesally contiguous, coxal joints that almost enclose the inner gonopods, which are directed caudally rather than projecting upward or forward, dissociate this genus from other recognized genera as also does the shape of the poriferous keels.

Description.-Body small, strongly convex; rather loose-jointed, a considerable amount of each prozonite exposed; surface of both divisions of segments finely and evenly reticulated; dorsal setae long, stiff, acuminate; males with 19 segments, 20 in females.

Head medianly sulcate on posterior portion of vertex; frontal, clypeal and labral areas flat and continuous; antennae clavate with joint 6 longest and thickest, a sensory area near outer distal end of joints 5 and 6 .

Segment 1 subsemicircular, without marginal rim; three transverse rows of long setae arising from small tubercles or granules. Segment 2 wider than 1 , the keels somewhat produced forward, outer margins each with three prominent teeth supporting long setae as also found on poreless keels behind segment 5 ; segments 3,4 and all poriferous ones with keels lacking a median tooth or seta, the poste- 
rior angle of poriferous keels large with pore opening from its extremity; pore formula normal; dorsum of metazonites with three transverse series of strong setae diminishing in length from first to third series, a broad depression between first and second series; keels of penultimate segment very small. Last segment conic, a median row of four long dorsal setae followed by a subapical pair.

Gonopods with coxal joints large but greatly flattened over entire ventral face, almost completely enclosing the terminal joints which are directed backward and visible only between the mesocaudal tips of coxae. Anterior male legs not specially modified.

\section{Leiogonopus echinus, new species. Figure 9, F-J.}

Description.-Male $4.5 \mathrm{~mm}$. long, .4 mm. wide; body appearing slender and loose-jointed, strongly convex, the posterior corners of keels raised but not extending to level of mid-dorsum.

Head finely sulcate along middle of back half of vertex; surface short setose to clypeus, which is smooth and shining; front of head flat from antennal sockets to anterior margin; sockets separated by little more than their own diameter; antennae clavate, the basal joints slender, joint 6 much the longest and about twice as thick as basal joints, a small sensory area near outer apical limit of joints 5 and 6 .

Segments 1 and 2 shown in figure 9, F, the longest setae of segment 1 twothirds as long as median line of segment but foreshortened in illustration; setae arising from small tubercles. Ensuing segments with four setae in first row and six each in next two, those of first row longest, those of third row shortest except on penultimate segment, where they are longer than in first two rows and less erect than on preceding segments; metazonites crossed by a broad shallow depression between the two front rows of setae; setae centered on large indefinite convexities. Keels of segments 3 and 4 and all poriferous ones with a projecting anterior corner and a prominent posterior one, from the extremity of which the pore opens on the usual segments; other poreless keels with three lateral teeth as shown in figure 9, G, which also shows an exposed prozonite and interzonal constriction; pore shown in figure $9, \mathrm{H}$; posterior angles of keels of segment 17 scarcely smaller than on foregoing keels but the angles of segment 18 very small, barely exceeding posterior margin, the pores reduced in size but opening as on other keels.

Last segment narrowly conical, longer than metazonite of segment 18 , crossed by a median row of four long, erect setae, a pair of subapical ones and the usual four terminal ones; preanal scale large, triangular, with apex acute and preceded by a setose tubercle on either side.

Fig. 9. A-E, Irogonus reniformis: A, segment 1, dorsal view; B, segments 4-6, dorsal view; C, segments 17-19, dorsal view; $D$, left gonopod, ventral view; $E$, left gonopod, lateral view.

F-J, Leiogonopus echinus: F, segments 1 and 2, dorsal view; G, segments 14 and 15 , dorsal view; $H$, posterior corner of segment 15 , vertical view; I, gonopods, ventral view; $J$, left gonopod, mesal view.

$\mathrm{K}-\mathrm{M}$, Pachygonopus apiculatus: $\mathrm{K}$, segment 1 , dorsal view; $\mathrm{L}$, keels of segments 14 and 15 , dorsal view; $M$, left gonopod, mesal view.

$\mathrm{N}-\mathrm{Q}$, Acakandra austrina: N, gonopods, anterior view; $\mathrm{O}$, gonopods, posterior view; $\mathbf{P}$, right gonopod, lateral view; $\mathbf{Q}$, ninth leg of male, anterior view. 
Gonopods (fig. 9, I) with coxae large but strongly and evenly flattened, almost completely enclosing the terminal joints, which are unusual in being caudally directed as shown in figure $9, \mathrm{~J}$, with only their tips visible without separation of the contiguous coxae. Legs of males unmodified.

Holotype.-Male, Almirante, Bocas del Toro Province, Apr. 1, 1959, (B-703) forest floor litter.

Paratype.-Male with 18 segments, with holotype.

\section{Leiogonopus bidentatus, new species}

Diagnosis.-A larger species than the genotype, with more pronounced dorsal swellings, the posterior corners of the keels of the three segments preceding the last distinctly smaller; preanal scale truncate at apex.

Description.-Length $7 \mathrm{~mm}$., width $.7 \mathrm{~mm}$.; body wider than in the genotype males, with dorsal setae a little shorter, rising from smaller tubercles which, however, are borne on higher and more evident swellings; depression between the first and second row of swellings deeper and more conspicuous; color brown in alcohol.

Segment 2 with lateral teeth not as strong as in genotype, ensuing keels with teeth and pores as in that species except at caudal end of body where the posterior corners of segment 17 are smaller and less produced backward than those of 16; segment 18 with angles still smaller, barely exceeding the posterior margin; pores of segments 17 and 18 more outwardly directed than in the genotype; segment 19 distinctly wider in relation to length, the posterior row of setae not longer than those in front, posterior angles minute, not projecting beyond the margin, the pore opening more laterally than caudally; preanal scale truncate between the two subterminal setae.

Holotype.-Female, El Valle, Cocle Province, Feb. 23, 1959, alt. $2400 \mathrm{ft.}$ (B-349) floor debris from steep stream bed, road to Las Minas.

\section{PACH YGONOPUS, new genus}

Genotype.-Pachygonopus apiculatus, new species.

Diagnosis.-Apparently as closely related to Irazunus as to any presently known genus but the dorsal setae more developed; pores borne farther back near apex of posterior angle; and gonopod with inner joint short, heavy, and lacking a slender branch arising near base.

Description.-Body small and slender; males with 19 segments, their surface reticulated; all dorsal setae arranged much as in Irazunus but longer and heavier.

Head sulcate on vertex; frontal-clypeal area flat longitudinally; antennae subclavate, separated by more than the diameter of a socket, joint 6 longest and thickest with a small sensory area near its outer end, a smaller such area on the side of joint 7 . 
Segment 1 subsemicircular, not margined. Ensuing segments with dorsal swellings poorly defined; a weak transverse depression between the first and second series of swellings; lateral keels lacking conspicuous teeth on outer margin but having projecting setae; posterior margin of keels with a small acute seta-bearing angulation at junction with body, the margin between the two angulations smooth and with four backwardly projecting setae; pores almost at the apex of the posterior angle of the keels of usual segments; preanal scale truncate at apex.

Gonopods with coxae hemispherical, the terminal joints short and thick and lacking prominent branches or projections. Anterior male legs not specially modified.

\section{Pachygonopus apiculatus, new species. Figure 9, K-M.}

Description.-Length of male $4.5 \mathrm{~mm}$., width $.5 \mathrm{~mm}$.; surface of body evenly reticulated; color in alcohol light brown.

Head finely, evenly setose and dull except on the clypeus, which is less setose and somewhat shining; vertex medianly sulcate behind; front and clypeus together flat lengthwise.

Segment 1 (fig. 9, K) lacking any raised rim. Ensuing segments with thick dorsal setae arranged much as in Irazunus, those of the first two rows longer, rising from small granules centered in large faint convexities; transverse depression shallow but evident between the two rows of swellings; the third row of six setae borne in the smooth margin, the outer seta on each side on an angulation where keel joins body, the six setae very short on segment 2 , becoming longer on the next two segments but uniform thereafter to segment 18 where they are slightly longer but not as long as the submedian row of four on the last segment; lateral keels with four stout marginal setae on those with pores but three on poreless keels as shown in figure $9, \mathrm{~L}$, where the position of the pore in the posterior angle also may be seen; pore swellings smaller than usual in the family; posterior corners of segments 17 and 18 small, subequal, not projecting as far as the tips of setae of the posterior row. Preanal scale rather short, broadly truncate at apex, with a setiferous tubercle at each lateral angle.

Gonopod shown in figure 9, M, the coxal joint being hemispherical. Anterior male legs not modified.

Holotype.-Male, Almirante, Bocas del Toro Province, Apr. 1, 1959, (B-703) forest floor litter.

TICHODESMUS Chamberlin

Tichodesmus Chamberlin, 1940, Bull. Univ. Utah, (9), 30, p. 13.

\section{Tichodesmus micrus Chamberlin}

Tichodesmus micrus Chamberlin, 1940, Bull. Univ. Utah, (9), 30, p. 13.

This species is not known to have been collected since the original report but the unusual formula of continuous pores on segments 1218 will make it instantly recognizable. 


\section{Suborder STRONGYLOSOMIDEA \\ Family STRONGYLOSOMIDAE}

\section{KEY TO GENERA OF STRONGYLOSOMIDAE OF PANAMA}

1. Lateral keels scarcely projecting, outer margin thick, convex; posterior angle rounded, not produced .....................................

Lateral keels strongly projecting, outer margin nearly straight; posterior angles

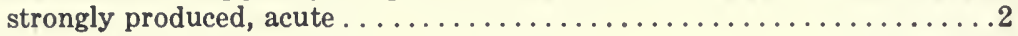

2. Gonopod a long, slender, nearly straight shaft ............ Orthomorpha

Gonopod rather stout, curved, and with several branches or prongs.... Oxidus

\section{MESTOSOMA Silvestri}

Mestosoma Silvestri, 1897, Boll. Mus. Zool. Torino, (283), 12, p. 3, illus.

Nearctoma Chamberlin, 1952, Ann. Ent. Soc. America, 45, p. 582, illus.

\section{Mestosoma isthmianum Loomis}

Mestosoma isthmianum Loomis, 1961, Proc. U.S. Nat. Mus., (3454), 113, pp. 107-108, illus.

Localities.-Several localities in Canal Zone and adjacent Panama Province.

\section{ORTHOMORPHA Bollman}

Orthomorpha Bollman, 1893, Bull. U. S. Nat. Mus., 46, p. 159.

For extensive synonymy of this genus and the following introduced species see Chamberlin and Hoffman (1958).

\section{Orthomorpha coarctata (Saussure)}

Polydesmus coarctatus Saussure, 1860, Mem. Soc. Phys. Nat. Geneve, 15, p. 297 , illus.

Localities.-Canal Zone: Barro Colorado Island.

Bocas del Toro Province: Male, one young, Almirante, March 21, 1959, G. A. Solem, leg.

\section{OXIDUS Cook}

Oxidus Cook, 1911, Proc. U. S. Nat. Mus., (1842), 40, pp. 628-631.

For synonymy of this genus and the following introduced species see Chamberlin and Hoffman (1958).

\section{Oxidus gracilis (Koch)}

Fontaria gracilis Koch, 1847, in Krit. Rev. Insect. Deutschlands, 3, p. 142.

Locality.-Canal Zone: Summit. 


\section{Order GHORDEUMIDA}

\section{Family GLEIDOGONIDAE}

The principal characters separating this from the other Panamanian family, the Dybasiidae, are the much less pronounced lateral shoulders of the segments and the lack of the anterior sternite joining the opposite sides of the gonopods.

\section{ACAKANDRA, new genus}

Genotype.-Acakandra austrina, new species.

Diagnosis.-In our present knowledge of the tropical craspedosomids it seems best to locate this genus in the Cleidogonidae, where it seems most closely associated with the type genus, Cleidogona, sharing many of its characters. It differs in lacking an obvious second, or caudal, pair of upright elements in the gonopods and in having no produced lobe on the sternum between the twelfth male legs.

Description.-Body small, scarcely fusiform, composed of 30 segments; males with faint shoulders on anterior segments, less evident in females; dorsal setae rather small and slender, the outer ones rising from small tubercles that are faint or lacking on caudal segments.

Head crossed by a depression between front and clypeus; ocelli in rows in a triangular patch; antennae rather long and slender.

Gonopods composed of a single pair of large simple elements that are broad, thick, and curving slightly caudad. Legs 1 and 2 of male smaller than the next five pairs, which are somewhat heavier than those behind the gonopods; ninth legs 5 -jointed, coxae moderately long with two ventral lobes, second joint equally long, not especially thickened except near distal third, outer three joints short, the last with a small terminal claw; legs 10 and 11 each with a single sub-basal coxal lobe; sternum of twelfth legs not specially produced.

\section{Acakandra austrina, new species. Figure 9, N-Q.}

Description.-Male $8 \mathrm{~mm}$. long, subterete rather than fusiform, the caudal segments narrowing rapidly.

Head quite broadly and evenly rounded along crest of vertex where descent to back margin begins; frontal area flat, depressed in front near junction with clypeus, which is a little convex; ocelli in seven rows, counting from lower side of head, $6,5,4,4,3,2,1$; antennal joint 3 longest, followed by joint 5 ; joints 6 and 7 subequal and together about as long as joint 5 , and slightly exceeding joint 4 .

Segment 1 subelliptic, the front margin almost evenly rounded, the back margin very slightly emarginate at middle but convex on each side, each outer angle rather abruptly rounded. Anterior segments of male with small outer shoulders bearing the outermost seta, the second seta considerably mesad. Dorsal setae shorter and more slender than in the Dybasiidae and rising from smaller tubercles, the outermost on each side evident to near caudal end of body, the inner ones much smaller and present on anterior segments only. 
Gonopods as in figure 9, N-P. First and second male legs a little smaller than the next ones, the last joint of each with a very fine ventral comb of short setae; legs 3-7 a little heavier than those following the gonopods but otherwise unmodified; ninth legs shown in figure $9, Q$; legs 10 and 11 with a large lobe at mesoventral corner of each coxa but lacking other peculiarities; sternum between twelfth legs with a vertical ridge in front, as on succeeding sterna, but with no produced lobe.

Holotype.-Male, Cerro Punta, Chiriquí Province, March 7, 1959, alt. $7000 \mathrm{ft} .,(\mathrm{B}-425)$ forest floor debris on steep slope.

Paratypes.-Chiriquí Province: Two 28-segmented females, with holotype; females and young, possibly of this species, from near Nueva California and Boquete, in several collections.

\section{DYBASIIDAE, new family}

This family is quite closely related to the Cleidogonidae but differs principally in the following characters.

Description.-Body of medium size, with 30 segments; lateral shoulders of the segments strongly developed, particularly in the males, and bearing two of the three macrosetae found on each side of the dorsum. Antennae of moderate thickness and not especially long. Gonopods with a large median plate or sternite joining them in front, the sternite very small or lacking in the Cleidogonidae; behind the sternite two pairs of processes, the anterior pair large and exceeding the sternite in height; posterior pair small, rudimentary, and hidden within the enlarged base of the anterior pair in lateral view. Legs 1 and 2 of male with a comb of setae beneath each of the three outer joints. Ninth legs of male composed of five joints and a tiny terminal claw, the basal joint with a large lobe projecting from or near the inner distal end; joint 2 long and slender, not hamate. Coxae of tenth legs, and usually eleventh, and the sternum of the twelfth legs specially modified.

\section{KEY TO GENERA OF DYBASIIDAE OF PANAMA}

1. Anterior sternite of gonopods twice as long as wide; second joint of ninth legs of male with a prominent lobe................... Dybasia

Anterior sternite of gonopods no longer than wide; second joint of ninth legs of male not lobed. . . . . . . . . . . . . . . . . . . . . . . .

2. Anterior sternite twice as broad as long, the anterior subdivisions rising twice

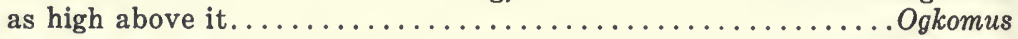

Anterior sternite about as broad as long, the anterior subdivisions rising above it less than its length.....................................

\section{DYBASIA, new genus}

\section{Genotype.-Dybasia humerosa, new species.}

Description.-Body of medium size; males more slender and slightly more fusiform than females; lateral keels large, subconic, with very thick base, prominent, especially in males, and extending from segment 2 or 3 to near the caudal end of the body, a large macroseta projecting from the outer angle, another mesocephalad of it, and a third half way between the outer angle and the median line of the 
metazonite; both subdivisions of segments with a fine continuous median line; surface of subdivisions reticulated.

Gonopods with a large, apically furcate, median sternite uniting the large anterior divisions in front; bases of divisions encircling and hiding laterally the two short rudimentary posterior divisions. Secondary sexual modifications of males include a comb of hairs along the ventral side of the outer joint of legs 1 and 2 and a transverse row along the distal end of the two preceding joints; legs 4-7 with a seta-bearing tubercle at the distoventral end of the second joint; ninth legs composed of five joints and a small terminal claw, the three basal joints long, the first two each with a distinct apical lobe, the last two joints short; legs 10 and 11 with a basal pouch on each coxa and a conical protuberance at the middle of the joint ventrally; sternum of the twelfth legs produced forward into a process reaching between the coxae of the tenth legs.

\section{Dybasia humerosa, new species. Figure 10, A-I.}

Description.-Length of both sexes $10 \mathrm{~mm}$.; males more slender and fusiform than females; segments reticulated above and below on both subdivisions, and dorsally with a fine median line; sides of body without striations; color somewhat mottled brown but lighter around base of macrosetae.

Head sparsely but quite evenly short setose except on the depressed clypeus which is densely beset with longer fine setae; labrum crossed by a row of 12 short setae near base; head rather broadly rounded at crest of vertex and descending quite abruptly to back margin only along median portion; antennae (fig. 10, A) capable of reaching along dorsum only to posterior margin of segment 3 or a little beyond, very widely separated, at least four times the diameter of a socket; ocelli in a triangular group in rows of $2,3,5,6,7$ or $2,4,5,6,7$ or $3,4,5,6,7$, counting upward from the lower anterior corner of the head; gnathochilarium as in figure $10, \mathrm{~B}$.

Segment 1 suboval, its anterior margin evenly rounded throughout. Ensuing segments with prominent, conic, basally greatly thickened lateral keels, especially in males (fig. 10, C), in which they extend from segment 2 to segment 26 or 27 , after which they become more like a tubercle; similar small keels extend from segments 3-24 or 25 in female; dorsum with six long stout macrosetae, the two outer ones on each side on the lateral keels except on segments 28 and 29 where all six are in a more continuous series projecting back from near the posterior margin; segments somewhat constricted between pro- and metazonites. Last segment with two caudally inclined setae near the middle and the usual terminal papillae.

Gonopods shown in figure 10, D-F. First two pairs of male legs (fig. 10, G) slightly shorter but very little more slender than ensuing legs; outer joints with a comb of setae along the ventral side, joints 4 and 5 with a row of setae along the distoventral end; second joint of legs 4-7 with a rounded seta-bearing tubercle distoventrally. Ninth legs five-jointed (fig. 10, H), joints 1-3 moderately long, decreasing in thickness outwardly, the two basal ones with a large distoventral process; the two outer joints small, the last with a tiny black terminal claw; legs 10 and 11 (fig. 10, I) with a large coxal lobe having a fleshy mass projecting from the perforated apex, also a conic tubercle at the middle of the ventral side; sternum of twelfth legs produced forward into a long, slenderly conic process reaching opposite the anterior limit of the tenth sternum. 
Holotype.-Male, "Casita Alta," Finca Lerida, near Boquete, Chiriquí Province, March 18, 1959, alt. 6900 ft., (B-543) concentrated floor debris in damp ravine.

Paratypes.-Chiriquí Province: Two females, one young, with holotype; Finca Lerida, two males, two females, eleven young, "Barca area," March 14, 1959, alt. 5650 ft., (B-490, B-491) concentrated floor litter; many young, March 17, 1959, alt. $7800 \mathrm{ft}$. , (B-524) concentrated forest floor litter; several young, March 17, 1959, alt. $7750 \mathrm{ft} .,(\mathrm{B}-525)$ concentrated forest floor litter under palms, etc.; many young, "Casita Alta," March 17, 1959, alt. 7750 ft., (B-526) forest floor litter; two females, Cerro Punta, March 7, 1959, alt. $6900 \mathrm{ft}$.

\section{OGKOMUS, new genus}

Genotype.-Ogkomus divergens, new species.

Diagnosis.-Related to Solemia, which it resembles in most outward particulars, but the males with a distinct lateral swelling on each side of segment 1, corresponding to the ensuing shoulders; outstanding differences, however, are in the gonopods, especially the very broad anterior sternite.

Description.-Body of intermediate size as in the other genera and resembling them in development of the lateral shoulders of the segments, arrangement of dorsal setae, and surface sculpturing.

Head shaped as in Solemia except that it is flat between the antennae and slightly depressed below them but the clypeal-labral area flat; eyes triangular, composed of 23-26 ocelli.

Segment 1 with a large oval swelling arising just mesad of each outer limit and extending inward behind the submedian seta.

Gonopods with anterior sternite large, much broader than high, the two sides widely and deeply separated; anterior gonopods erect, somewhat concave on outer side, truncate at apex and with a distinct hook at posterior corner; posterior gonopods small and curving caudad. Legs in front of gonopods much like those of Dybasia; ninth legs 5-jointed with coxae as in Solemia but the lobe shorter, thicker

FIG. 10. A-I, Dybasia humerosa: A, antenna; B, gnathochilarium; C, segments 8 and 9 , dorsal view; D, gonopods and joint 2 of ninth legs, anterior view; $\mathrm{E}$, left gonopod, lateral view; F, gonopods of paratype, posterior view; $\mathrm{G}$, first leg of male, anterior view; $H$, ninth leg of male, posterior view; $I$, tenth leg and sternum, anterior view.

J-L, Ogkomus divergens: J, gonopods, anterior view; K, apex of left gonopod, enlarged mesal view; $\mathrm{L}$, ninth leg of male, anterior view.

M-P, Solemia chiriquia: M, back of head and segment 1 , dorsal view; $N$, gonopods, anterior view; 0 , gonopods, posterior view; $\mathrm{P}$, ninth leg of male, anterior view. 

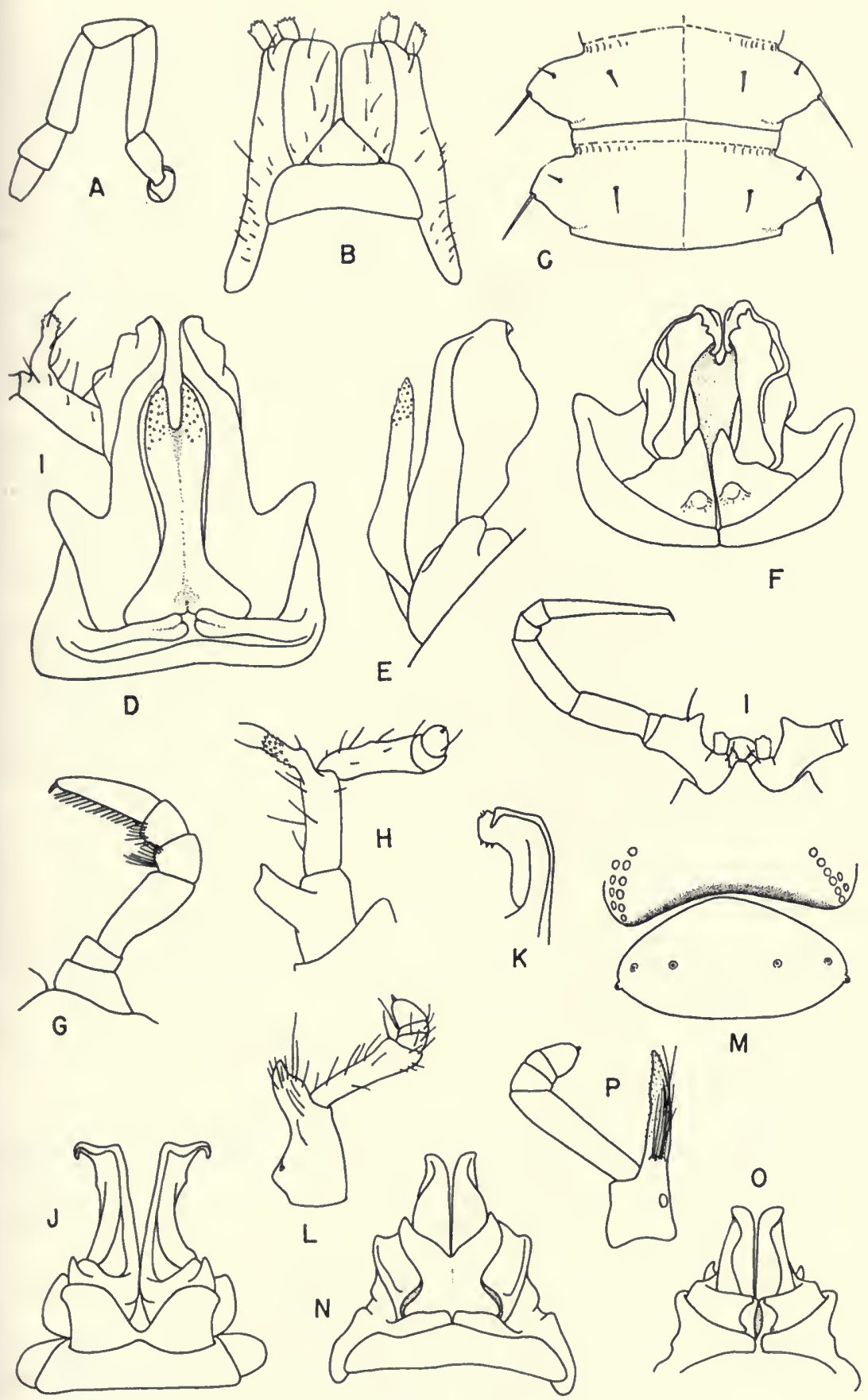

103 
and lacking a distinct brush of long setae in front; legs 10 and 11 with a lobe at each mesal angle of coxae, and a small swelling near apex of tenth coxae, a scarcely evident one on eleventh coxae; sternum of twelfth legs with a short slender anterior production.

Ogkomus divergens, new species. Figure 10, J-L.

Description.-Males 11-12 mm. long, females 9-9.5 mm. long but this probably not maximum length; males definitely more fusiform.

Head sharply descending behind from side to side between the upper corners of the eyes, which are triangular with ocelli in rows-6, $5,4,4,3,1$ to $7,5,4,4$, $3,2,1$-counting from margin of head adjacent to mandibulary stipes; surface between antennae flat but a little concave below them, becoming flat farther forward to labral margin.

Segment 1 subtriangular as in Solemia, a large oval swelling beginning at each outer angle in male only, and extending mesad behind the inner seta; a similar swelling on each side of segment 2 and succeeding segments forms the outer part of each shoulder, the shoulders increasing in size to about segment 6 or 7 and then gradually reduced to about segment 20 behind which they are represented by only the rather conspicuous tubercle of the outer seta. Dorsal surfaces reticulated and somewhat shining as in the other genera.

Anter!or gonopods and sternite as in figure $10, \mathrm{~J}-\mathrm{K}$; the posterior ones small, simple, and curving backward. Legs 1 and 2 of male with setae essentially as in Dybasia; legs 4-7 with a tubercle near distoventral end of joint 2; ninth legs shown in figure 10, L; legs 10 and 11 with a lobe at mesal corner of each coxa and a faint swelling on ventral side of coxa of tenth legs near apex, a faint indication of a lobe on coxae of eleventh legs; sternum of twelfth legs produced forward into a slender conic process reaching between coxae of eleventh legs.

Holotype.-Male, Almirante, Bocas del Toro Province, Apr. 1, 1959, (B-703) forest floor litter.

Paratypes.-Male, three females, ten young, with holotype and from holotype locality; female, March 26, 1959, (B-623) decaying palm fruit stalk and litter beneath; female, many young, March 27, 1959, (B-638) forest floor litter.

\section{SOLEMIA, new genus}

Genotype.-Solemia chiriquia, new species.

Diagnosis.-Outwardly much resembling Dybasia, the principal differences being the shorter, broader anterior sternite of the gonopods and the less extensively lobed ninth legs, which have the third joints much shorter.

Description.-Size intermediate, the males distinctly more tapering behind than the females and with shoulders more prominent.

Head with approximately 26 ocelli in a triangular group; posterior portion of vertex more broadly and abruptly descending to the back margin than in Dybasia; between antennae a vertical median ridge with a depression along either side. 
Segment 1 subtriangular, the front margin broadly angled at middle. Ensuing segments essentially as in Dybasia, with prominent shoulders on anterior two-thirds of body and strong setae similarly arranged and rising from like tubercles; dorsal surface also reticulated and shining.

Gonopods with anterior sternite about as broad as high and with divergent acute tips; anterior gonopods each ending in a thin, simple, erect plate, strongly concave along its mesal side. Legs 1-7 of male essentially as in Dybasia; ninth legs 5 -jointed, only the coxal joints with lobes, the three outer joints short, the last with a tiny blunt claw; legs 10 and 11 with basal coxal lobes, the tenth coxae also lobed near the apex; sternum of twelfth legs produced forward into a truncated process.

Solemia chiriquia, new species. Figure 10, M-P.

Description.-Males and females 11-12 mm. long; males much attenuated behind and with lateral shoulders more evident and extending to about segment 20 , behind which the tubercle bearing the outer seta is directly on the surface of the metazonite.

Head with two vertical channels separated by a ridge between the antennae, which are similar to those of Dybasia; surface of front continuous with the clypeus and vertex, the latter almost angular behind, between the back limits of the eyepatches, where the surface descends abruptly to the posterior margin (fig. 10, M); ocelli in a triangular group in rows $-5,6,5,4,3,2,1$-beginning at margin of head near mandibulary stipes.

Segment 1 somewhat triangular and about twice as wide as long. Ensuing segments with shoulders, setae, and surface sculpturing not noticeably different from Dybasia.

Gonopods shown in figure $10, \mathrm{~N}-\mathrm{O}$. Legs 1 and 2 of male with a ventral comb of setae along ventral side of outer joint and setae arranged transversely near apex of joints 4 and 5; legs 4-7 with a small distoventral swelling on second joint; ninth legs (fig. 10, P) with a slender conical lobe at mesodistal end of each coxa bearing a slender brush of long setae at its base in front, an open pore on inner basal face of joint; legs 10 and 11 with a lobe at mesal angle, the tenth coxa also with a prominent subcylindric lobe near distoventral limit; sternum of twelf th legs produced forward as a terete, apically truncated lobe between coxae of eleventh legs.

Holotype.-Màle, Finca Lerida, near Boquete, Chiriquí Province, March 12, 1959, alt. $5600 \mathrm{ft}$., coffee finca.

Paratypes.-Chiriquí Province: Cerro Punta, two females, six young, March 7, 1959, alt. $7000 \mathrm{ft} .,(\mathrm{B}-425)$ forest floor debris on steep slope; one female, March 7, 1959, alt. $6700 \mathrm{ft}$. , G. A. Solem, leg.

\section{Order STEMMIULIDA \\ Family STEMMIULIDAE}

For practical purposes the genus Prostemmiulus may be distinguished from the genus Stemmiulus by its having two instead of a single ocellus on each side of the head. 


\section{PROSTEMMIULUS Silvestri}

Prostemmiulus Silvestri, 1916, Boll. Lab. Zool. Portici, 10, p. 313, illus.

\section{KEY TO SPECIES OF PROSTEMMIULUS OF PANAMA}

1. Head and next few segments black or very dark, rest of segments dark in front, strikingly lighter behind........................nnulatus

Head and first segment lighter than others or concolorous with them, remainder

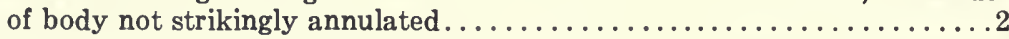

2. Body small, $10-12 \mathrm{~mm}$. long, cylindrical, dorsal striae parallel to median sulcus; third male legs with a comb of thickened setae beneath outer joint. .teres

Body larger, $15 \mathrm{~mm}$. or more long, more or less fusiform; dorsal striae oblique; outer joint of third male legs without a ventral comb of setae.........3

3. Body strongly fusiform; head and segment 1 distinctly lighter than succeeding segments; second male legs with a brush of setae on anterior face of outer

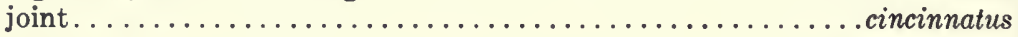

Body not strongly fusiform; head and segment 1 almost concolorous with next segments; outer joint of second male legs without an anterior brush of

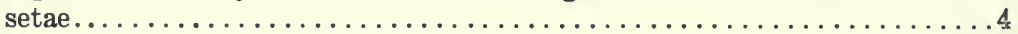

4. Body about $15 \mathrm{~mm}$. long; gonopods each with a strong, subapical, hispid lateral projection in front....................................

Body $23 \mathrm{~mm}$. or more long; gonopods without lateral projections in front.

oculeus

\section{Prostemmiulus annulatus, new species. Figure 11, A-D.}

Diagnosis.-Distinguished by the small size, strongly banded body, and unusual form of gonopods.

Description.-Body of both sexes similar, small, slender and distinctly compressed laterally, length $12-14 \mathrm{~mm}$., width $1 \mathrm{~mm}$., widest at segments $1-3$, much of body with sides parallel, the posterior end gradually but very inconspicuously narrowed; number of segments 38-42. Head black except at labrum; segments 1-3 or 4 mostly black above and below, the ensuing ones with anterior two-thirds black or very dark to low on the sides, except for a narrow median line and a series

Fig. 11. A-D, Prostemmiulus annulatus: A, right gonopod, anterior view; $\mathrm{B}$, same, posterior view; C, second male leg, mesocaudal view; D, third male leg, posterior view.

E-F, Prostemmiulus cincinnatus: E, gonopods, anterior view; F, second leg of male, anterior view.

G-K, Prostemmiulus teres: G, left gonopod, posterior view; $\mathrm{H}$, same, posterior view; I, first leg of male, anterior view; J, second leg and penis, anterior view; $\mathrm{K}$, last joint of third leg of male, anterior view.

L-N, Prostemmiulus vallaris: L, gonopods, anterior view; M, second leg of male, anterior view; $\mathrm{N}$, third leg of male, anterior view.

O-R, Stemmiulus marginandus: O, right gonopod, anterior view; P, same, posterior view; $Q$, second leg of male, posterior view; $R$, third leg of male, anterior view.

S-U, Stemmiulus parallelus: S, gonopods, anterior view; $\mathrm{T}$, second leg of male, anterior view; U, outer joints of third leg of male, anterior view. 


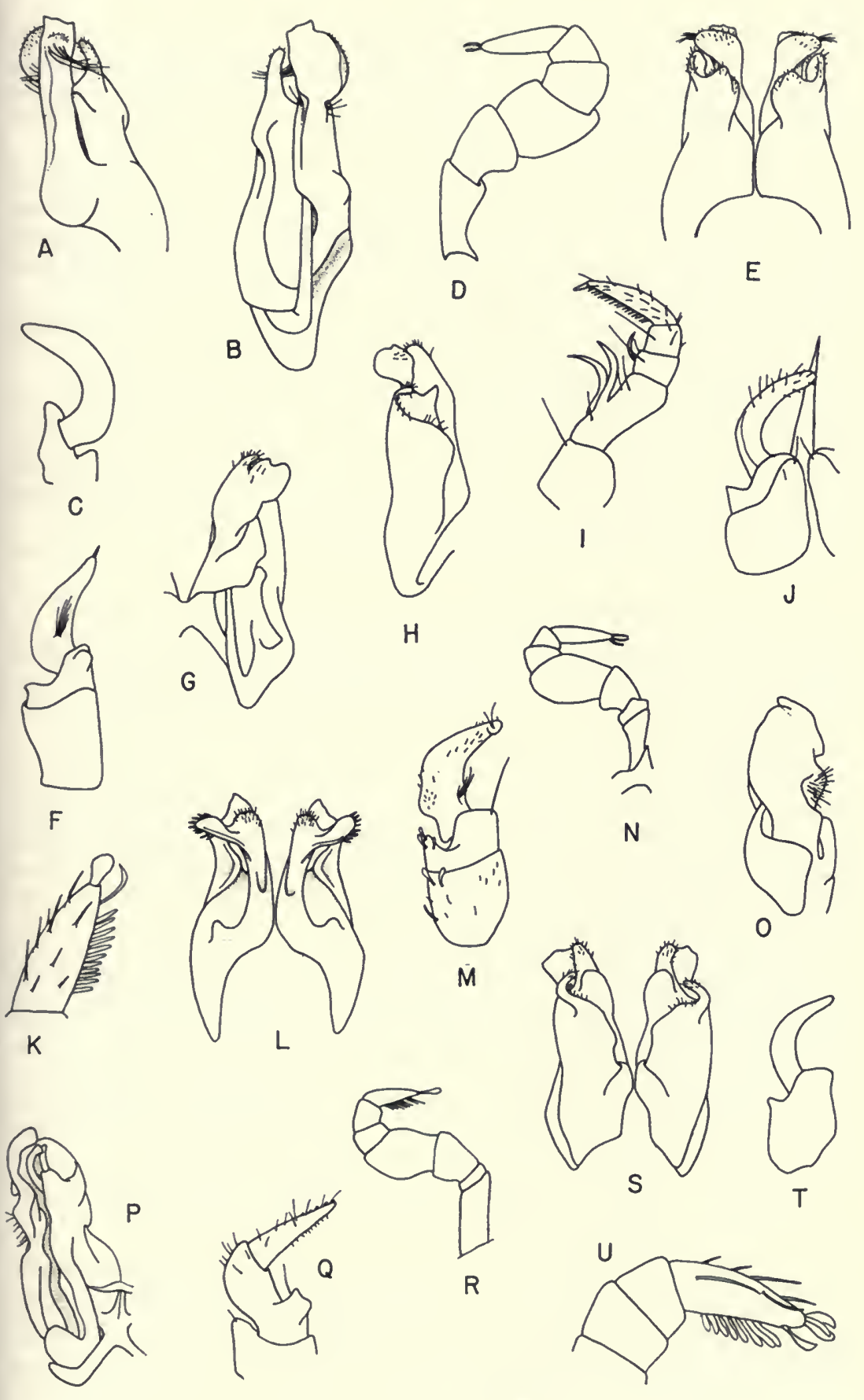


of more or less confluent light maculations beginning at pore and curving forward and downward, ending in a large spot below middle of side; posterior third of segments light, transparent, the body appearing strongly annulate with light and dark; ventral surfaces, legs and antennae light.

Head with lower ocellus over half as wide as upper one. Segment 1 with two long lateral striae, the lower reaching to behind the upper ocellus, the upper extending considerably above it. Segments with a fine median sulcus ending in a shallow nick that is widely open behind; lateral striae first reaching mid-dorsum at front of segment 10,11 or 12 .

Gonopods shown in figure 11, A-B. First legs of male with usual comb of setae beneath outer joint; second and third legs shown in figure 11, C-D.

Holotype.-Male, Almirante, Bocas del Toro Province, Apr. 1, 1959, (B-703) forest floor litter.

Paratypes.-Three females, with holotype; female, March 26, 1959 , and two males, two females, five young, March 27, 1959 (B-622, B-638) forest floor litter, holotype locality.

Prostemmiulus cincinnatus, new species. Figure 11, E-F.

Diagnosis.-On the basis of the gonopods this species seems most closely related to $P$. teres but differs in the body shape, lighter color of head and segment 1 , and features of the gonopods and anterior legs of male.

Description.-Body strongly fusiform and noticeably compressed laterally; holotype $18 \mathrm{~mm}$. long, $1.5 \mathrm{~mm}$. wide, with 45 segments; a very large female $28 \mathrm{~mm}$. long, $2 \mathrm{~mm}$. wide, with 48 segments; color moderately dark with no distinct median light line, lateral spotting of usual type, head and first segment lighter than next segments; in young specimens the head and segment 1 are almost colorless and frequently only a single ocellus is present.

Segment 1 with two lateral striae, the upper extending above the large ocellus, the lower extending only half or three-fourths as far. Ensuing segments with median sulcus fine, ending in a small narrow notch, the margin appearing almost continuous; lateral striae fine, reaching mid-dorsum on segment 11 or 12 .

Gonopods shown in figure 11, E. First legs of male with usual fine comb of setae beneath outer joint; second legs shown in figure 11, F, a dense brush of long fine setae on anterior face of outer joint; third legs not noticeably thicker than following legs in dorsal view but vertically expanded.

Holotype.-Male, Almirante, Bocas del Toro Province, March 27, 1959, (B-638) forest floor litter.

Paratypes.-Female, with holotype and from holotype locality; male, two females, three young, March 26, 1959, (B-623) decaying palm fruit stalk and litter beneath; female, one young, March 30, 1959, (B-676) forest floor litter; two females, two young, March 30,1959 , (B-703) forest floor litter. 


\section{Prostemmiulus oculeus Loomis}

Prostemmiulus oculeus Loomis, 1961, Proc. U. S. Nat. Mus., (3454), 113, p. 109, illus.

Locality.-Cocle Province: El Valle.

Prostemmiulus teres, new species. Figure 11, G-K.

Diagnosis.-The nearly terete body of the male, with dorsal striae paralleling the median sulcus, in addition to peculiarities of the first three pairs of legs and gonopods readily identify this species.

Description.-Male with 40 segments, $10 \mathrm{~mm}$. long, $.6 \mathrm{~mm}$. wide, almost uniformly cylindrical throughout, scarcely compressed laterally; female stouter than male and noticeably fusiform, with 41 segments, $12 \mathrm{~mm}$. long, $1 \mathrm{~mm}$. wide; color rather dark throughout except for lighter spotting adjacent to pores, no light median fascia present.

Head of holotype with a single large ocellus on one side, two on opposite side, anterior one a third or fourth as broad as posterior one; female with two ocelli on each side.

Segment 1 with a stria forming an anterior rim behind eye and continuing to posterior margin, no striae above it and only two short ones below; surface of segment with 20-30 long setae scattered over it, the longest near anterior margin; segments 2-4 with a row of setae, decreasing in length, a moderate distance in front of posterior margin; succeeding segments with a similar row of very short setae, and several others sometimes scattered in front of it; lateral striae reaching near middle of dorsum on segment 9 or 10 , the dorsal striae thereafter parallel to median impressed line, the more lateral striae slightly oblique; female with dorsal and lateral striae slightly oblique.

Gonopods shown in figure 11, G-H. First legs of male (fig. 11, I) with two long, curved, spine-like elements below joint 2, perhaps representing fused setae; a smaller similar element below joint 3 ; joint 5 with a comb of fine setae along lower side. Second legs of male (fig. $11, \mathrm{~J}$ ) with last joint rather long, evenly curved and of uniform diameter throughout, the tip bluntly rounded. Third legs of male much thicker than ensuing ones, the last joint (fig. $11, \mathrm{~K}$ ) with a comb of long thick setae below; claw a thin spatulate blade. Pleura of segment 3 not produced forward, that of segment 4 somewhat produced but flat and only visible in subventral view.

Holotype.-Male, west of Finca Palo Santo, near Nueva California, Chiriquí Province, March 10, 1959, alt. 5000 ft., (B-457) concentrated floor litter at base of log and cut stump.

Paratype.-Female, with holotype.

Prostemmiulus vallaris, new species. Figure 11, L-N.

Diagnosis.-Differing markedly from all other species in having a strong lateral projection near the apex of each anterior gonopod.

Description.-Body $15 \mathrm{~mm}$. long, $1.3 \mathrm{~mm}$. wide, with 41 segments; shape fusiform, tapering backward from near middle of body, moderately compressed later- 
ally. Head and segment 1 somewhat lighter than rest of body, which is dark to low on the sides and lacks a pronounced median light stripe but has the usual light areolations beginning near pore and extending downward, the posterior portion of segments transparent and appearing lighter, especially when partially dried.

Head with upper ocellus large, in contact with the lower one, which is more than half as wide.

Segment 1 with two oblique, moderately impressed striae, the lower extending to behind the large ocellus, the upper reaching well above it; outer limits scarcely bent inward. Ensuing segments with the striae first attaining mid-dorsum on the anterior portion of segment 12 or 13; median sulcus fine, ending in a deep narrow slit that spreads open a little behind but is not conspicuous.

Gonopods as shown in figure 11, L. First legs of male with usual comb of setae beneath outer joint; second and third legs as shown in figure $11, \mathrm{M}-\mathrm{N}$, the third joint of the latter pair long and strongly thickened, the three outer joints contrasting strongly with it.

Holotype.-Male, El Valle, Cocle Province, Feb. 23, 1959, alt. $2400 \mathrm{ft}$. (B-349) floor debris from steep stream bed, trail to "Las Minas."

\section{STEMMIULUS Gervais}

Stemmiulus Gervais, 1844, Ann. Soc. Ent. France, ser. 2, 2, p. 29.

\section{KEY TO SPECIES OF STEMMIULUS OF PANAMA}

1. Size small, not over $10 \mathrm{~mm}$. long; striae present on both dorsum and sides of all segments. ......................................

Size larger; striae not present on dorsum of anterior segments. . . . . . . . 2

2. Size intermediate; segment 1 with a single stria lying close to anterior margin from near lower angle to above ocellus.............. marginandus

Size large, $25 \mathrm{~mm}$. long or more; segment 1 with two oblique striae, neither closely following the front margin ..........................

\section{Stemmiulus canalis Chamberlin}

Stemmiulus canalis Chamberlin, 1940, Bull. Univ. Utah, (9), 30, pp. 14-15.

Localities.-Canal Zone: Many locations; female, Barro Colorado Island, Jan. 22, 1959, Berlese, compost pile.

Panama Province: Adjacent to Canal Zone.

Stemmiulus marginandus, new species. Figure 11, O-R.

Diagnosis.-Gonopods most closely resembling those of the Colombian S. cognatus Silvestri but the body only half the length and with fewer segments; striation of segment 1 and the rapid dorsal ascent of the striae on the anterior segments are other outward recognizable differences. 
Description.-Body of intermediate size, a male $10 \mathrm{~mm}$. long, a female $14 \mathrm{~mm}$. long, another $20 \mathrm{~mm}$. long, $1.3 \mathrm{~mm}$. wide; number of segments $46-48$; male barely fusiform, females less so, both sexes with body narrowing rather suddenly through the last eight or nine segments; color uniformly dark with lighter median line along dorsum and variable areolations from the pores downward.

Segment 1 with a single fine stria beginning low on the back margin and closely paralleling the front margin to behind the single large ocellus, thus the margin appearing finely rimmed; subventral surface with two short and inconspicuous striae. Ensuing segments with lateral striae strongly impressed, oblique, reaching the dorsal median sulcus near front of segment 7 or 8; sulcus strong, ending in a deep slender notch.

Gonopods shown in figure 11, O-R. First legs of male with usual comb of setae beneath outer joint; second legs with joints cephalocaudally compressed and expanded but no thicker in lateral view than other legs; shaped as shown in figure 11, Q; third legs shown in figure $11, \mathrm{R}$; fourth and fifth legs of holotype greatly reduced in size, possibly a malformation, as the right leg of the third pair also is greatly reduced and differs in shape from that illustrated.

Holotype.-Male, Almirante, Bocas del Toro Province, March 30, 1959, (B-676) forest floor litter.

Paratypes.-Two females, with holotype.

\section{Stemmiulus parallelus, new species. Figure 11, S-U.}

Diagnosis.-A very small species differing in dorsal sculpture from all other known species as well as having unusual gonopods. Possibly closest to $S$. marginandus but still distantly related.

Description.--Sexes not differing in outward particulars; 9-10 $\mathrm{mm}$. long; 3940 segments; slender, almost cylindrical but appearing faintly compressed when a segment is seen in end view; color light mottled brown above and below, the usual large light spotting near pores and below them, no conspicuous median light line; all segments with lateral striae continuing upward to mid-dorsum, where they are close together and parallel the fine median sulcus which ends in a deep, very narrow notch; on anterior segments dorsal striae not always continuous across segment but farther back the striae complete and more conspicuous than the median sulcus.

Head with the ocellus of small to medium size, half the diameter of an antennal socket; antennae with joint 2 slightly longer than any other, joints 3-6 subequal in length, joint 5 a little the thickest; clypeal area convexly raised above the surface behind it.

Segment 1 with a single long stria extending obliquely upward from the posterior margin to behind the ocellus, not paralleling the margin as in marginandus; striae similar to those of succeeding segments, faintly visible on the posterior dorsal surface.

Gonopods and anterior legs shown in figure 11, S-U; first pair of male legs with the usual ventral comb of setae on outer joint.

Holotype.-Male, road west of Finca Palo Santo, near Nueva California, Chiriquí Province, March 5, 1959, alt. 4700 ft., (B-385) leaf debris in ravine. 
Paratypes.-Male, two females, with holotype; male, holotype locality, March 5, 1959, alt. $4750 \mathrm{ft} .,(\mathrm{B}-377)$ chips, etc., at base of cut Stamp.

\section{Order SPIROBOLIDA \\ Family RHINOCRICIDAE}

Members of this family differ from the Spirobolellidae in being of medium to large size; in having the midbelt and hindbelt of each segment separated by a more or less impressed sulcus passing close to the pore; and in differences of the gonopods, especially the inner ones.

\section{KEY TO GENERA OF RHINOCRICIDAE OF PANAMA}

1. Anal valves each produced backward near upper limit into a pointed process. Oxypyge

Anal valves not produced near upper limit...................

2. Segments with a single transverse sulcus near each pore....... Rhinocricus Segments with a secondary transverse sulcus in advance of the usual one.

Eurhinocricus

\section{EURHINOCRICUS Brolemann}

Eurhinocricus Brolemann, 1903, Ann. Soc. Ent. France, 72, p. 131, illus.

\section{Eurhinocricus biolleyi Brolemann}

Eurhinocricus biolleyi Brolemann, 1903, Ann. Soc. Ent. France, 72, p. 132, illus.

Rhinocricus cocos Chamberlin, 1947, Proc. Acad. Nat. Sci. Philadelphia, 99, pp. $38-39$, illus.

Eurhinocricus cocos Hoffman, 1953, Proc. Biol. Soc. Washington, 66, p. 182.

This species is distinguished from the next by having only the secondary sulcus well marked across each segment; pores seldom followed by a lengthwise sulcus; and differences of the gonopods.

Localities.-Canal Zone: Barro Colorado Island, male, Jan. 14, 1959 , Berlese, woody frass at base of dead stub; male, Jan. 21, 1959, from old log.

Bocas del Toro Province: Almirante, 2 males, female, March 30, 1959.

\section{Eurhinocricus cooki Loomis}

Eurhinocricus cooki Loomis, 1961, Proc. U. S. Nat. Mus., (3454), 113, pp. 110111 , illus.

Localities.-Canal Zone: Barro Colorado Island and Piña area. 
Rhinocricus ferrugineus Pocock, 1907, Biol. Centr.-Amer., p. 70.

Locality.- "Panama." Not reported since original description.

\section{Rhinocricus hagedussii (Daday)}

Spirobolus hagedussii Daday, 1889, Term. Füzetek, 12, p. 130.

Rhinocricus hagedussii Pocock, 1907, Biol. Centr.-Amer., p. 70.

Locality.- "Panama." Not reported since original description.

Rhinocricus ocraceus Brolemann (= Rhinocricus insulatus Chamberlin), new synonymy.

Rhinocricus ocraceus Brolemann, 1900, Mem. Soc. Zool. France, 13, pp. 124125 , illus.

Rhinocricus insulatus Chamberlin, 1925, Proc. Biol. Soc. Washington, 38, p. 39. Rhinocricus williamsi Chamberlin, 1940, Bull. Univ. Utah, (9), 30, p. 15.

Eurhinocricus insulatus Hoffman, 1955, Proc. Biol. Soc. Washington, 68, p. 35. Eurhinocricus williamsi Hoffman, 1955, loc. cit.

The type locality of ocraceus, "Isthmus of Panama, Bas Obispo," was found on an old map of the Canal Zone to be about opposite Gamboa, within a few miles of the type locality of insulatus, and adjacent to other localities (Loomis, 1961) where insulatus has been found. Reference to the description and illustrations of ocraceus leaves no doubt as to the similarity of the two species and necessitates return to use of the older name.

Localities.-Canal Zone, Barro Colorado Island: 25 specimens, Jan. 14, 1959, Berlese, woody frass at base of dead stub; 20 specimens, Jan. 21, 1959, from old log; 7 specimens, Jan. 22, 1959, Berlese, compost pile.

Panama Province: Adjacent to Canal Zone.

Rhinocricus pedrocola Chamberlin

Rhinocricus pedrocola Chamberlin, 1947, Proc. Acad. Nat. Sci. Philadelphia, 99, pp. 41-43, illus.

Locality.-Canal Zone: Pedro Miguel. Not reported since original description.

Family SPIROBOLELLIDAE

MICROSPIROBOLUS Silvestri (=Barrobolus Chamberlin), new synonymy. 
Microspirobolus Silvestri, 1898, Ann. Mus. Nac. Buenos Aires, 6, p. 75.

Barrobolus Chamberlin, 1925, Proc. Biol. Soc. Washington, 38, p. 41.

Microspirobolus grammicus (Chamberlin), new combination. Figure 12, A-B.

Barrobolus grammicus Chamberlin, 1925, Proc. Biol. Soc. Washington, 38, p. 41.

This species has not been reported since it was originally described from Barro Colorado Island. I am indebted to R. L. Hoffman for the accompanying gonopod drawings, made from slides of a specimen belonging to Chicago Natural History Museum and found on Barro Colorado Island, July 25, 1938, by E. C. Williams. Hoffman also pointed out that Barrobolus is a synonym of Microspirobolus, as I had suspected, and he has permitted me to publish this determination.

\section{Microspirobolus trifasciatus, new species. Figure 12, C-D.}

Diagnosis.-Closely related to $M$. grammicus but differing in color pattern; the straight rather than rounded lateral limits of segment 1; and details of the gonopods.

Description.-Body short and stout; 11-13 mm. long, 1-1.3 mm. wide, the females stouter than the males; number of segments 29-32, the last three of all mature specimens being legless. Dorsum very broadly more or less light-colored, contrasting with a dark band along each side, below which the lower sides and ventral surfaces are light-colored.

Head with ocelli low and flat, arranged in four rows (holotype), 6-5-5-3 on one side, 6-7-4-3 on the other side, counting forward from near segment 1 ; antennal joint 1 slightly thicker and about as long as joints 2 and 6 , which are subequal in length, exceeding joints 3,4 and 5 ; clypeal fovea 2-2; lower side of head, mandibulary cardo and stipes together evenly and deeply concave, the stipes squarely and broadly truncate in front.

Segment 1 with quite long, straight lateral limits ascending caudad, the anterior angle more sharply rounded than the posterior; margin rimmed, the rim continuing up to behind the eye-patch.

Body widest at segment 1, segments 2 and 3 narrowing, those thereafter of uniform width to caudal end; segments with a strong constriction well in advance of the pore, the constriction crossed by fine raised longitudinal lines on the dorsum; surface in front of constriction moderately convex, that behind it strongly and evenly so and shining; pores small, the one on segment 5 at the anterior fourth of subdivision and lower than those following, where the pore is at the anterior third. Last segment ending in a rather broadly rounded apex equaling the strongly convex anal valves, the inner margins of which meet at a re-entrant angle; preanal scale large, rounded in front, angular behind. 
Gonopods shown in figure $12, \mathrm{C}-\mathrm{D}$, the anterior median plate sharply and deeply concare just below apex. Males with coxal joints of legs 1 and 2 thicker than those that follow, the nert three pairs distally lobed, the second joint of these legs somewhat expanded medianly along the rentral side.

Holotype.-Male, Almirante, Bocas del Toro Province, March 22, 1959.

Paratypes.-Two 26-segmented males, March 30, 1959, (B-676) forest floor litter on hill, and two males, female, same date, all from holotype locality.

\section{Order SPIROSTREPTIDA}

Two families represent this order in Panama, the first, Spirostreptidae, containing large, heary-bodied species with quite complicated gonopods, from the front of each of which a long, contorted branch arises near apex; the Epinannolenidae are small to intermediate in size, slender, with much more simple gonopods lacking long, contorted anterior branches.

\section{Family SPIROSTREPTIDAE}

\section{ISOPOROSTREPTUS Silvestri}

Ieoporatreptus Silvestri, 1898, Ann. Mus. Nac. Buenos Aires, 6, p. 73.

For complete synonymy of this genus see Hoffman (1953a).

This genus is separated from Orthoporus on the basis of having the long contorted terminal branch of the anterior gonopod divided just distad of its point of emergence from the sheathing basal portion, one of the divisions resembling that of Orthoporus but the additional one nearly as long and more or less slender-acuminate.

FIG. 12. A-B, Microspirobolus grammieus: A, gonopods, anterior view; B, inner gonopod. (Drawings contributed by R. L. Hottman.)

$C-D$, Microspinobolus trifasciatus: C, gonopods, anterior view; D, aper of inner gonopod, showing beyond tip of posterior joint.

E, Epirannolene sulocta: apical portion of right gonopod, lateral view.

F-H, Epinanwoleme cacca: $F$, segment 1 and part of head, lateral view; $G$, right gonopod, anterior view; H, apex of same, enlarged posterior view.

I-K, Siphonotus pancmanus: I, last two segments, dorsal view; J, apical joints of anterior gonopods, posterior view; $\mathbf{K}$, posterior gonopod, posterior view.

L-N, Siphonocybe latioollis: L, head and antenna, ventral view; $\mathbf{M}$, bead and segment 1 , dorsal view; $\mathbf{N}$, right anterior gonopod with apex of posterior gonopod showing, lateral view.

O-P, Siphomophora coclensis: $\mathbf{O}$, bead, anteana and segment 1 , dorsal view; $P$, left anterior gonopod, lateral view. 

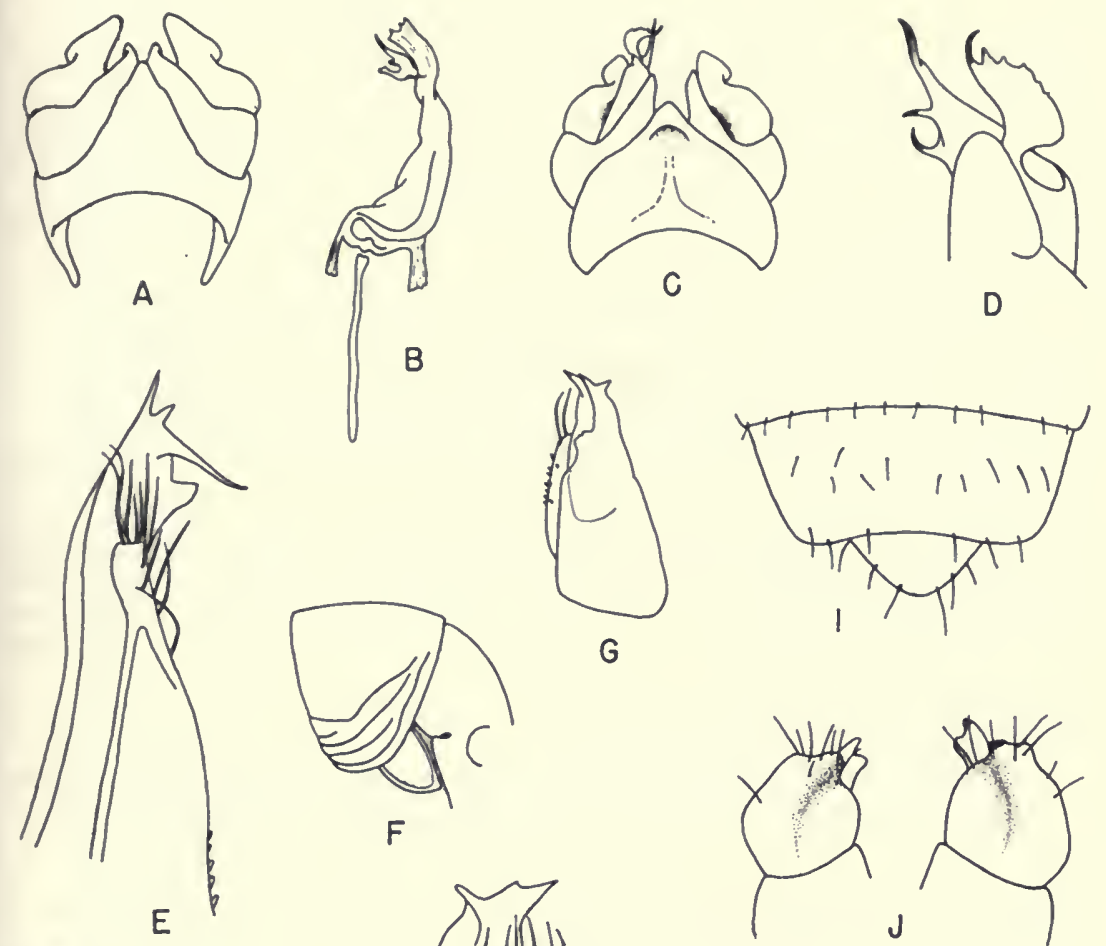

B
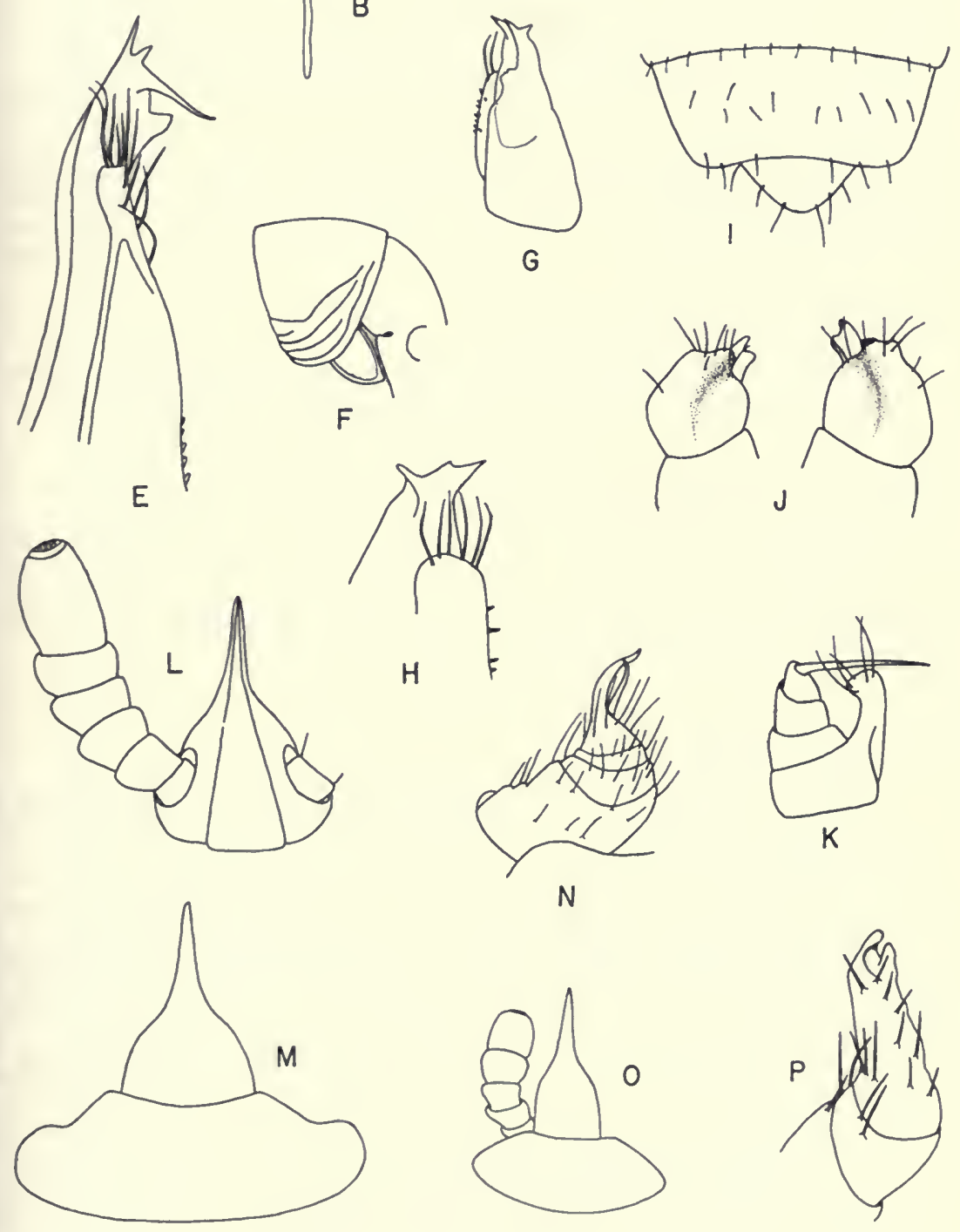


\section{Isoporostreptus pittieri Hoffman}

Isoporostreptus pittieri Hoffman, 1953, Lloydia, (2), 16, pp. 151-154, illus.

Locality.-Chiriquí Province: Las Siguas.

\section{ORTHOPORUS Silvestri}

Orthoporus Silvestri, 1897, Boll. Mus. Zool. Torino, (283), 12, p. 7.

\section{KEY TO SPECIES OF ORTHOPORUS OF PANAMA}

1. Segments longitudinally ridged or channeled behind the transverse sulcus.

Segments not ridged or channeled behind sulcus . .

2. Size large, $c a .85 \mathrm{~mm}$. long; posterior gonopods each with a long acuminate lateral production at tip ............................ chiquensis

Size smaller, ca. $50 \mathrm{~mm}$. long; posterior gonopods each with almost no lateral

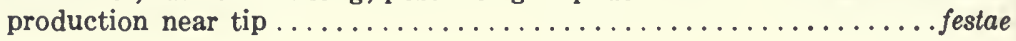

Orthoporus canalis Chamberlin

Orthoporus canalis Chamberlin, 1925, Proc. Biol. Soc. Washington, 38, p. 38. Localities.-Canal Zone and adjacent Panama Province.

\section{Orthoporus chiriquensis Pocock}

Orthoporus chiriquensis Pocock, 1909, Biol. Centr.-Amer., Chilopoda and Diplopoda, p. 97, illus.

Diaporus chiriquensis Chamberlin, 1922, Proc. U. S. Nat. Mus., (8), 60, p. 18. Locality.-Chiriquí Province: Volcan de Chiriquí.

\section{Orthoporus festae (Silvestri)}

Plusioporus festae Silvestri, 1896, Boll. Mus. Zool. Torino, (254), 11, p. 3.

Orthoporus festae Pocock, 1909, Biol. Centr.-Amer., Chilopoda and Diplopoda, p. 102 .

Diaporus culebrae Chamberlin, 1922, Proc. U. S. Nát. Mus., (8), 60, p. 18, illus. Diaporus barroensis Chamberlin, 1925, Proc. Biol. Soc. Washington, 38, p. 39.

Localities.-Canal Zone: Barro Colorado Island, female, one young, Jan. 21, 1959; young male, Feb. 1-3, 1959, Monte Lirio, Piña area.

Chiriquí Province: Finca Lerida, near Boquete, March 12, 14, 1959, two males.

Cocle Province: El Valle, female, Feb. 20, 1959, alt. $2200 \mathrm{ft}$.

Darien Province: Punta Sabana.

Panama Province: Juan Dias; Taboga Island. 


\section{Family EPINANNOLENIDAE}

\section{EPINANNOLENE Brolemann}

Epinannolene Brolemann, 1903, Ann. Soc. Ent. France, 72, pp. 135-136, illus.

\section{KEY TO SPECIES OF EPINANNOLENE OF PANAMA}

1. Species eyeless and colorless except for spots on sides caused by repugnatorial

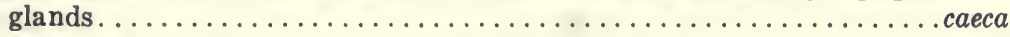

Species with numerous ocelli; body mostly colored. . . . . . . . . . . 2

2. Metazonites not separated from prozonites by a transverse sulcus on dorsum. plana (see p. 131)

Metazonites separated from prozonites by a dorsal sulcus............

3. Body stout, a little over 10 times as long as thick and with less than 40 segments................................ robusta (see p. 131)

Body more slender, at least 14 times as long as thick; segments numbering 40

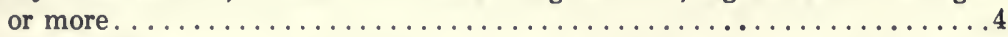

4. Pores rimless and opening from the flat surface; principal branch of gonopod ending in four projections, the largest at a right angle to main axis. . . sulcata

Pores rimmed and in a depression of the surface; principal branch of gonopod ending in two subequal erect prongs. . . . . . . . . . . . . . . 5

5. Secondary branch of gonopod with four or five terminal setae....... affinis Secondary branch of gonopod with eight or more setae at end...... bicornis

\section{Epinannolene affinis Loomis}

Epinannolene affinis Loomis, 1961, Proc. U. S. Nat. Mus., (3454), 113, pp. 114115 , illus.

Localities.-Canal Zone: Piña area.

Cocle Province: El Valle.

\section{Epinannolene bicornis Brolemann}

Epinannolene bicornis Brolemann, 1905, Ann. Soc. Ent. France, 74, pp. 356358 , illus.

Localities.-Chiriquí Province: Cerro Punta: male, March 6, 1959, alt. $6250 \mathrm{ft}$., under bark of log on ground; female, two young, (B-403) leaves, etc., under log on ground, and male, March 7, 1959, alt. 6900 ft. Finca Lerida, near Boquete: male, March 12, 1959, alt. $5650 \mathrm{ft}$., G. A. Solem, leg.; male, March 14, 1959, alt. 5650 ft., under sawn tree slabs; 14 males and females, "Barca area," (B-491) concentrated floor litter; male, March 15, 1959; three females, March 15, 1959, (B-507) frass under nest in tree hole, $3 \mathrm{ft}$. above ground; male, March 16, 1959, alt. 6000-7000 ft. 
Epinannolene caeca, new species. Figure 12, F-H.

Diagnosis.-It is difficult to determine relationship of this eyeless and almost wholly colorless species to other members of the genus. Despite the unusual differences, features of the gonopods appear to associate it with the much larger E. bicornis.

Description.-Length $14 \mathrm{~mm}$., width $.8 \mathrm{~mm}$.; body composed of 51 segments, widest at segments 1 and 2 , narrowing to segment 4, after which it broadens slightly and then continues of uniform thickness to caudal end; color lacking except for a dark spot on each side of segment showing through integument, undoubtedly the repugnatorial gland; surface of segments brilliantly shining.

Head without eyes; clypeal setae 3-3; labral setae 6-6; antennal joint 6 longest and thickest, joint 2 next in length but more slender than any other joint; stipes rather short and broad, rimmed above and below.

Segment 1 (fig. 12, F) with lateral limits broadly rounded and having a raised rim that extends far up the anterior margin; above it are three deep striae increasing in length upward, the surface between them raised and forming distinct ridges. Segment 2 with lateral striations reaching high on the sides but exceeded by those of segments 3-7 after which they gradually recede. Segments with a narrow but sharply impressed constriction separating the strongly and evenly convex posterior division from the less convex anterior one, the constriction containing a series of widely and irregularly spaced tiny punctations across the dorsum; pores beginning on segment 5 , readily seen, about two-fifths of the way back in the posterior subsegment, opening from a sharp depression of the surface that is about twice as wide as the pore, the two segments preceding the terminal one without pores and also legless.

Last segment longer along dorsum than preceding segments, the apex broad but somewhat angularly rounded and not exceeding the anal valves, whose inner margins are rather thin, strongly raised and separated from the very convex and brilliantly shining adjacent surface by a distinct channel; preanal scale transverse, narrowly suboval but with each outer limit truncated, beyond which is a prominent seta-tipped conic tab-process or tubercle.

Gonopods shown in figure $12, \mathrm{G}-\mathrm{H}$.

Holotype.-Male, Barro Colorado Island, Canal Zone, Jan. 1, 1959, Berlese, compost pile.

Epinannolene sulcata, new species. Figure 12, E.

Diagnosis.-The gonopods indicate close relationship with $E$. plana but that species lacks an impressed sulcus across the median portion of each segment between the two subdivisions as found in the present one.

Description.-Broken male approximately $21 \mathrm{~mm}$. long, $1.5 \mathrm{~mm}$. wide; with 42 segments of which the two preceding the last are legless; color in life apparently rather light.

Ocelli in three rows: 4-7-7 one side of head, 3-7-8 on opposite side. 
Segment 1 rather narrowly and evenly rounded on sides with a margining rim extending from behind the upper corner of the eye to the posterior margin; above the rim on each side is an equally long stria with another one, half as long, extending forward from the back margin above it, on one side only; anterior margin behind eye very faintly emarginate. Ensuing segments shining, very finely, faintly, and sparsely scratched with long aciculations; crossed near the middle by a fine but sharply impressed sulcus which bends forward broadly in front of each pore and contains no sculpturing; surface behind sulcus weakly convex, posterior margin thin; pore of moderate size, lacking an encircling rim but opening from surface a third of the way behind the sulcus; lateral striae highest on segments 4 and 5 , reaching two-thirds of distance to pore on latter, gradually reduced to two or three striae adjacent to pleural suture on posterior segments. Last segment slightly produced and thickened at rounded apex; anal valves evenly convex, meeting in a shallow groove; preanal scale nearly half as long as wide, broadly rounded at apex, the tab-process conspicuous each side at base.

Gonopods (fig. 12, E) rather thick at base.

Segment 7 of male raised ventrally at middle, laterad of which the surface is depressed to receive the tip of a gonopod before rising into what appears as a posteriorly directed lobe when viewed from the side.

Holotype.-Male, west of Finca Palo Santo, near Nueva California, Chiriquí Province, March 9, 1959, alt. 4900 ft., (B-433) concentrated forest floor litter in damp ravine.

\section{Order POLYZONIIDA \\ Family POLYZONIIDAE}

\section{SIPHONOTUS Brandt}

Siphonotus Brandt, 1836, Bull. Sci. Acad. Sci. Saint-Petersbourg, 1, p. 179.

\section{KEY TO SPECIES OF SIPHONOTUS OF PANAMA}

1. Body approaching $9 \mathrm{~mm}$. in length, number of segments about $46 \ldots$ angulifer Body half as long or less, segments much fewer, $25-35 \ldots \ldots \ldots \ldots \ldots . \ldots 2$

2. Body of intermediate length; color solid except adjacent to pores; antennae

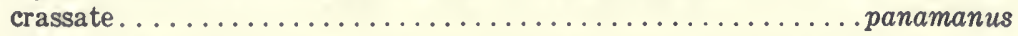

Body only about $3 \mathrm{~mm}$. long; dorsum with light spots; antennae more slender. centralis

Siphonotus angulifer Chamberlin

Siphonotus angulifer Chamberlin, 1940, Bull. Univ. Utah, (9), 30, p. 16. Localities.-Canal Zone: Barro Colorado Island and elsewhere.

\section{Siphonotus centralis Chamberlin}

Siphonotus centralis Chamberlin, 1940, Bull. Univ. Utah, (9), 30, p. 16. 
Locality.-Canal Zone: Known only from the original male, collected on Barro Colorado Island.

Siphonotus panamanus, new species. Figure 12, I-K.

Diagnosis.-A considerably more slender species than $S$. parvus Chamberlin (1923c), or $S$. centralis, by inference from the description of the latter. For neither species did Chamberlin present illustrations of the gonopods with the original descriptions. This species differs further from parvus in the greater exposure of the last segment and from centralis in the more crassate antennae and nearly solid color of the body.

Description.-Male $4.5 \mathrm{~mm}$. long, $.5 \mathrm{~mm}$. wide; 31 segments; color pinkishpurple, quite evenly distributed over the dorsum except for a small light area around each pore.

Head with the ocellus on each side small, circular, but its dark subsurface portions large, irregular, and showing through the integument surrounding the socket. Antennae much as shown by Chamberlin for parvus.

Segment 1 with quite long setae sparsely scattered over the surface; ensuing segments crossed by two rows of erect setae, one near the posterior margin, the other near the middle of the metazonite. Penultimate segment (fig. 12, I) long, the median row of setae more irregular than on the preceding segments. Last segment well exposed behind the penultimate. Anal valves rather long and narrow, moderately inflated, and with distinct, shining, thin, raised margins.

Gonopods shown in figure $12, \mathrm{~J}-\mathrm{K}$.

Holotype.-Male, Chilibrillo Cave, near Chilibre, Panama Province, Feb. 7, 1959, (B-222) from drift along stream in cave.

Paratypes.-Two females, with holotype; 14 males and females, same data but collected on moss by stream at cave entrance.

Canal Zone, Barro Colorado Island: male, two females, Jan. 10, 1959, under bark; 35 males and females, Jan. 22, 1959, Berlese, compost pile; male and female, Feb. 15, 1959, (B-262) pile of leaves and grass along stream; two females, Madden Forest Preserve, Feb. 15, 1959.

\section{Family SIPHONOPHORIDAE}

\section{SIPHONOCYBE Pocock}

Siphonocybe Pocock, 1903, Biol. Centr.-Amer., Chilopoda and Diplopoda, p. 50.

This genus was separated from Siphonophora on the basis of having pronounced lateral keels bearing the pores, but its maintenance has been questioned by Loomis (1961) because of similarities of the 
gonopods of the two genera. It is continued here until more extensive studies can be made to determine its proper status.

Siphonocybe laticollis, new species. Figure 12, L-N.

Diagnosis.-The largest member of the genus and also recognizable by the very wide first segment with its keel-like lateral extensions; the gonopods also are distinctive in separating it from the related $S$. pilosa.

Description.-Body ranging from $21 \mathrm{~mm}$. long and $1.9 \mathrm{~mm}$. wide with 65 segments (male) to $36 \mathrm{~mm}$. long, $2.3 \mathrm{~mm}$. wide with 96 segments (largest female); color in life probably light with median portion of dorsum somewhat darker; dorsal surface with erect velvety pubescence, distinctly shorter but more abundant than that in pilosa.

Head with basal portion subhemispherical, the beak about equal to it in length, weakly deflexed; antennae short and stout (fig. 12, L), the five basal joints short and subequal in length but gradually increasing in thickness, joint 6 narrower but longer than joints 4 and 5 together.

Segment 1 very wide, two and a half times wider than base of head, the outer limits separately extended, inflated and resembling the keels that follow (fig. 12, M). Ensuing segments, including the penultimate, with dorsum strongly convex, the inflated keels projecting from it almost horizontally and thus well set off; keels little produced backward except faintly on caudal segments as seen in dorsal view.

Anterior gonopods as shown in figure $12, \mathrm{~N}$; posterior gonopod with basal joints and basal portion of last joint much thicker than in pilosa. First male legs without anterior coxal lobes; second legs somewhat stouter than those immediately following.

Holotype.-Male, "Barca area," Finca Lerida, near Boquete, Chiriquí Province, March 14, 1959, alt. 5650 ft., (B-491) concentrated floor litter.

Paratypes.-Chiriquí Province: Two females, with holotype; female, Cerro Punta, March 8, 1959, alt. 5600 ft., G. A. Solem, leg.; male, Finca Lerida, March 14, 1959, alt. 5650 ft., G. A. Solem, leg.

Siphonocybe pilosa Loomis

Siphonocybe pilosa Loomis, 1961, Proc. U. S. Nat. Mus., (3454), 113, pp. 118119 , illus.

Localities.-Canal Zone and Panama Province, Cerro Campana.

\section{SIPHONOPHORA Brandt}

Siphonophora Brandt, 1836, Bull. Sci. Acad. Sci. Saint-Petersbourg, 1, p. 179. 


\section{KEY TO SPECIES OF SIPHONOPHORA OF PANAMA}

1. Size large, $20-70 \mathrm{~mm}$. long, body with $75-175$ segments......... panamensis Body less than $20 \mathrm{~mm}$. long with not over 65 segments............2

2. Head subglobular, exclusive of beak, hiding base of beak from above... aviceps Head more attenuated, beak fully exposed from above............. 3

3. Head with sides almost parallel, beak as long as basal portion .......coclensis Head with sides more or less oblique, beak shorter than basal portion.....4

4. Size very small, 3.5-6 $\mathrm{mm}$. long; upper margin of antennal sockets visible in vertical view of head; segment 1 little wider than head.......... parvula

Body two or three times longer; antennal sockets not visible from above; segment 1 considerably wider than head .................montana

\section{Siphonophora aviceps Loomis}

Siphonophora aviceps Loomis, 1961, Proc. U. S. Nat. Mus., (3454), 113, pp. 119-121, illus.

Localities.-Canal Zone, Barro Colorado Island: Twelve males and females, Jan. 1959, Berlese, log debris; male, female, Jan. 22, 1959, Berlese, compost pile. Piña area.

Chiriquí Province: Three males, west of Finca Palo Santo, near Nueva California, March 10, 1959, alt. 5000 ft., (B-457) concentrated floor litter at base of log and cut stump.

Panama Province: Juan Dias.

Siphonophora coclensis, new species. Figure 12, O-P.

Diagnosis.-Apparently close to $S$. montana as suggested by size, general shape, coloration and the heavy terminal joint of each anterior gonopod, which, however, differs in details. The slender head of coclensis also distinguishes it.

Description.-Body about $14 \mathrm{~mm}$. long, $1 \mathrm{~mm}$. wide, with 48 segments, the first six or seven of which gradually widen, the last four or five gradually narrowing with the intervening ones subequal in width; segments thick, strongly convex lengthwise, moderately so across dorsum, which is continuous with the keels, their outer limits thick and bluntly rounded; pores definitely raised above surrounding surface; dorsum densely setose but the surface shining between the setae; color dark purplish-brown in alcohol.

Head narrow (fig. 12, 0), basal half about as long as beak, the sides almost parallel, the upper surface weakly convex, the beak almost continuous with it, very little curved downward; mentum long and slender, the sides diverging caudally very slowly; antennal sockets low on sides of head and opening outward, the antennae short, thick and not reaching tip of beak.

Segment 1 well over twice as wide as base of head, the anterior margin nearly straight across but in the foreshortened drawing it appears slightly emarginate. Anterior legs similar in size, the coxae of the first pair without anterior lobes. 
Anterior gonopods shown in figure 12, P.

Holotype.-Male, El Valle, "trail to Las Minas," Cocle Province, Feb. 23, 1959, alt. $2400 \mathrm{ft} .,(\mathrm{B}-350) \log$ debris.

Siphonophora montana, new species. Figure 13, A-D.

Diagnosis.-The size, proportions of body, shape of head and segment 1, indicate closer relationship with S. columbiana Carl (1914) than with any other species in northern South America or Central America, but the heavier antennae and more slender anterior gonopods distinguish it.

Description.-Body $19 \mathrm{~mm}$. long, $1.5 \mathrm{~mm}$. wide, with 65 segments (holotype); paratype $12 \mathrm{~mm}$. long, $1.2 \mathrm{~mm}$. wide, with 52 segments; color in alcohol dark reddish brown, indicating a rather dark color in life. Dorsum strongly arched, the lateral keels continuous with it, their outer limits thick above the pleurae; dorsal surface with setae relatively long and dense.

Head short (fig. 13, A), the beak composing a third of its length and only slightly decurved; basal two-thirds of head broadly conic; antennal sockets low on sides, extending inward and downward (fig. 13, B); antennae short and stout; joint 1 and part of joint 2 hidden in dorsal view; joints 2 and 5 subequal, longer than subequal joints 1,3 and 4 ; joint 6 double the length of 5 but of same diameter; mentum broad basally, sides straight.

Gonopods of much the same type as in columbiana but the anterior ones more slender (fig. 13, C); posterior ones with last joint of somewhat different shape from that in that species (fig. 13, D). First legs without anterior coxal lobes; first two pairs of legs no heavier than those that follow.

Holotype.-Male, Cerro Punta, Chiriquí Province, March 7, 1959, alt. $6900 \mathrm{ft}$.

Paratype.-Chiriquí Province: Male, Finca Lerida, March 17, 1959, alt. $7800 \mathrm{ft}$., (B-524) concentrated forest floor litter.

\section{Siphonophora panamensis Loomis}

Siphonophora panamensis Loomis, 1961, Proc. U. S. Nat. Mus., (3454), 113, pp. 121-122, illus.

Localities.-Canal Zone: Several localities; female, Barro Colorado Island, Jan. 24, 1959.

Cocle Province: El Valle.

Panama Province: Alajuela; Juan Dias.

Siphonophora parvula, new species. Figure 13, E-F.

Diagnosis. - This is the smallest known member of the genus, smaller even than the Cuban S. senaria Loomis (1937) to which it is 
only remotely related; also, it has fewer segments; the antennae are unusually thick and short, rising from sockets opening high on the sides of the head, their upper limits plainly visible from above.

Description.-Body 3.5-6 mm. long, .4-.5 mm. wide and with 26-32 segments; color in life apparently white to cream; dorsum moderately convex, rather densely beset with relatively long pubescence; lateral keels continuous with dorsum and outwardly not greatly thickened.

Head (fig. 13, E) short, subconic, the base nearly as wide as segment 1; antennal sockets opening high on sides, easily visible from above; antennae straight, very short and thick, the first four joints subequal in length but gradually thickening; joint 5 slightly longer and thicker than joint 4 ; joint 6 narrower than 5 but slightly longer; beak short and straight, half as long as basal portion of head, the tip reaching the distal end of antennal joint 5 ; mentum wide at base, a seta each side at base of beak reaching to its tip.

Gonopods (fig. 13, F) with posterior pair almost fully exposed in lateral view, behind the more crassate anterior pair. First two pairs of legs not thicker than those that follow, the first pair without anterior coxal lobes.

Holotype.-Male, "Barca area," Finca Lerida, near Boquete, Chiriquí Province, March 14, 1959, alt. 5650 ft., (B-490) concentrated floor litter.

Paratypes.-Chiriquí Province: Finca Lerida, male, March 12, 1959 , alt. $5250 \mathrm{ft}$; three males, two females, March 14, 1959, alt. $5250 \mathrm{ft}$.; from holotype locality, three males, March 14, 1959, (B-491) concentrated floor litter; male, March 15, 1959, sawed slabs; from "Casita Alta," male, March 18, 1959, alt. 6900 ft., (B-543) concentrated forest debris in damp ravine; female, west of Finca Palo Santo, near Nueva California, March 9, 1959, alt. $5000 \mathrm{ft}$.

\section{Order PLATYDESMIDA}

\section{Family PLATYDESMIDAE}

\section{DESMETHUS Chamberlin}

Desmethus Chamberlin, 1922, Proc. U. S. Nat. Mus., (2403), 60, p. 6, illus.

This genus is distinguished from Platydesmus by having the metazonites densely scattered with setiferous granules, whereas Platydesmus has the granules or tubercles in two transverse rows.

Desmethus chiriquensis, new species. Figure 13, G-I.

Diagnosis.-Apparently a smaller but slightly broader species than the Guatemalan $D$. setifer Chamberlin (1922) with the penulti- 
mate segment of different shape and projecting farther behind the last segment.

Description.-Body $12 \mathrm{~mm}$. long, $3 \mathrm{~mm}$. wide, composed of 39 segments; dorsum with setiferous granules apparently as in setifer but the light color more restricted, consisting of a narrow median line and only the outer third or fourth of each keel yellow. Head colored as in setifer except that below the antennae it is entirely light; in shape longer, with antennae more clavate (fig. 13, G); surface not granular, shining, sparsely beset with fine short setae. Anterior end of body shown in figure 13, H. Segment 1 longer in relation to width than in setifer, and of somewhat different shape; surface granular-setose with a median depression each way; anterior surface on each side more swollen than posterior surface. Posterior end of body (fig. 13, I) with keels of penultimate segment extending much behind last segment, their inner sides straight. Anal valves projecting, strongly inflated, brilliantly shining, smooth, with a few tiny short scattered setae; preanal scale lacking. Legs with tips reaching or slightly exceeding outer margin of keels; sterna not as broad as length of first two joints of legs.

Holotype.-Female, Cerro Punta, Chiriquí Province, March 7, 1959 , alt. $6900 \mathrm{ft}$.

R. L. Hoffman kindly checked the U. S. National Museum specimens of $D$. setifer and reported four males with 40-50 segments, the smallest $12 \mathrm{~mm}$. long and $2.8 \mathrm{~mm}$. wide, and five females with 41-49 segments, the largest $19 \mathrm{~mm}$. long and $3.8 \mathrm{~mm}$. wide.

\section{PLATYDESMUS Lucas}

Platydesmus Lucas, 1843, Ann. Soc. Ent. France, (2), 1, p. 51.

Piestodesmus Lucas, 1849, Rev. et Mag. Zool., (2), 1, p. 598.

\section{Platydesmus subovatus, new species. Figure $13, \mathrm{~J}-\mathrm{L}$.}

Diagnosis.-A larger and broader species than P.taureus; segments with about double the number of tubercles in each row, the tubercles smaller and not extending onto lateral keels, which project farther from sides of body.

Description.-Body $20 \mathrm{~mm}$. long, $6 \mathrm{~mm}$. wide, elongate-suboval, only a few median segments of uniform width; number of segments 55; color in alcohol light brown with a narrow median line and outer portion of keels lighter; median portion of head brown, the "eyes," antennae and anterior part of head colorless.

Head flattened; "eye" each side large, the surface finely and evenly beset with short erect setae as is the surface of the head elsewhere.

Segment 1 in outline in figure $13, \mathrm{~J}$, the anterior mid-margin rough and almost vertically raised behind the head, the margin on either side produced forward into a broad lobe with anterior margin thick and shining; disk crossed in each direction at middle by a very deep narrow depression dividing the surface into quarters, each of which has about five indefinite setose tubercles along its crest. Segment 2 with lateral keels produced almost straight forward, their tips approximating the 
lobes of segment 1; middle of dorsum with two transverse rows of 10-12 small low tubercles each, the rows not separated by a sulcus; surface of keels with smaller scattered tubercles.

Ensuing segments broadening rapidly to segment 10 or 11, those at mid-body very wide and short (fig. 13, K), about 16 times as wide as long; posterior 16 or 17 segments narrowing caudally, the penultimate one with long keels produced straight back a little beyond the tip of the last segment; inner ventral margins of penultimate segment rounded and widely separated (fig. 13, L), exposing the anterior ventral margin of the last segment. Dorsum of the metazonites with the tubercles of the two rows small, definitely flattened, increasing in number to 40-50 on mid-body segments but the rows not extending onto the keels, which have numerous small scattered tubercles; surface including segment margins finely setose, spaces between the tubercles somewhat shining; segments with a sharply impressed median sulcus present through the penultimate one, and a finely impressed and shining sulcus between the two rows of tubercles, first becoming evident at about segment 7 and continuing thereafter, the sulcus not extending onto the lateral keels; keels with outer half or two-thirds of anterior margin rimmed.

Last segment long and narrow; dorsum bearing small scattered tubercles; apex asymmetrical (in holotype), with three lobes on one side and two on the other; valves strongly inflated and shining, with a few erect surface setae; preanal scale almost completely recessed in an emargination of the last segment, as shown in illustration.

Legs with tip of last joint not reaching beyond middle of keels; sterna at midbody wider than the length of the two basal joints of legs.

Holotype.-Female, Almirante, Bocas del Toro Province, March $22,1959$.

\section{Platydesmus taureus, new species. Figure $13, \mathrm{M}-\mathrm{N}$.}

Diagnosis.-A more slender species than $P$. subovatus and differing from it in the sloping mid-margin of segment 1 , and the fewer, larger tubercles in each row on the other segments, the inner pair in each row being especially prominent.

FIG. 13. A-D, Siphonophora montana: A, head, antenna and segment 1, dorsal view; $\mathbf{B}$, head, ventral view; C, apical joints of left anterior gonopod, lateral view; D, left posterior gonopod, lateral view.

E-F, Siphonophora parvula: E, head, antenna and segment 1, dorsal view; $\mathrm{F}$, right gonopods, lateral view.

G-I, Desmethus chiriquensis: G, head and antenna, anterior view; H, head and two segments, dorsal view; I, caudal end of body, dorsal view.

J-L, Platydesmus subovatus: J, head and segment 1, dorsal view; $\mathrm{K}$, right half of metazonite from mid-body, dorsal view; $L$, caudal end of body, ventral view.

M-N, Platydesmus taureus: $\mathrm{M}$, head and segment 1 , dorsal view; $\mathrm{N}$, right half of metazonite from mid-body, dorsal view.

O, Hypsiloporus erosus: right gonopod, posterior view.

$\mathrm{P}$, Hypsiloporus serratus: keels of segments 14 and 15, dorsal view. 

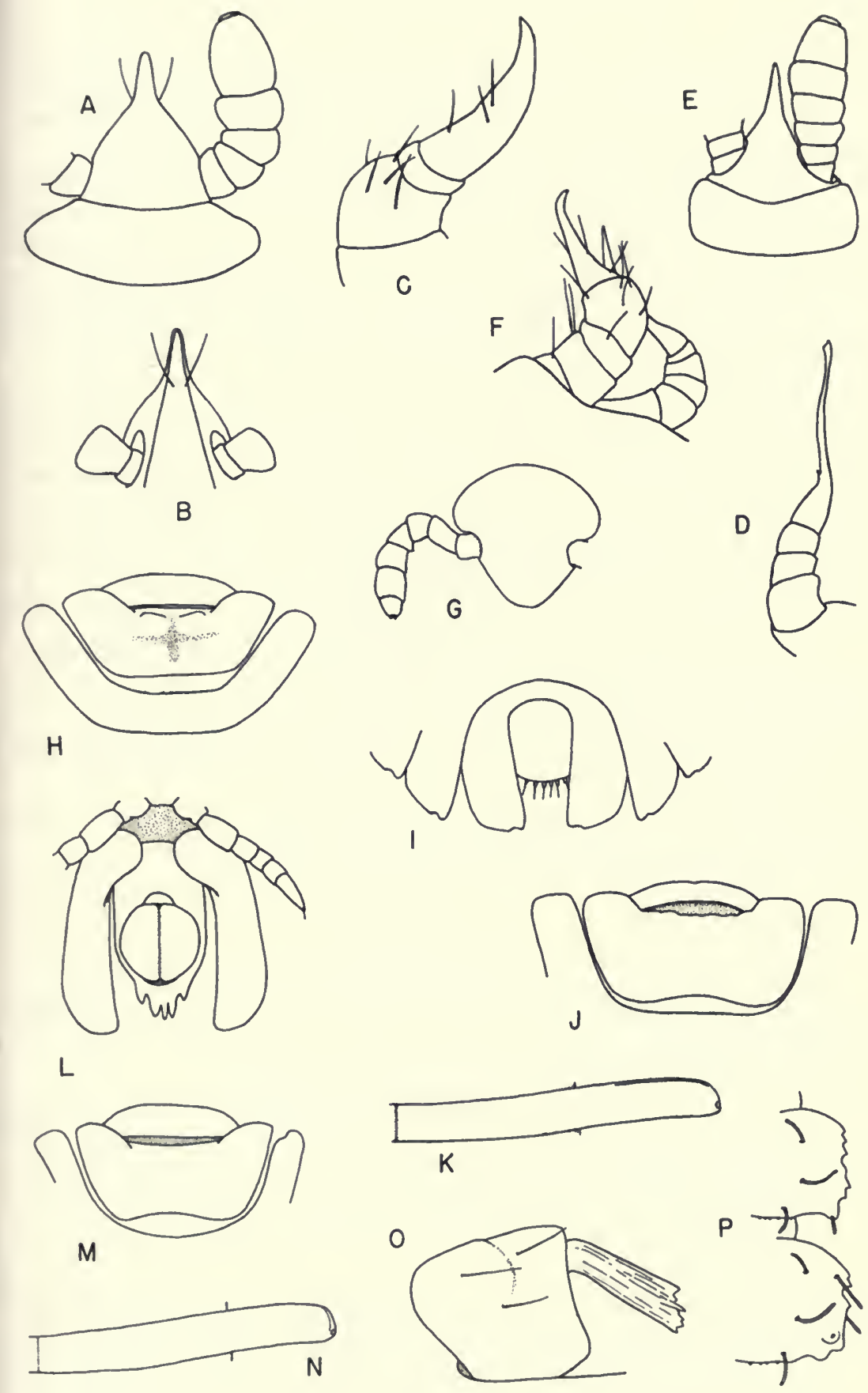
Description.-Body $14 \mathrm{~mm}$. long, $3.3 \mathrm{~mm}$. wide, with 45 segments, the first six or seven widening rapidly, the last nine or ten narrowing somewhat more gradually; dorsal surface dull and, with margins of segments, more obviously setose than subovatus; color pattern the same as in that species but lighter.

Head flattened; each "eye" large, shining and with almost no surface setae, the surface elsewhere less setose than in subovatus.

Segment 1 shown in outline in figure $13, M$, the anterior mid-margin obliquely inclined behind the head; median surface crossed in each direction by a deep depression, with four large rounded tubercles on the crest of each of the quarters thus formed. Segment 2 with two transverse rows of about 14 rounded tubercles, the number in each row increasing to about 18-22 on the wider segments, the rows extending beyond the base of the keels, the outer surface of which, however, is dull, somewhat roughened but without definite tubercles; median line of segments, while actually not strongly impressed, is made very evident by the enlargement of the inner pair of tubercles, which it separates in each row; no transverse sulcus or depression present between the two rows of tubercles but the tubercles more elevated than those of subovatus, the spaces between them dull; lateral keels without a definite rim along the anterior margin as in that species, and not as wide (fig. 13, N). Penultimate segment with inner ventral margins rounded as in subovatus but in contact and hiding the ventral surface of the last segment.

Last segment shaped much as in subovatus, the dorsum with 6-8 rather large scattered tubercles; anal valves evenly and quite densely beset with erect setae; preanal scale not as deeply recessed as in subovatus.

Legs with the tips slightly exceeding the outer limits of the keels; sterna narrower than the length of the two basal joints of the legs.

Holotype.-Female, Negra Creek, Almirante, Bocas del Toro Province, March 23, 1959, under logs, G. A. Solem, leg.

\section{ADDENDUM}

While this paper was in press it was found that the following species had been omitted.

\section{Family CHELODESMIDAE}

Alocodesmus silvestrii (Attems) (=Leptodesmus (Desmoleptus) silvestrii Attems), new combination.

Leptodesmus (Desmoleptus) silvestrii Attems, 1931.

Type locality.-Panama.

\section{Chondrodesmus frauenfeldianus (Humbert and Saussure)}

Polydesmus frauenfeldianus Humbert and Saussure, 1870.

Polydesmus (Oxyurus) frauenfeldianus Saussure and Humbert, 1872. 
?Leptodesmus frauenfeldianus Silvestri, 1896.

Chondrodesmus frauenfeldianus Carl, 1914.

Type locality.- "Nouvelle Grenade."

Other localities.-Sta. Marta, Nova Granada (Karsch, 1881). ?Darien: Punta Sabana, Rio Cianati, Rio Lara, Panama (Silvestri, 1896).

Chondrodesmus murphyi Chamberlin, 1946

Type locality.-San José Island, Pearl Islands, Panama.

Proletus foetidus Attems, 1931

Genotype locality.-Panama.

\section{Family STRONG YLOSOMIDAE}

Orthomorpha festae Silvestri, 1896

Type locality.-Rio Cianati, Darien Province, Panama.

Jeekel (in Diplopoda of Guiana, Nat. Stud. Suriname en de Nederlandse Antillen, no. 27, pp.1-57, illus., 1963) lists this species under "species incertae sedis."

\section{Family SPIROSTREPTIDAE}

Orthoporus margarites (Chamberlin) (=Diaporus margarites Chamberlin), new combination.

Diaporus margarites Chamberlin, 1946.

Type locality.--San José Island, Pearl Islands, Panama.

\section{Family EPINANNOLENIDAE}

Epinannolene plana Loomis

Epinannolene plana Loomis, 1961, Proc. U. S. Nat. Mus., (3454), 113, pp. 116-117, illus.

Locality.-El Valle, Cocle Province.

Epinannolene robusta Loomis

Epinnanolene robusta Loomis, 1961, Proc. U. S. Nat. Mus., (3454), 113, pp. 115-116, illus.

Locality.-Cerro Campana, Panama Province. 


\section{REFERENCES}

\section{AtTEms, CARL}

1900 System der Polydesmiden. Denk. Akad. Wien, 68, pp. 251-435, illus.

1931. Die Familie Leptodesmidae und andere Polydesmiden. Zoologica, Stuttgart, (Lief 3-4), 30, pp. 1-149, illus.

1933. Neue Polydesmiden von Costa Rica. Ann. Naturhist. Mus. Wien, 46, pp. 257-269, illus.

1940. Das Tierreich. Polydesmoidea. III, 70, pp. 1-576, illus.

\section{BERG, G.}

1899. Substitucion de nombres genericos. III. Comun. Mus. Nac. Buenos Aires, (3), 1, pp. 77-80.

Bollman, C. H.

1893. The Myriapoda of North America. Bull. U.S. Nat. Mus., 46, pp. 1-210.

BRANDT, J. F.

1837. Note sur un ordre nouveau de la classe Myriapodes et sur l'establissement des sections de cette classe d'animaux en general. Bull. Sci. Acad. Sci. Saint Petersbourg, (1836, no. 23), 1, pp. 178-179.

BrolemanN, H. W.

1898a. Voyage de M. E. Simon au Venezuela. Myriapodes. Ann. Soc. Ent. France, 67, pp. 241-313, illus.

1898b. Myriapodes du haut et Bas Sarare (Venezuela) donnes par M. F. Geay a Museum d'Histoire Naturelle de Paris. Ann. Soc. Ent. France, 62, pp. 314336 , illus.

1900. Myriapodes d'Amerique. Mem. Soc. Zool. France, 13, pp. 89-131, illus. 1903. Myriapodes recueillis a l'isla Cocos par M. le Professeur P. Biolley. Ann. Soc. Ent. France, 72, pp. 128-143, illus.

1905. Myriapodes de Costa Rica recueillis par M. le Professeur P. Biolley. Ann. Soc. Ent. France, 74, pp. 337-380, illus.

CARL, J.

1902. Exotische Polydesmiden. Rev. Suisse Zool., 10, pp. 563-679, illus.

1914. Die Diplopoden von Colombien nebst beitragen der Stemmatoiuliden. Mem. Soc. Neuchat. Sci. Nat., 5, pp. 821-993, illus.

Chamberlin, R. V.

1914. On a collection of Myriapoda from Costa Rica. Trans. Amer. Ent. Soc., 40 , pp. 185-194, illus.

1918. The Chilopoda and Diplopoda of the West Indies. Bull. Mus. Comp. Zool., (5), 62, pp. 151-262.

1922. The millipeds of Central America. Proc. U. S. Nat. Mus., (8), 60, pp. 1-75, illus.

1923a. Four termitophilous millipeds. Zoologica, New York Zool. Soc., (21), 3 , pp. 411-421, illus.

1923b. A new cryptodesmoid milliped from Santo Domingo. Proc. Biol. Soc. Washington, 36, pp. 189-190. 
1923c. Results of the Bryant Walker Expedition of the University of Michigan to Colombia, 1913, and British Guiana, 1914. Occ. Pap. Mus. Zool., Univ. Michigan, no. 133, pp.1-143, illus.

1925. Notes on chilopods and diplopods from Barro Colorado Id., and other parts of the Canal Zone, with diagnosis of new species. Proc. Biol. Soc. Washington, 38, pp. 35-44.

1933. On a collection of centipeds and millipeds from Costa Rica. Pan-Pacific Ent., 9, pp. 11-24, illus.

1940. On a diplopod collection from Barro Colorado Island, Panama. Bull. Univ. Utah, (9), 30, pp. 3-16.

1941a. A new oniscodesmid diplopod from Barro Colorado Island. Pomona Coll. Jour. Ent. Zool., 33, pp. 57-58, illus.

1941 b. On a collection of millipedes and centipedes from northeastern Peru. Buli. Amer. Mus. Nat. Hist., 78, pp. 473-535, illus.

1946. A new centiped and two new millipeds from the Pearl Islands, Colombia (Panama correct). Pan-Pacific Ent., 9, pp. 145-147, illus.

1947a. Some records and descriptions of diplopods chiefly in the collections of the Academy. Proc. Acad. Nat. Sci. Philadelphia, 99, pp. 21-58, illus.

1947b. Two new species of Trichomorpha from Panama. Proc. Biol. Soc. Washington, 60, pp. 63-66, illus.

1951. On Diplopoda of north-east Angola. Public. Cult. Comp. Diamant. Angola, (Sept. 10), pp. 63-94, illus.

1955. New millipeds from Peru and adjacent parts. Univ. Utah Biol. Ser., (5), $11, \mathrm{pp} .1-47$, illus.

Chamberlin, R. V., and Hoffman, R. L.

1958. Checklist of the millipeds of North America. Bull. U. S. Nat. Mus., 212, pp. 1-236.

Coок, O. F.

1896a. A new diplopod fauna in Liberia. Amer. Nat., p. 415.

$1896 \mathrm{~b}$. Brandtia. A series of occasional papers on Diplopoda and other Arthropoda. pp. 1-75.

1896c. Summary of new Liberian Polydesmoidea. Proc. Acad. Nat. Sci. Philadelphia, pp. 257-267.

1898. American oniscoid Diplopoda of the order Merocheta. Proc. U. S. Nat. Mus., 21, pp. 451-468, illus.

1911a. New tropical millipeds of the order Merocheta, with an example of kinetic evolution. Proc. U. S. Nat. Mus., (1831), 40, pp. 451-473, illus.

1911b. The hothouse milliped as a new genus. Proc. U. S. Nat. Mus., 40, pp. 625-631.

Cook, O. F., and Cook, A. C.

1894. A monograph of Scytonotus. Ann. New York Acad. Sci., 8, pp. 233-248, illus.

DADAY, E.

1889. Myriapoda extranea musaei nationalis Hungarici. Term. Füzetek, 12, pp. 115-156, illus.

Gervais, $P$.

1844a. Etudes sur les myriapodes. Ann. Sci. Nat., (ser. 3), 2, pp. 51-80, illus.

1844b. Description de trois especes de Scolopendra; sur le genre Cambala. Ann. Soc. Ent. France, (ser. 2), 2, p. 29.

1847. Myriapodes. In Walckenaer, Hist. Nat. de Insectes, Apt. 4. 
Gervais, P., and Goudot, J.

1844. Description des myriapodes recueillis par J. Goudot en Colombie. Ann. Ent. Soc. France, (2), 2, pp. 27-29.

HOFFMAN, R. L.

1950. Systematic notes on some Central American millipeds. Proc. Biol. Soc. Washington, 63, pp. 69-72.

1951. A new genus of Central American milliped (family Euryuridae) with notes on American genera. Proc. U. S. Nat. Mus., 102, pp. 235-243, illus.

1953a. Studies on spirostreptid millipeds. I. The genus Isoporostreptus Silvestri. Lloydia, 16, pp. 149-156, illus.

1953b. Psammodesmus, a neglected milliped genus (Polydesmida: Platyrhacidae). Jour. Washington Acad. Sci., (9), 43, pp. 299-304, illus.

1953c. A new Central American milliped of the genus Platyrhacus. Proc. Ent. Soc. Washington, 55, pp. 251-258, illus.

1953d. Studies on spiroboloid millipeds. I. The genus Eurhinocricus Brolemann. Proc. Biol. Soc. Washington, 66, pp. 179-183.

1954. Further studies on American millipeds of the family Euryuridae (Polydesmida). Jour. Washington Acad. Sci., (2), 44, pp. 49-58, illus.

1955. Studies on spiroboloid millipeds. II. A second paper on the genus Eurhinocricus. Proc. Biol. Soc. Washington, 68, pp. 31-36.

KARSCH, F.

1881. Neue Juliden des Berlinen-Museums, als Prodromus einer Juliden Monographie. Zeitschr. Naturw., (ser. 3, vol. 6), 54, pp. 1-79.

KocH, C. L.

1847. System der Myriapoden. In HeRRICH-SCHAFFER, Kritische Revision der Insectenfaune Deutschlands, 3, pp. 1-196, illus.

KRAUS, $\mathrm{O}$.

1954. Myriapoden aus Peru, II. Senckenberg Biol., Frankfurt-am-Main, 35, pp. 17-55, illus.

1955. Myriapoden aus Peru, III. Senckenberg Biol., Frankfurt-am-Main, 36, pp. $173-200$, illus.

1959. Myriapoden aus Peru, VII. Senckenberg Biol., Frankfurt-am-Main, 40, pp. 191-208, illus.

LoomIs, H. F.

1934. Millipeds of the West Indies and Guiana collected by the Allison V. Armour Expedition in 1932. Smithsonian Misc. Coll., (3244), 89, pp. 1-69, illus.

1937. New Jamaican and Cuban millipeds, with notes on several other species. Bull. Mus. Comp. Zool., (3), 80, pp. 215-228, illus.

1958. A new milliped family on Barro Colorado Island, Canal Zone. Jour. Washington Acad. Sci., (7), 48, pp. 235-237, illus.

1959. New myrmecophilous millipeds from Barro Colorado Island, Canal Zone, and Mexico. Jour. Kansas Ent. Soc., 32, pp. 1-7, illus.

1961. New and previously known millipeds of Panama. Proc. U. S. Nat. Mus., (3454), 113, pp. 77-123, illus.

LUCAS, H. M.

1843. Observations sur un nouveau genre de la classe des Myriapodes, etc. Ann. Soc. Ent. France, (2), 1, pp. 43-53, illus.

1849. Observations sur un nouveau genre de la classe des Myriapodes, etc. Rev. et Mag. Zool., (2), 1, pp. 594-601, illus. 
Peters, W.

1864. Übersicht der im kön. zool. Museum befindlichen Myriapoden aus d. fam. der Polydesmi, sowie beschreibung einer neuen Gatt. der Iuli und neuer Arten d. Gatt. Siphonophora. Monatsb. Kön. Akad. Wiss. Berlin, pp. 529$551,617-627$.

Pocock, R. I.

1903-1910. Chilopoda and Diplopoda. Biol. Centr.-Amer., pp. 41-217, illus.

Porat, C. O.

1889. Om nagra exotiska Myriapoder. Bihang K. Sv. Vetensk. Akad. Handl., (7), 4, pp. 3-48.

SAUSSURE, H.

1860. Essai d'une faune des Myriapodes du Mexique, avec la description de quelques especes des autres parties de l'Amerique. Mem. Soc. Phys. Hist. Nat. Geneve, (pt. 2), 15, pp. 259-393, illus.

Silvestri, Filippo

1896. Chilopodi e Diplopodi raccolti dal Dott. E. Festa a La Guayra, nel Darien e a Cuenca. Boll. Mus. Zool. Torino, (254), 11, pp. 1-6, illus.

1897a. Viaggio del Dott. Alfredo Borelli nel Chaco Boliviano e nella Repubblica Argentina. Boll. Mus. Zool. Torino, (283), 12, pp. 1-11.

1897b. Viaggio del Dr. Enrico Festa nell' Ecuador e regioni vicine. Boll. Mus. Zool. Torino, (305), 12, pp. 1-13, illus.

1898a. Viaggio del Dott. E. Festa nella Repubblica dell' Ecuador. Boll. Mus. Zool. Torino, (324), 13, pp. 1-11, illus.

1898b. Diagnosticos de nuevos diplopodos Sudamericanos. Ann. Mus. Nat. Buenos Aires, 6, pp. 53-79.

1908. Myriapoda from Porto Rico and Culebra. Bull. Amer. Mus. Nat. Hist., (28), 26, pp. 563-578, illus.

1910. Descrizione preliminari di nuovo generi di diplopodi. I. Polydesmoidea. Zool. Anz., 35, pp. 357-364.

1916. Contribuzione alla conoscenza degli Stemmiuloidea (Diplopoda). Boll. Lab. Zool. Portici, 10, pp. 287-355, illus.

1925. Descripcion de un nuevo genero de Polydesmidae (Myriapoda, Diplopoda) de Espana Meridional. Bol. Real Soc. Espanola de Hist. Nat., 23, pp. 368-375, illus. 


\section{INDEX TO FAMILIES AND GENERA}

New names in bold face; synonyms in italics

Acakandra, 99

Aceratophallus, 64

Airocaulon, 66

Alocodesmus, 16, 130

Aphelidesmus, 51

Augesmus, 67

Barrobolus, 114

Barrodesmus, 56

Barroxenus, 9

Botrydesmus, 67

Calymmodesmus, 70

Catapleuradesmus, 71

Chelodesmidae, 15

Chondrodesmus, 16,130

Chytodesmidae, 17

Cleidogonidae, 99

Comodesmidae, 26

Cryptodesmidae, 30

Cyclopsodesmus, 80

Cylindrogonus, 83

Cyrtodesmidae, 32

Cyrtodesmus, 34

Desmacrides, 17

Desmethus, 126

Diaphanacme, 31

Diaporus, 131

Dirhabdophallus, 16

Docodesmiella, 19

Dorsoporidae, 51

Dorsoporus, 51

Dybasia, 100

Dybasiidae, 100

Enantiogonus, 86

Epinannolene, 119

Epinannolenidae, 119

Eurhinocricus, 112
Euryuridae, 51

Eutynellus, 86

Gasatomus, 72

Glomeridesmidae, 9

Glomeridesmus, 9

Huanucodesmus, 56

Hypsiloporus, 27

Inodesmus, 29

Irazunus, 87

Irogonus, 92

Isoporostreptus, 116

Leiogonopus, 93

Lignydesmus, 56

Mesesmus, 56

Mestosoma, 98

Microspirobolus, 114

Nabatomus, 73

Nyssodesmus, 59

Ogkomus, 102

Oniscodesmidae, 56

Orthomorpha, 98, 131

Orthoporus, 118, 131

Oxidus, 98

Oxypyge, 113

Pachygonopus, 96

Panamadesmus, 56

Peridontodesmidae, 58

Peridontodesmus, 58

Platydesmidae, 126

Platydesmus, 127

Platyrhacidae, 59

Platyrhacus, 60

Polyxenidae, 9
Polyzoniidae, 121

Poratia, 73

Prionodesmus, 67

Proletus, 131

Prosopodesmus, 75

Prostemmiulus, 106

Psammodesmus, 62

Ptyxodesmus, 24

Pycnotropis, 52

Rettenmeyeria, 75

Rhachodesmidae, 64

Rhinocricidae, 112

Rhinocricus, 113

Sarolepis, 75

Seminellogon, 54

Siphonocybe, 122

Siphonophora, 123

Siphonophoridae, 122

Siphonotus, 121

Solemia, 104

Sphaeriodesmidae, 65

Sphaeriodesmus, 65

Spirobolellidae, 114

Spirostreptidae, 116

Stemmiulidae, 105

Stemmiulus, 110

Strongylosomidae, 98

Stylodesmidae, 65

Teinorhachis, 64

Tichodesmus, 97

Tracheloaspis, 78

Trichodesmiella, 25

Trichomorpha, 17

Trichopolydesmidae, 79

Typophallus, 17

Xenoporus, 79 





\section{Publication 976}







